Purdue University

Purdue e-Pubs

Open Access Dissertations

Theses and Dissertations

4-2016

\title{
Neural activity reveals effects of aging on inhibitory processes during word retrieval
}

Ranjini Mohan

Purdue University

Follow this and additional works at: https://docs.lib.purdue.edu/open_access_dissertations Part of the Gerontology Commons, and the Speech and Hearing Science Commons

\section{Recommended Citation}

Mohan, Ranjini, "Neural activity reveals effects of aging on inhibitory processes during word retrieval" (2016). Open Access Dissertations. 683.

https://docs.lib.purdue.edu/open_access_dissertations/683 


\section{PURDUE UNIVERSITY \\ GRADUATE SCHOOL \\ Thesis/Dissertation Acceptance}

This is to certify that the thesis/dissertation prepared

By Ranjini Mohan

\section{Entitled}

NEURAL ACTIVITY REVEALS EFFECTS OF AGING ON INHIBITORY PROCESSES DURING WORD RETRIEVAL

For the degree of Doctor of Philosophy

Is approved by the final examining committee:

Dr. Christine M. Weber

Chair

Dr. Alexander L. Francis

Dr. Jiyeon Lee

Dr. Daniel J. Olson

To the best of my knowledge and as understood by the student in the Thesis/Dissertation Agreement, Publication Delay, and Certification Disclaimer (Graduate School Form 32), this thesis/dissertation adheres to the provisions of Purdue University's "Policy of Integrity in Research" and the use of copyright material.

Approved by Major Professor(s): Dr. Christine M. Weber

Approved by: Dr. Keith R. Kluender

4/19/2016 

NEURAL ACTIVITY REVEALS EFFECTS OF AGING ON INHIBITORY

PROCESSES DURING WORD RETRIEVAL

\author{
A Dissertation \\ Submitted to the Faculty \\ of \\ Purdue University \\ by \\ Ranjini Mohan \\ In Partial Fulfillment of the \\ Requirements for the Degree \\ of \\ Doctor of Philosophy
}

May 2016

Purdue University

West Lafayette, Indiana 
To Thatha. 


\section{ACKNOWLEDGMENTS}

I would like to express my deepest gratitude to a number of people who have been instrumental to my happiness at Purdue. Every one of them has a deep place in my heart and their support is reflected in every word of this dissertation.

A very special thank you goes to my doctoral adviser, Dr. Christine Weber, who is everything I could ask in a mentor and more. I have come a long way since my first year at Purdue because of her unwavering support and patience. Her constructive feedback and immeasurable knowledge have helped me become an independent researcher and critical thinker. Working in her lab has truly been a turning point in my life, guiding me towards a future I would never have imagined without this experience.

I thank my committee members whose input and feedback shaped my dissertation and pushed me to perform at a higher standard. My sincere thanks to Dr. Alexander Francis for teaching me to constantly think about relationships rather than single units to better understand a problem. I thank Dr. Daniel Olson for persistently urging me to think about the bigger impact of my work (and to think he almost refused to be on my committee!); and Dr. Jiyeon Lee, who helped me explore and understand the details that shaped my research.

My sincerest gratitude to Dr. Jessica Huber, whose research productivity and entrepreneurship are highly inspiring. She saw my potential when I didn't and helped me explore a new perspective on aging and disease. She has been an amazing mentor and friend. 
My interest in aging was fueled by a number of colleagues and mentors at the Center for Aging and the Life Course at Purdue. I would like to especially thank Dr. David Waters, who is the best teacher I have ever had the privilege of knowing. Every meeting with him is a booster shot I need to be inspired by Nature. I no longer see aging, science, or life the same way. I would consider myself successful if I can be a fraction as inspiring as him. I would also like to thank Dr. Kenneth Ferraro for providing me with multiple opportunities in professional development and engagement.

Thank you to my current and former lab mates, Katie Lippitt, Lindsay Rozynek, Connor Slavich, Vanessa LaFond, and Skylar Powlen, who have made my time here at Purdue brighter. Thank you to Eileen, whose work ethic is truly motivational. I also thank Evan Usler for making days in the lab more fun with his interesting rants on a multitude of topics. His efficient use of time and worldly knowledge are enviable. I also found an amazing friend in Kate Kreidler; I treasure our deep conversations about life, love, and food.

To my friends at Purdue, Rohith, Shankar, Upasna, Sarath, and Varsha - thank you for the wonderful memories. Hopefully we will end up together again. A special thank you goes especially to my friends, and now family, Anusha \& Surya, who have truly made life more joyous and worth sharing. My deepest love to Tatvam and Purdue Taal, who gave me a life beyond work, filled with music and laughter.

I would never have pursued a $\mathrm{PhD}$ if not for the constant encouragement from my late grandfather, Mr. Gopalakrishnan. He instilled in me, a thirst for knowledge and a foundation of respect. I miss him every day. Thank you to my parents, P. R. Mohan and Parvathy Mohan, who encouraged me to follow my heart and expand my ideas. I could never have maintained my sanity without their weekly doses of love and support. I know they are proud of me, but I give them credit for all my success. Being separated by five continents has only brought my sister, Rohini Mohan, and me closer. She and my brother-in-law, Shailesh, have taught me to be ambitious, righteous, to believe in myself, and to see the story behind the words. I especially miss our hugs and laughs. My sincere 
gratitude and respect to my in-laws, Mr. \& Mrs. Lakshminarayanan, for their support, encouragement, and patience through this time, and for raising a kind and handsome man.

I would also like to thank my study participants, who were perfect examples of graceful aging. Through their active participation and recruitment of their friends, I had the fortune of meeting some amazing people.

Finally, I owe my entire graduate success to my loving husband, Pradeep. He has been the biggest reason for my happiness these past five years. He has been my sound board, my mirror, and my guiding spirit. Words cannot do justice in expressing my gratitude for his unconditional support and love. I am forever grateful to God for his soul. 
TABLE OF CONTENTS

Page

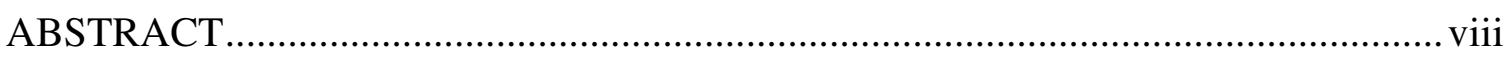

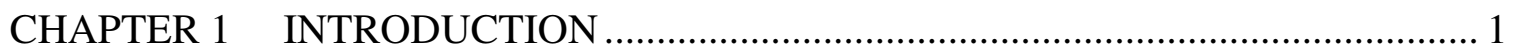

1.1 Anatomical and Physiological Brain Changes with Aging........................................ 2

1.2 Cognitive and Language Changes in Aging ........................................................... 4

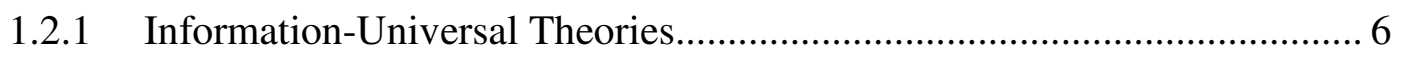

1.2.2 Information Specific Theories ............................................................ 10

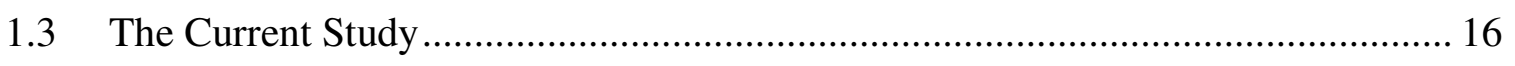

1.4 ERP Components Elicited by Picture Naming Paradigms ...................................... 19

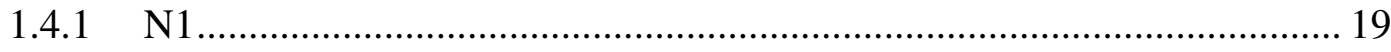

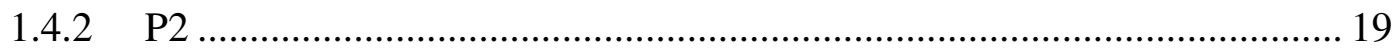

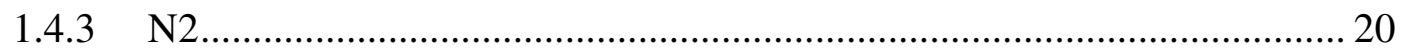

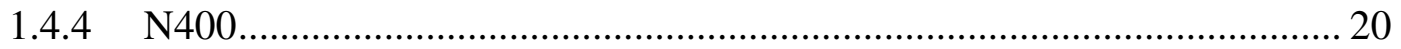

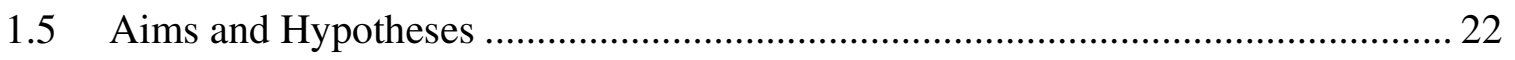

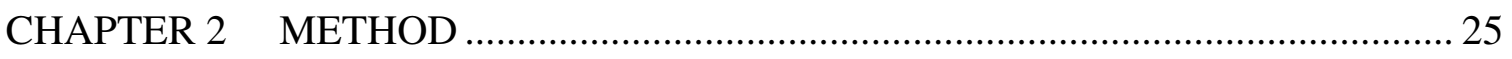

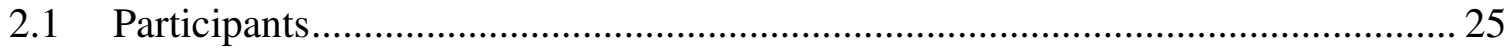

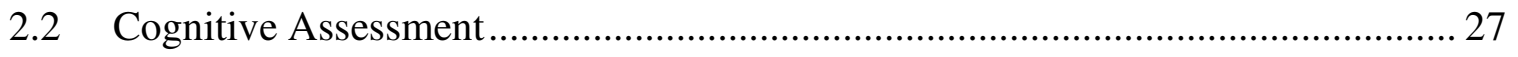

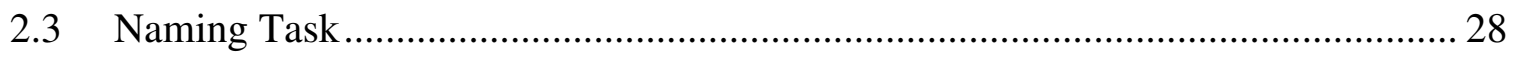

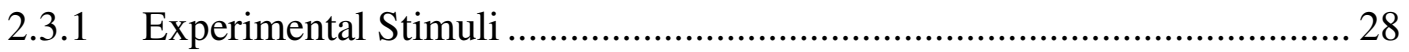

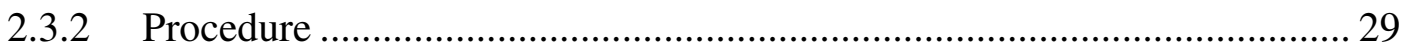

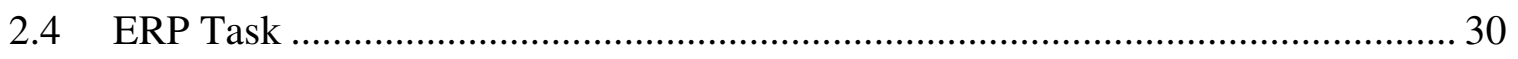

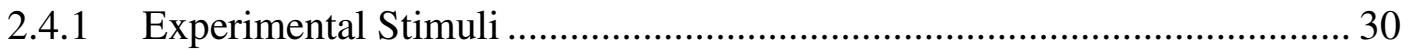

2.4.2 Electrophysiological Recordings ............................................................... 31

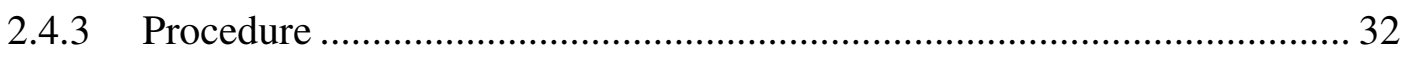




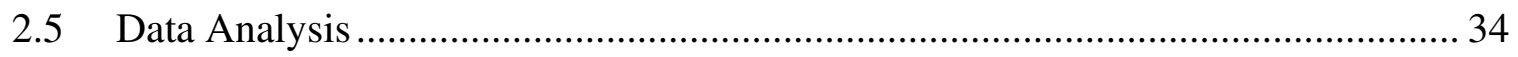

2.5.1 Behavioral Measures from the Naming Task ......................................... 34

2.5.2 Behavioral Measures from the ERP Task............................................ 34

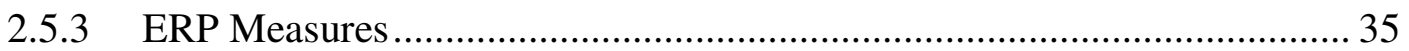

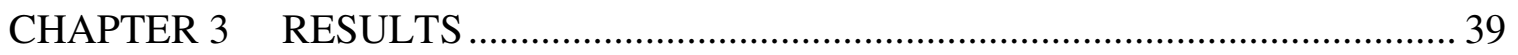

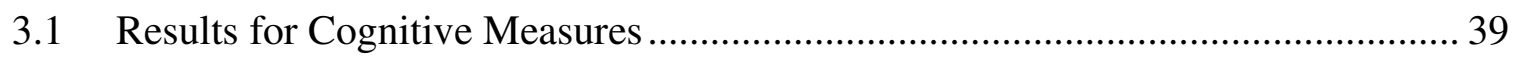

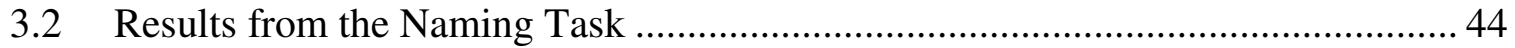

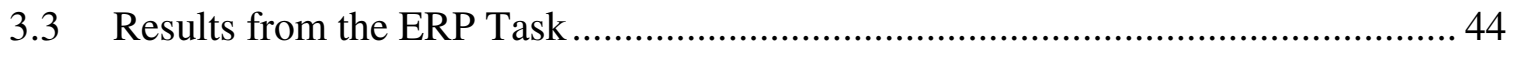

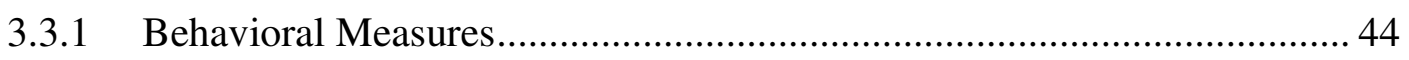

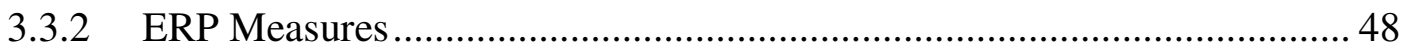

3.3.2.1 Prime (Auditory Pseudo-Word) ........................................... 48

3.3.2.2 Target (Picture) ............................................................. 52

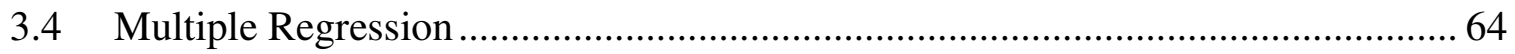

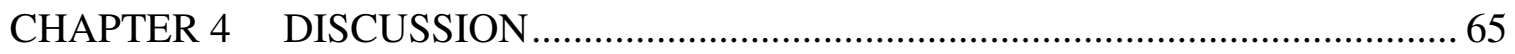

4.1 Word Frequency Modulated Naming Latency and Phonological Judgment .......... 66

4.2 Phonological Priming Facilitated Word Retrieval Similarly Across Groups ......... 69

4.3 Neural Indices of Word Retrieval Reveal Age Invariance in Phonological Priming . 73

4.4 Inhibitory Processes Associated with Target Activation Show Age Differences... 75

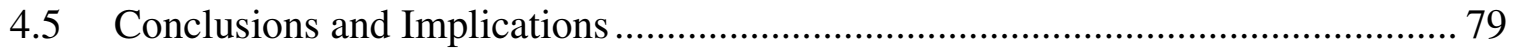

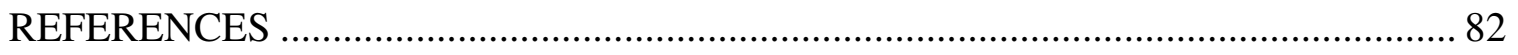

APPENDICES

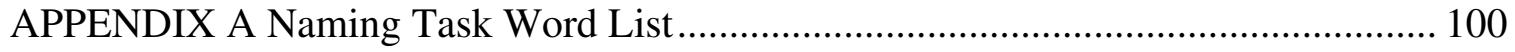

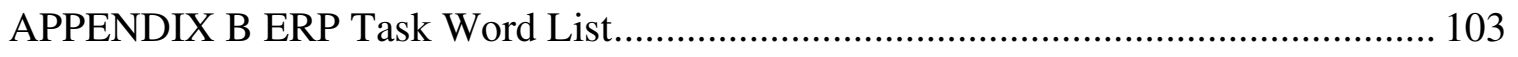

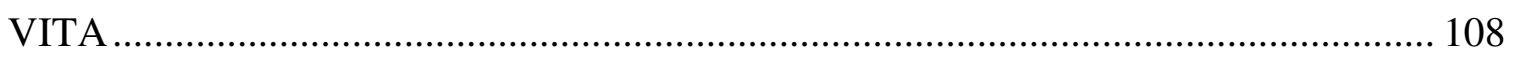




\begin{abstract}
Ranjini Mohan, Ph.D., Purdue University, May 2016. Neural Activity Reveals Effects of Aging on Inhibitory Processes During Word Retrieval. Major Professor: Christine Weber.
\end{abstract}

Word retrieval difficulties are one of the most frustrating problems in older adults. Poorer access to phonological (speech sound) representation of the target word has been postulated as the underlying deficit, supported by findings of improvement in word retrieval after phonological priming. But the great variability in naming performance among older adults may reflect cognitive scaffolding or compensatory neurophysiological processes related to maintenance or decline of naming abilities. In order better understand aging effects in the underlying neurophysiological changes associated with phonological retrieval, the present study examined electrophysiological correlates of phonological priming and word retrieval in adults across the lifespan. Young, middle-aged, and older adults viewed pictures (targets) that were preceded by pseudo words (primes) that either shared phonemes with or were unrelated to the picture's name. Participants used a button press to indicate whether the prime pseudo word and target picture shared the same initial sound. Behavioral and event-relatedpotential correlates of phonological priming and word retrieval were recorded. All age groups benefitted from phonological priming, as evidenced by faster phonological 
judgment response times and increased ease of word retrieval for primed pictures, indexed by the mean amplitudes of the $\mathrm{N} 400$. The peak latency of the $\mathrm{N} 2$, however, showed a linear increase with age. The high correlation between the N2 peak latency and clinical measures of inhibition suggested that the $\mathrm{N} 2$ indexed inhibition of primed lexical competitors. Taken together, our results indicated intact access to phonological representation of the picture's name, but age-related deficits in the cognitive ability to inhibit incompatible lexical competitors. Interestingly, our findings revealed that the delays in inhibiting lexical competitors may begin as early as middle age, highlighting the importance of including multiple age groups to better represent the trajectory of agerelated cognitive processing. Our findings have important implications for understanding domain-specific changes in cognitive processing even within the same task. The present study lays the foundation for studying word retrieval in individuals with atypical word retrieval difficulties. 


\section{CHAPTER 1 INTRODUCTION}

Developed countries today are seeing substantial increases in the proportion of elderly adults in the population due to decreased birth rates and increased longevity. According to the U.S. Census Bureau 2010, the number of older adults has increased by $15.1 \%$ in the last ten years, with the Baby Boom generation contributing majorly to this growth. By 2050, it is expected that there will be more numbers of older adults than children in most developed countries (Cohen, 2003). A consequence of this population decline is an increased rate in cognitive decline and dementia (Hebert, Scherr, Bienias, Bennett, \& Evans, 2003). Fortunately, the field of cognitive neuroscience has grown tremendously in the past few decades, ushering a great amount of knowledge about the aging process. Assessing cognitive aging in healthy older adults is important to distinguish healthy aging from disease. Cognitive aging is not a disease or a level of dysfunction, and is distinct from Alzheimer's disease and other neurogenic disorders that affect older adults' cognitive health. Contrary to popular belief, neurons do not die with

aging, but synaptic structure and function become diminished and this suggests potential for improving cognitive health (Blazer, Yaffe, \& Karlawish, 2015).

The aim of the present study was to increase our understanding of the neural correlates of language processing, specifically word retrieval, in healthy aging. While 
the overall picture might indicate that aging is associated with cognitive decline, there is enormous variability within and across individuals. For example, many older adults outperform or are on par with young adults for some cognitive tasks (Craik \& Jennings, 1992), including language processing. What are some of the factors that contribute to this variability? In order to address this question in the present study, we characterized the relationships between cognitive functions and language processing across the adult lifespan. Along with cognitive abilities, there is also variability in motor skills and in brain structure and function (Bartrés-Faz \& Arenaza-Urquijo, 2011). The following section will describe some of the structural and functional changes associated with aging.

\subsection{Anatomical and Physiological Brain Changes with Aging}

The anatomical characteristics of the brain, including grey matter volume and white matter integrity, change with age (Goh \& Park, 2009; Raz et al., 2005; ReuterLorenz \& Park, 2010). The rate of grey matter shrinkage accelerates after the age of 50, with an annual rate of $0.5-1 \%$ cortical thinning in most brain regions (Raz, et al., 2005). Greatest volumetric reductions have been reported in the prefrontal cortex, followed by the parietal cortex and occipital cortex (Fjell \& Walhovd, 2010). Reductions in grey matter have been observed to occur earlier and at a slower rate compared to white matter, while white matter loss begins later and progresses more precipitously, with greatest volume changes in frontal/prefrontal lobes and temporal lobes (Raz et al., 2005).

While cognitive models and anatomical neuroimaging studies present a pattern of age-related cognitive decline, functional imaging data reveal widespread activation patterns across frontal sites in older adults during cognitive functioning (Davis, Dennis, 
Daselaar, Fleck, \& Cabeza, 2008; Park \& Reuter-Lorenz, 2009). There is increasing evidence that bilateral frontal activation in older adults as compared to left frontal activity in young adults is compensatory and facilitative of task performance (Cabeza, 2002;

Reuter-Lorenz et. al., 2000; see Park \& Reuter-Lorenz, 2009 for review). Such compensatory activations are consistent with the idea of age-related dedifferentiation of functional brain activity (Cabeza, 2002; Madden, Bennett, \& Song, 2009). According to this model, brain regions specialized for one cognitive process becomes less specialized with age and respond more similarly across several cognitive conditions.

Similar to the neural correlates of general cognition, the neurophysiological functions of language comprehension and production also show asymmetric changes with age. For example, the left-hemisphere syntax network (Broca's area and left posterior middle temporal gyrus) is associated with reduced within-network connectivity and greater interhemispheric connectivity (Meunier, Stamatakis, \& Tyler, 2014). But this residual connectivity in the left hemisphere may be sufficient for syntactic processing in typical, contextually-rich environments. Word production, on the other hand, may be associated with age-related impairment. During successful naming, older adults additionally activate the right insula along with the left insula, indicating that they use additional cognitive control to overcome reduced phonological activation even for easy retrieval. During difficult retrieval, however, older adults exhibited reduced left insula activity during tip-of-the-tongue (TOT) states compared to young adults, indicating that the phonological system may be too weak to trigger additional cognitive control mechanisms (Shafto, Stamatakis, Tam, \& Tyler, 2010). These complex activities within 
and between language systems indicate that the aging brain is capable of dynamic and flexible network interactions in order to facilitate maintenance of language performance. Evidence from the above studies indicates that characterizing cognitive aging requires understanding the dynamic neural interactions that underlie cognition.

\subsection{Cognitive and Language Changes in Aging}

Since the term 'gerolinguistics' was introduced (Cohen, 1979), there has been an increasing interest in understanding how language functions change with age. Declines in language abilities with age can impede communication and decrease quality of older adults' social interactions and psychological well-being (Cavanaugh \& Blanchard-Fields, 2006; Kemper \& Lacal, 2004). One of the core questions asked is whether aging affects language processing universally or only in specific domains. In general, aging is largely characterized by asymmetric patterns of decrement, with language comprehension being largely maintained compared to language production (Burke, MacKay, \& James, 2000). When sensory decrements are controlled, aspects of language comprehension such as access to lexical representations and online construction of syntactic and semantic representations are well preserved (Burke \& Shafto, 2008). At the word level, older adults often outperform young adults on tests of vocabulary, possibly due to greater experience with language, greater education, incremental reading, or life experience (Bowles \& Salthouse, 2008; Kavé \& Halamish, 2015; Kavé \& Yafe, 2014). On the other hand, language production shows distinct age-related declines. Older adults above the age of 65 years use propositionally and syntactically simpler sentences (Kemper, 2001) and those between 68 and 80 years have difficulty accessing phonological representations 
while making judgments about picture names (Neumann, Obler, Gomes, \& Shafer, 2009). Older adults often complain of word finding difficulties (Burke, 2006; Condret-Santi, Barbeau, Matharan, Le Goff, Dartiques, \& Amieva, 2013). Word finding difficulties are considered to be one of the most frustrating and embarrassing of memory problems among older adults (Lovelace \& Twohig, 1990). Word retrieval difficulties are most frequently manifested as TOT states, where one is temporarily unable to retrieve a known word. TOTs are a hallmark of old age, increasing in frequency with normal aging in experimental and naturalistic settings (James, 2006; Stine-Morrow \& Shake, 2009).

Studies assessing word retrieval over the lifespan have generally used confrontation naming tasks where the participant is asked to name pictures presented. For example, Albert, Heller, and Milberg (1988) found that significant differences on the Boston Naming Test (Kaplan et al, 1983) did not appear until the age of 70, and 50-year olds performed on par with those in their 30's. Zec, Markwell, Burkett, and Larsen (2005; 2007) administered the Boston Naming Test to individuals between 50 and 99 years. They found an annual rate of 1-word improvement in individuals in their 50's, no change for those in the 60's, and a 1.3-word decline and increased variability for participants in their 70's and 80's.

Cognitive models that attempt to explain age-related language deficits have to take into account the general asymmetry between language comprehension and production, and specific variability within the language production network. Based on the underlying mechanisms postulated to describe age-related changes, cognitive models have been characterized as information-universal or information-specific theories. 


\subsubsection{Information-Universal Theories}

These theories predict that aging will yield consequences independent of the domain of language processing and assumes a disruption across all language subdomains. Specifically, resource theory postulates that older adults have fewer available mental resources as compared to young adults in order to complete a task (McCoy et al., 2005; Murphy, Craik, Li, \& Schneider, 2000). The term 'resource' in the field of language and aging has frequently been used with reference to processing speed, inhibition, and working memory (Burke \& Shafto, 2008).

General Slowing Theory: General slowing theories postulate that age-related cognitive declines are due to slowing of the component processes (Madden, 2001; Salthouse, 1996), implying a single factor influencing cognitive functioning independent of the task or mental operations involved. Salthouse (1996) proposed that each cognitive operation may be executed too slowly for successful completion of higher order functions such as abstraction and elaboration. This theory has received support from studies demonstrating that measures of speed account for $50-75 \%$ of age-related variance on a variety of cognitive tasks (Henninger, Madden, \& Huettel, 2010; Salthouse, 2000). Some researchers consider the slowing as caused by generalized slowing of the nervous system for all processes (Cerella, 1990), while others view it as domain specific slowing, with processes within the domain showing variable slowing (Alle, Sliwinski, \& Bowie, 2002). In the event-related potential (ERP) literature, increased latency of the N2b and P3b components indexing novelty and attention required to make task-related decisions have provided evidence for the slowing theory (Luck \& Kappenman, 2012). 
General slowing theories, however, fail to address a few critical issues. For example, while age-related slowing has been suggested as universal, language performance is not. These theories also fail to explain why some aspects of language, such as vocabulary (Schaie, 2005) and semantic processing (Burke \& Shafto, 2008; Thornton \& Light, 2006) remain intact. Moreover, the slowing theories also assume that both young and older adults use isomorphic processes to perform a task, which may be invalid (Fisher, Fisk, \& Duffy, 1995; Stine, 1995).

Inhibition Deficit Hypothesis: The inhibition deficit hypothesis assumes that aging weakens the inhibitory processes required to ignore irrelevant information (Hasher, Lustig, \& Zacks, 2007). During working memory span tasks, age-related deficits may be associated with the failure to delete from working memory digits or stimuli from prior trials, thus reducing the capacity for new stimuli (Hasher et. al., 2007). The Stroop task has also been used to investigate inhibition in the aging population. Relative to the baseline condition where individuals have to name colors of neutral stimuli, older adults display an increase in reaction time or in the number of errors when naming colors of incongruent words compared to young adults (Verhaeghen \& De Meersman, 1998). West (2004) examined the neural correlates of context and conflict processing in the Stroop task using ERPs. Participants were provided with block or trial-by-trial cues regarding whether to name the color or word presented. Results revealed that older adults were slower and less accurate on the task. The P300 component, associated with stimulus encoding or updating working memory based on the cue, was delayed in older adults as compared to young adults. In addition, the amplitude of the N450 associated with conflict 
detection and error related negativity was attenuated, suggesting an age-related decline in the efficiency of neural processes supporting conflict detection.

Other ERP studies also support the inhibition deficit hypothesis. In a task where participants performed Go/NoGo decisions based on the direction of visually presented arrows, the peak latency of the $\mathrm{N} 2$ indexing response inhibition, was greater in older adults by about $35 \mathrm{~ms}$ as compared to young adults (Tachibana, Aragane, \& Sugita, 1996). In a N400 ERP paradigm involving semantic processing of targets and distractors, young adults showed reduced N400 to distractor probes, indicating that they ignored the task-irrelevant distractors (Phillips \& Lesperance, 2003). On the other hand, older adults processed both the target and distractor probes similarly, and their behavioral data suggested a susceptibility to distraction.

Word retrieval difficulties in older adults may be related to deficits in inhibition abilities associated with language processing. Berg and Schade (1992) propose that spreading activation models of language production include an inhibition component, particularly lateral inhibition of same-level nodes. According to the authors, presentation of a stimulus will trigger spreading of activation through the lexicon. Once a node receives a minimum level of activation for selection, “...it sends inhibition through the network along the pre-established paths" (Berg \& Schade, 1992). This balance between activation and de-activation is important for creating a stable network for word production. The inhibition deficit hypothesis postulates an age-related failure to suppress alternate words that come to mind as an explanation for word retrieval deficits (Burke, MacKay, Worthley, \& Wade, 1991). However, the inhibition deficit theory does not 
consistently explain the asymmetric language changes in older adults. It may be the case that there are multiple inhibitory systems or that the deficits are task- or paradigmspecific (Burke et al., 2000).

Working Memory Theory: The Baddeley model for working memory (Baddeley, 1986, 2003) provides a basis for suggesting that older adults experience a reduction in working memory storage (Braver \& West, 2008; Reuter-Lorenz \& Sylvester, 2005). Language production requires domain-specific working memory processes to maintain and organize linguistic information. For example, speech errors during word production such as repetition of sounds or syllables within words may reflect breakdowns in verbal working memory underlying phonological encoding, the serial ordering of phonemes after word selection in preparation for articulation (Acheson \& MacDonald, 2009; Burke, et al., 1991). The idea that a reduction in working memory may account for more global deficits in cognitive function in older adults is supported by evidence that reveals age-differences in span tasks such as reading span and N-back tests (Bopp \& Verhaeghen, 2005). A metaanalysis of 14 studies revealed that age-differences were smaller on forward digit span than backward digit span tasks (Babcock \& Salthouse, 1990). However, there exists a conflict in interpretation of these results, with some researchers arguing that the agedifference on span tasks may reflect a decline in executive control processes such as selective attention or management of interference, and not storage capacity per se (Braver \& West, 2008).

The age-differences in working memory do not, however, imply a downregulation of brain activity during working memory tasks as compared to young adults. 
Functional neuroimaging data reveal an up-regulation in a number of neural regions during many working memory tasks (Riecker et al., 2006; see Reuter-Lorenz \& Lustig, 2005 for review). In some instances, data reveal bilateral activations in older adults compared to unilateral activations in young adults (Cabeza et al., 2004).

Overall, by suggesting that all age-related cognitive changes are associated with a single, disrupting underlying factor, information-universal theories do not account for the asymmetric aging effects on language comprehension and production. These asymmetric effects are better explained by information-specific models that consider age-related language changes at the level of specific linguistic subsystems.

\subsubsection{Information-Specific Theories}

The most articulated information-specific theory to account for age-related asymmetries in language comprehension and production and differential age effects within the language production system is the Transmission Deficit model (TD; Burke et. al., 1991; Burke, MacKay, \& James, 2000; MacKay \& James, 2004). The TD account of word retrieval is based on interactive or activation spreading models, specifically the node structure theory (NST). Our mental lexicons are rich with information, containing linguistic properties of tens of thousands of words. Each word is associated with conceptual, lemma, phonological word form, phonemic, and phonetic information that are organized into independent, yet interconnected layers in the mental lexicon (MacKay, 1987). The NST suggests that as a speaker prepares to produce an utterance, priming occurs across the connections within the lexicon (see Figure 1.1). "Priming is a form of subthreshold excitation that is transmitted across connections linking nodes and that 
prepares a node for activation, the basis for retrieval of its information." (Burke et al., 2000). A node is selected for activation only if it reaches a critical priming threshold, and therefore, the rate and amount of priming transmitted across connections determines whether it becomes available in memory. Connections become stronger with use, more so with recent use, and weaken as a result of disuse.

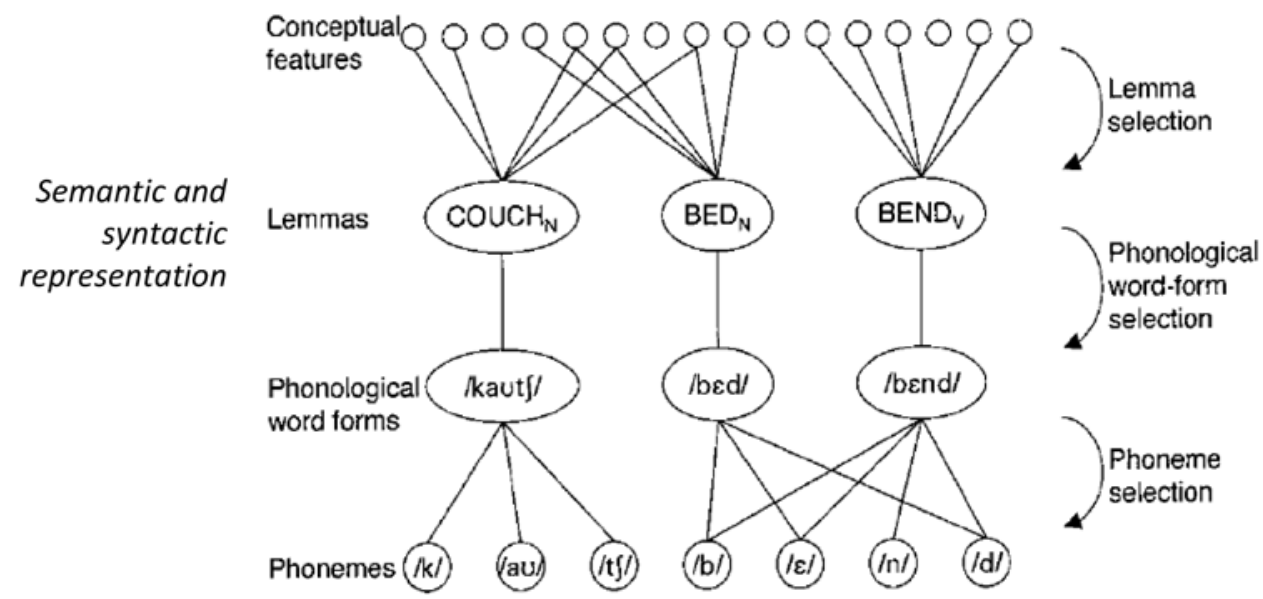

Figure 1.1. A network model of the mental lexicon (adopted from Ferreira \& Pashler, 2002).

Figure 1.1 illustrates the various nodes activated during word retrieval, representing an interactive word production model similar to Dell (1986), and Levelt, Roelofs, and Meyer (1999). For a task such as picture naming, a speaker first activates conceptual features that constitute the message to be expressed. Activation then spreads to lemma representations that include information about semantic and syntactic features of the word. Once the lemma is selected, activation spreads to connected phonological nodes that constitute information about whole-word morphological processes such as phonological word form, plurality, compounding, suffixation, etc. Activation then 
spreads to phoneme representations that include segmental information and serial ordering of syllables that are required for articulation. Note that some models define 'lemma' as a word's syntactic properties (Levelt, 1989; Roeflofs, 1992, 1997). Others define 'lemma' as the link between semantic and syntactic features (Jescheniak \& Levelt, 1994; Levelt, Roelofs, \& Meyer, 1998). In the present study, we will use the latter definition for lemma.

When looking at specific language networks, the investigation of word finding difficulties in older adults has revealed an asymmetric pattern of decline between semantic and phonological processing, and specific to the model delineated above, between lemma and phonological word form. Semantic representation seems to be generally spared (see Burke \& Shafto, 2008 for review); older adults display richer vocabulary (Schaie, 2005), better performance on tests of general knowledge (Beier \& Ackerman, 2001) and greater semantic interference that is interpreted as the result of richer sematic networks (e.g., Taylor \& Burke, 2002). During word retrieval failures, a person can typically recollect semantic, syntactic, and some phonological properties such as number of syllables of the target word, although complete phonology remains inaccessible. Word finding, therefore, has been interpreted as a selective decline in phonological word form retrieval. Why are phonological representations more susceptible to retrieval failures than semantic representations? During naming, priming proceeds topdown from conceptual to the lemma node. The greater redundancy in the interconnected nature of the semantic system and many-to-one connections to lemma nodes will offset any priming deficits within one of these connections. Following lemma activation, 
excitation transmits along one-to-one connections to the phonological node. Because of one-to-one correspondence between lemma and phonological word form level, weakened connections will prevent the phonological node from being activated. Unlike the semantic system, phonological nodes are not interconnected, except through shared phoneme nodes (E.g. /bed/ and /bsnd/ are connected through lower level phonemes /b/ and $/ \varepsilon /$ ) (MacKay \& Burke, 1990). Therefore, the TD model postulates that the phonological node is more vulnerable to retrieval failures in aging.

The TD model has received support from studies that suggest that priming with words that share phonology with the target word help in strengthening the lemmaphonological connections, as evidenced by increased TOT resolution (e.g., Abrams et. al., 2003; Farrell \& Abrams, 2011; James \& Burke, 2000; White \& Abrams, 2002; White, Abrams, \& Frame, 2013). Specifically, young adults resolved more TOTs when presented with primes that shared first syllable with the target, as compared to the first phoneme, first letter (Abrams et. al., 2003), the middle or last syllable (Abrams \& White, 2001, Experiment 2). This finding of TOT resolution after first syllable prime presentation was replicated in older adults between the ages of 60 and 72 years (White \& Abrams, 2002). However, older adults between the ages of 73 and 85 years did not benefit from any of the primes.

The TD model postulates that regardless of age, frequent or recent activation of a word will strengthen the connection between nodes. Correspondingly, words that are not frequently activated will be more prone to retrieval failures (Harley \& Bown, 1998; White \& Abrams, 2002). Lexical properties such as word frequency, neighborhood 
density, and neighborhood frequency influence word retrieval in young adults (Harley \& Bown, 1998; Vitevitch, 2002) and in older adults (Vitevitch \& Sommers, 2003). Word frequency has been considered a metric of the strength of network connections, with high frequency words having stronger or greater number of connections between the various levels of word representation as compared to low frequency words. Based on regression analysis, Spieler and Balota (2000) found that word frequency had a greater contribution to older adults' naming latency as compared to orthographic word length and orthographic neighborhood density, indicating that older adults rely on more whole-word level representations rather than sublexical features for word reading. Beyond lexical frequency, Vitevitch and Sommers (2003) also investigated the effects of phonological neighborhood frequency and density of words on TOTs in young and older adults. Both young and older adults produced fewer TOTs for high frequency words and words with dense phonological neighbors. However, older adults also produced more TOT states for words with low neighborhood frequency as compared to young adults, and displayed greater latency in naming pictures with low neighborhood frequency relative to those with high phonological neighborhood frequency (Vitevitch \& Sommers, 2003). Findings from these studies suggest that word frequency, and phonological neighborhood density and frequency may have differential influence on naming latencies in young and older adults.

Researchers have used a number of behavioral measures to assess older adults' word retrieval, including inducing TOT states (e.g., Burke et. al., 1991; James \& Burke, 1998), naming reaction times (e.g., Salthouse, 1996), and standardized naming tests (e. 
g., Baressi, Nicholas, Connor, Obler, \& Albert, 2000; Zec, et al., 2007, 2005). Since word finding deficits may be more easily circumvented in spontaneous speech by using synonyms, descriptions, or circumlocutions, using picture naming paradigms highlight age-related lexical access deficits by specifying the target word to be retrieved (e.g., Goral, Spiro, Albert, Obler \& Connor, 2007; Connor, Spiro, Obler \& Albert, 2004). Results from these studies suggest that older adults' picture naming is slower and less accurate as compared to young adults.

The TD model has received support from neuroimaging data that indicates agerelated grey matter atrophy in the left anterior insula (Indefrey \& Levelt, 2004) as well as significant correlations between TOT frequency and grey matter density of the left insula, a region of the brain mediating top-down phonological retrieval (Shafto, Burke, Stamatakis, Tam, \& Tyler, 2007). Older adults who experienced more TOTs also had reduced left insula activity as measured using fMRI (Shafto, Stamatakis, Tam, \& Tyler, 2010).

To our knowledge, there is only one study that has used electrophysiology to compare phonological retrieval in young and older adults. Neumann, Obler, Gomes, and Shafer (2009) used ERPs in an implicit picture naming task to examine the relative timing of substages of phonological word retrieval. Participants were required to make syllable and segmental judgments about picture names in a Go/No-Go paradigm. Increased behavioral reaction time and delayed N2d effect (No-Go minus Go amplitude measured in a $251-500 \mathrm{~ms}$ temporal window postulated to entail phonological encoding) 
in older adults for both syllable and segmental tasks was interpreted as delays at the phonological level of encoding.

In summary, older adults who exhibit word retrieval difficulties or TOTs are postulated to exhibit deficits in access to phonological word form due to one-to-one connections between lemma and phonological representations, and absence of lateral connections within phonological word form representations. Older adults below 75 years, however, benefit from presentation of phonologically related words, as evidenced by resolution of TOTs. In the present study, we aim to explore changes in the neural correlates of word retrieval and its potential modulation with phonological primes in healthy older adults that may offer insights into the relationship between aging and phonological processing.

\subsection{The Current Study}

Comparison of behavioral measures of naming between young and older adults has revealed an age-related decline in naming abilities. Functional imaging studies and neurophysiological models of aging described in the previous sections indicate that even for comparable behavioral performance, young and older adults recruit different or additional neural resources. Therefore, there is much to be understood about the neural mechanisms of word retrieval that may differentiate older adults' performance from young adults. Our main research question was: Do the neural indices mediating phonological processing during word retrieval differentiate young, middle-aged, and older adults? Most studies in the literature have compared young and older adults in order to assess age-related changes in language abilities. This, however, provides an incomplete 
picture about the trajectory of language changes as a function of age. In the present study, we included the third group, the middle-aged adults, in order to understand how naming performance and the underlying mechanisms of word retrieval unfold across the adult lifespan.

Behavioral and electrophysiological data was collected as participants listened to phonologically related or unrelated primes prior to viewing pictures. This cross-modal priming paradigm was considered to be ecologically valid as it paralleled priming methods utilized clinically. For example, in a clinical setting, the clinician often provides phonological primes or cues verbally to facilitate target picture naming during word retrieval failures. Phonological priming effects were assessed with the purpose of examining if it facilitates word retrieval similarly across the lifespan. The participants were required to make phonological judgments about the auditory prime and target picture and then name the picture. Behavioral measures such as reaction time and accuracy alone may be insufficient to understand the particular mechanisms individuals use during retrieval. Relying on the end-product of speech production will only offer a limited view of the different processes that operate during naming. Electrophysiological measures offer greater potential to investigate how different subdomains of the linguistic system activate in real-time. Also, recent literature has emphasized the importance of viewing language in the aging brain as a dynamic system. ERPs provide an opportunity to investigate interactive brain regions necessary to explain age-related cognitivelinguistic functioning. An advantage of using electrophysiological measures is that it provides a reliable picture of the cognitive processes involved in a task, even if 
behavioral performance is variable (Hagoort \& Kutas, 1995). ERPs offer a unique measure of neural functioning that can help to identify mechanisms that contribute to word retrieval failures with high temporal resolution.

Not everyone ages similarly. Just as age-related brain structure and function changes are not uniform across the entire brain or across individuals; enormous variability exists in age-related decline across cognitive domains in the older population. As individuals age, cognitive functions such as implicit memory, knowledge storage, and vocabulary remain relatively protected while speed of information processing, working memory and inhibitory functions become less efficient (see Park \& Reuter-Lorenz, 2009 for review). Higher level language functions such as language and decision making rely on some of these basic cognitive functions, and hence, are also affected by age. Interindividual variability in brain plasticity and cognitive functioning also exists among the older population as a function of physical and leisure activity, educational and occupational activities, bilingualism, and cognitive enrichment activities. (Bialystok, Craik, \& Freedman, 2007; Craik, Bialystok, \& Freedman, 2010; Kramer, Bherer, Colcombe, Dong, \& Greenough, 2004; Springer, Mcintosh, Winocur, \& Grady, 2005; Valenzuela and Sachdev, 2006). In the current study, we will address some of the heterogeneity of language and cognitive functions by characterizing relationships between the behavioral and neural indices mediating phonological processing and word retrieval and cognitive functions known to influence language processing (working memory, inhibition, vocabulary, and word finding) in adults across the lifespan. 


\subsection{ERP Components Elicited by Picture Naming Paradigms}

In the current study, we use auditory primes and picture stimuli to assess the influence of phonological priming on word retrieval. Therefore, brief descriptions of the ERP components typically elicited in such picture naming paradigms are provided below.

\subsubsection{N1}

The N1 is an exogenous, obligatory potential that typically occurs at approximately $100 \mathrm{~ms}$ after stimulus onset. It has a number of subcomponents, including an early peak at 100-150ms at anterior electrode sites and a later peak at 150-200ms posteriorly. The N1 is associated with selective attention to stimulus characteristics (Vogel \& Luck, 2000). Auditory stimuli elicit a N1 with greater amplitude and earlier latency than visual stimuli. Older adults displayed greater peak latency of the N1 elicited by auditory tone bursts relative to young adults at posterior electrode sites, indicating a slowing of neural transmission at an early stage of information processing (Anderer, Semlitsch, \& Saletu, 1996).

\subsection{2. $\mathrm{P} 2$}

The $\mathrm{P} 2$ is a positive-going wave peaking at $150-275 \mathrm{~ms}$ post-stimulus onset. It often occurs with the N1 (N1/P2 complex) and has been identified in tasks involving selective attention, feature detection, and short-term memory. The auditory P2 distribution is less localized than the N1, with an amplitude highest at the vertex $(\mathrm{Cz})$. The auditory and visual P2 is associated with longer peak latency in older adults (Anderer, et al., 1996; Finnigan, et al., 2011). 


\subsection{3. $\mathrm{N} 2$}

The $\mathrm{N} 2$ is the second negative going waveform elicited by pictures and is considered to index a variety of cognitive processes, including stimulus discrimination and target selection (Ritter, Simson, \& Vaughan, 1983), response inhibition in Go/NoGo tasks (Eimer, 1993; Mathalon, Whitfield, \& Ford, 2003), early sublexical processing of visual words (N250; Grainger, Kiyonaga, \& Holcomb, 2006; Holcomb \& Grainger, 2006; Kiyonaga, Grainger, Midgley, \& Holcomb, 2007), perceptual mismatch in shape, color, and orientation between prime and target (N270; Cui, Wang, Wang, Tian, \& Kong, 2000; Kong, Wang, Zhang, Wang, Wei, et al., 2000), detecting differences between expected and perceived phonological word form (N280/Phonological Mapping Negativity; Archibald \& Joanisse, 2012), and access to structural semantic features (frontally distributed N300; Demiral, Malcolm, \& Henderson, 2012; McPherson \& Holcomb, 1999). Aging has been associated with increased peak latency for both Go and No-Go $\mathrm{N} 2$, indicating delayed inhibitory processes underlying visual and semantic discrimination (Tachibana, Aragane, \& Sugita, 1996) and reduced amplitude of the NoGo N2 for number identification, suggesting reduced inhibitory control in older adults (Bokura, Yamaguchi, Matsubara, \& Kobayashi, 2002).

\subsection{4. $\mathrm{N} 400$}

The N400 is a negative-going waveform that peaks at about $400 \mathrm{~ms}$ post-stimulus onset and has a central-parietal right lateralized distribution for visual stimuli. The 'classic N400' is associated with processing semantically incongruous words (Kutas \& Hillyard, 1980), but is a component that is elicited by anomalies in auditory speech 
(Connolly \& Phillips, 1994; Holcomb, Coffey, \& Neville, 1992) and American Sign Language (Neville, 1985). The N400 has also been shown for single words (Pratarelli, 1994), and is larger for pictures that are semantically unrelated to a previous prime (McPherson \& Holcomb, 1999), and pictures that are not phonologically related to a previous prime (Blackford, Holcomb, Grainger, \& Kuperberg, 2012; Grainger, Lopez, Eddy, Dufau, \& Holcomb, 2012; Holcomb \& Grainger, 2006; Praamstra, Meyer, \& Levelt, 1994), indicating that the amplitude of the N400 is sensitive to the strength of excitation that arrives from a primed context (Van Petten \& Kutas, 1990). Words or pictures whose activation has been primed by a preceding stimulus will elicit a smaller N400 relative to those that have not been primed. For example, auditory probes that shared phonemes with the preceding picture target elicited smaller N400s relative to unrelated picture targets, indicating greater ease of probe word retrieval (Jescheniak, Schriefers, Garrett, \& Friederici, 2002). Semantic congruity in sentence final words as well as in picture priming paradigms also elicit a smaller amplitude N400, indicating greater ease of lexical integration relative to semantically incongruous endings (Brown \& Hagoort, 1993; Holcomb \& Anderson, 1993). The N400 is also sensitive to the time course with which phonological information is available in auditory word recognition, as evidenced by earlier N400 for prime-target pairs with word-initial overlap than for primetarget pairs with word-final overlap (Praamstra et al., 1994). The N400 elicited by semantic incongruities in spoken sentences in older adults is smaller and somewhat delayed relative to young adults, indicating greater delay in registering sentence meaning (King \& Kutas, 1995; Kutas \& Iragui, 1998; Woodward, Ford, \& Hammett, 1993). 


\subsection{Aims and Hypotheses}

The present study used phonologically related and unrelated pseudo word primes to assess behavioral and electrophysiological correlates of phonological processing, when healthy young, middle-aged, and older adults implicitly named pictures. In addition, we required participants to make phonological judgments regarding the prime and picture's name. While we expected differences between young and older adults in some of the variables, our general hypotheses for the middle-aged group are based on studies that have shown intact confrontation naming and vocabulary in the 50s (Albert et al., 1988; Bowles \& Salthouse, 2008; Zec et al., 2005, 2007). Therefore, the middle-aged adults were expected to perform on par with young adults on behavioral measures of naming. Our specific aims were:

\section{To determine word frequency influences on behavioral and neural indices of} phonological priming and covert picture naming. Infrequent words are prone to greater retrieval failures than frequent ones, owing to weak lemma-phonological associations (Harley \& Bown, 1998). We predicted that high frequency pictures would be named faster than low frequency pictures (Brysbaert, 1996; Meschyan \& Hernandez, 2002). Due to the lack of evidence regarding influence of target word's frequency on priming effects, we could not make strong predictions, but speculated that the priming effects would be greater for low-frequency words in older adults as they may benefit more from phonological cues for retrieval of low-frequency words as compared to younger adults.

2. To determine how behavioral measures of reaction time and accuracy differ between young, middle-aged, and healthy older adults in picture naming, when the 
targets are either preceded by a phonological prime or not. We predicted that the phonological judgment response times for all three groups would be faster and more accurate when primed with phonologically related pseudo words compared to unprimed trials, as priming would strengthen the lemma-phonological connections (James \& Burke, 2000; White \& Abrams, 2002) by pre-activating the target's phonological representation. We predicted that the behavioral priming effect (unprimed minus primed) for phonological judgment response time would be similar across the three groups based on behavioral evidence that suggests that repetition or phonological priming does not produce larger effects for older than young adults (White \& Abrams, 2002; Burke, Austin $\&$ Kester, 1998). Older adults are predicted to exhibit overall slower reaction times as compared to the younger groups (Der \& Deary, 2006; Gorus, De Raedt, Lambert, Lemper, \& Mets, 2008).

3. To evaluate differences in neural correlates of phonological priming in young, middle-aged, and older adults during word retrieval. Priming with words that share initial phonemes with the target word prior to naming resolves tip-of-the-tongue (TOT) experiences in older adults (Abrams, White, \& Eitel, 2003; Meyer \& Bock, 1992). Since phonological priming facilitates more efficient processing of the target picture name, we hypothesized that all three groups would exhibit smaller amplitudes of the N400 elicited by primed relative to unprimed targets. Based on previous reports of smaller and delayed N400 for semantic tasks (King \& Kutas, 1995; Kutas \& Iragui, 1998; Woodward, Ford, \& Hammett, 1993) and the TD model's hypothesis regarding weaker access to phonological nodes for older adults, we predicted reduced amplitude and increased peak latency of the N400 indexing lexical-phonological integration in older adults (King \& 
Kutas, 1995). Also, based on brain imaging data that suggest age-associated increase in frontal and right hemisphere activity during word retrieval (Park \& Reuter-Lorenz, 2009; Shafto et. al., 2010;), we predicted the scalp distribution of the ERP components elicited in the primed and unprimed conditions would distinguish the older from the younger participants.

To our knowledge, few studies have assessed neural correlates of single word processing in middle-aged adults. For processing of semantically incongruous words within sentences, middle-aged adults showed reduced amplitude (Faustmann, Murdoch, Finnigan, \& Copland, 2007) and increased latency of the N400 (Gunter, Jackson, \& Mulder, 1992). It is likely that N400 amplitude reduces or latency increases with advancing age even at the single word level.

4. To determine how variances in clinical indices of naming performance, verbal working memory, and/or inhibitory abilities are associated with behavioral and neural functions mediating phonological processing and word retrieval. Accurate word retrieval requires involvement of cognitive functions such as working memory and inhibition that are reported to decline with age (Bopp \& Verhaeghen, 2005; Brown, 1991; Myerson, Emery, White, \& Hale, 2002;). The priming paradigm utilized in the study also requires holding the prime in verbal working memory in order to make decisions about the target picture name as well as vocabulary and word finding abilities to name the picture. Specific relationships between the clinical indices of cognition and behavioral and neural indices of word retrieval were used to help elucidate the role of cognitive factors in word retrieval and aging. 


\section{CHAPTER 2. METHOD}

The design of the present study is a cross-sectional comparison of healthy young, middle-aged, and older adults' phonological judgment and word retrieval abilities. We used two tasks to assess these abilities: a) a behavioral naming task for high- and lowfrequency pictures, and b) an electrophysiological task to explore the neural correlates of word retrieval when participants covertly named phonologically primed or unprimed high- and low-frequency pictures. We used behavioral measures of naming to assess accuracy and speed of phonological judgment and word retrieval. In addition, we used clinical indices of cognitive functions to explore any relationships with the electrophysiological indices and behavioral measures of naming. The screening tests, cognitive tests, and picture naming task were performed in one session. The participants returned for the second session within seven days and performed the ERP task.

\subsection{Participants}

Forty-three healthy adults were recruited from the Greater Lafayette area of Indiana, USA, who included 15 older adults (10 females, 4 males; Mean age: 66.1 years), 13 middle-aged adults (13 females; Mean age: 49 years) and 15 young adults (11 females, 4 males; Mean age: 24.7 years). On arrival to the Neural Systems for Language Processing lab, participants completed a questionnaire that 
probed the participants' medical and family history for physical or neurological impairments. All participants included in the study were right handed and native speakers of American English, with no reported history of speech, language, hearing, physical, and neurological impairments. The groups were matched for education level, as measured by Hollingshead education scale (Hollingshead, 1975), $F(2,40)=.93, p=.09$. A vision screening was performed using the Snellen chart; only individuals with better than 20/25 corrected or uncorrected vision were included in the study. Only individuals who had bilateral thresholds below $20 \mathrm{~dB} \mathrm{HL}$ at $500 \mathrm{~Hz}, 1 \mathrm{kHz}$, and $2 \mathrm{kHz}$ and below $40 \mathrm{~dB}$ at $4 \mathrm{kHz}$ $\& 6 \mathrm{kHz}$, as determined by recording audiometric thresholds using a portable audiometer in a sound attenuating room, were included. Participants performed within normal limits on composite score of The Cognitive-Linguistic Quick Test (CLQT; Helm-Estabrooks, 2001) and had normal range scores on the subtests of attention, memory, language, executive functions, and visuospatial skills.

One of the questions probed in the questionnaire ('Do you experience trouble finding the right word when talking?') required participants to rate any experience with word finding difficulty along a five point scale, with ' $0=$ Never', ' $1=$ Seldom', ' 2 = Sometimes', ‘3 = Often', and ' $4=$ All the time'. Middle-aged and older adults reported relatively more word finding difficulties (Middle-aged $M=1.46, S E=0.14$; Older $M=$ $1.46, S E=0.13)$ compared to young adults $(M=0.86, S E=0.13), F(2,40)=6.52, p=$ $0.004, \eta_{\mathrm{p}}{ }^{2}=.25$. The results suggested that young adults reported word finding difficulties less than 'Seldom', while middle-aged and older adults reported word finding difficulties between 'Seldom' and 'Sometimes'. 


\subsection{Cognitive Assessment}

Participants' proficiencies were assessed in four cognitive domains necessary for understanding and using language: verbal working memory, inhibition ability, vocabulary, and word finding. The Digit Span Backward (DSB) subtest of the Wechsler Memory Scale-III (WMS-III; The Psychological Corporation, 1997) was used to assess verbal working memory. Strings of digits of increasing length were read aloud and the participants were required to repeat them in the reverse order. Repeating digits backwards is considered to require information storage as well as concurrent processing to mentally reorder the stimuli, resulting in a heavy load on working memory (The Psychological Corporation, 2002). The Stroop Color -Word Test (Golden \& Freshwater, 2002) was used to measure inhibition abilities. The test included two control subtests involving wordreading and color naming, and a third subtest involving color-naming when the ink color and word were incongruent. The Stroop test is believed to measure cognitive inhibition, or the ability to inhibit an overlearned response (e.g. reading) in favor of an unusual one (e.g. color naming). The Peabody Picture Vocabulary Test, Fourth Edition (PPVT-4, Dunn \& Dunn, 2007) was used to measure receptive vocabulary. The examiner said a word while the participant viewed a page with four color pictures as response options. The participant selected the picture that best illustrated the word's meaning. The Test of Adolescent/Adult Word Finding (TAWF; German, 1990) is a test for assessing word retrieval ability in adults. Five subtests were administered - picture naming for nouns, picture naming for verbs, sentence completion naming, description naming, and category 
naming. The raw and standardized scores of the PPVT and TAWF are reported as they each revealed different relationships between the groups.

\subsection{Naming Task}

\subsubsection{Experimental Stimuli}

Forty black-and-white line drawings of nouns were selected from the International Picture Naming Project (Szekely, et. al., 2003). The majority of the pictures from this database were from the Snodgrass and Vanderwart (1980) stimuli. The pictures selected from the International Picture Naming Project were matched for name agreement, image agreement, familiarity, and visual complexity. Twenty of these pictures had high frequency monosyllable names (>8.1 per million) and 20 had low frequency monosyllable names ( $<2.5$ per million) based on the Corpus of Contemporary American English (Davies, BYU) that included a corpus of 520 million words. For example, 'book' (Freq: 231.1) and 'bear' (Freq: 52.5) are high frequency words as compared to 'lamp' (Freq: 0.5) and 'globe' (Freq: 1.4), which are low frequency words. Appendix Tables A1 and A2 show the stimuli in the high frequency and low frequency lists respectively, along with phonological neighborhood density and phonological neighborhood frequency values (Cross-Linguistic Easy-Access Resource for Phonological and Orthographic Neighborhood Densities, CLEARPOND, Brysbaert \& New, 2009). Univariate ANOVA between the two lists revealed a frequency effect, $F(1,38)=11.965, p<0.001$, but no differences for phonological neighborhood density, $F(1,38)=0.707, p=0.41$, or phonological neighborhood frequency, $F(1,38)=6.184, p=0.14$. Therefore, we were able to test the unique effect of word frequency on the latency and accuracy of picture 
naming. All the pictures were resized to 567 x 567 pixels to maximize resolution and maintain consistency across the stimuli.

\subsubsection{Procedure}

The behavioral word retrieval task was self-paced, therefore allowing for variation in response times between participants. The pictures were presented through Presentation Version 16.3. Participants sat approximately $60 \mathrm{~cm}$ from a computer monitor. They responded by speaking into a microphone placed $5 \mathrm{~cm}$ away from their mouth that was attached to a voice key (Cedrus SV-1 Smart Voice Key, San Pedro, CA) to record naming latencies. Each participant's loudness threshold was adjusted on the voice key by asking them to count to ten using normal pitch and loudness. Each trial started with a 'Ready?' prompt on the screen. The participants pressed the 'Enter' key on a keyboard when they were ready to start the trial, following which a picture appeared on the screen for $300 \mathrm{~ms}$. The duration between their button press response and onset of the picture varied between $1000 \mathrm{~ms}$ and $1300 \mathrm{~ms}$. Participants were instructed to name the picture as quickly as possible using single words. Eight example trials were practiced first. Responses were scored for naming accuracy. Only correct responses were included to calculate the average for naming latencies.

The vision, hearing, and cognitive screenings, cognitive assessments, and the naming task were administered in a single session. The electrophysiological experiment was conducted within one week of the first session. 


\subsection{ERP Task}

\subsubsection{Experimental Stimuli}

ERP stimuli included 88 black-and-white line-drawings of nouns from the International Picture Naming Project with 44 high frequency ( $>7.8$ per million) and 44 low frequency $(<5.6$ per million) monosyllable names that comprised the picture targets (Appendix Tables B1 and B2). There was no overlap between the stimuli in the naming task and ERP task. The two lists for the ERP task also differed in terms of word frequency, $F(1,86)=18.60, p<0.001, \eta_{\mathrm{p}}^{2}=.17$, but not in terms of phonological neighborhood density, $F(1,86)=1.39, p=0.24$, or phonological neighborhood frequency, $F(1,86)=1.02, p=0.32$. Eighty-eight monosyllable auditory pseudo-word primes were developed by replacing the final consonant or consonant cluster of the target picture name with another unrelated consonant or consonant cluster. These prime-target pairs constituted the phonologically primed condition (E.g., /tref/-/tren/;/skəv/-/skəךk/). Pseudo-words were used to avoid confounds of word frequency of the primes on the target words. The phonologically unprimed condition was created by paring each target picture with a pseudo-word that did not share any phonology with it (E.g., /fætf/-/tren/; $/ \mathrm{mul} /-/ \mathrm{sk} \not \mathrm{k} /$ ). Therefore, there were a total of 44 primed high frequency pictures, 44 unprimed high frequency pictures, 44 primed low frequency pictures, and 44 unprimed low frequency pictures. Each picture appeared twice throughout the experiment, once for each priming condition. The primed and unprimed pairs were pseudo-randomized between the blocks. The prime-target pairs were presented in four blocks, with 44 pairs per block. Each block was separated by a 2-3 minute break. 
The pseudo-words were recorded by a native American-English female speaker in a sound-attenuating booth. Recordings were made using a voice recorder and digitized using PRAAT program. The pseudowords were each approximately $510 \mathrm{~ms}$ long. They were presented at a level of 70-75 dB SPL through an overhead speaker that was mounted directly above the computer monitor on which the picture stimuli were presented.

\subsubsection{Electrophysiological Recordings}

An elastic electrode cap containing $32 \mathrm{Ag}-\mathrm{Cl}$ electrodes arranged according to the international 10-10 system (American Electroencephalographic Society, 1994) was used to record electrical activity from the scalp. The electrode channels included lateral sites F7/F8, FC5/FC6, T7/T8, CP5/CP6, and P7/P8; medial sites F3/F4, FC1/FC2, C3/C4, $\mathrm{CP} 1 / \mathrm{CP} 2, \mathrm{P} 3 / \mathrm{P} 4, \mathrm{PO} 3 / \mathrm{PO} 4$, and $\mathrm{O} 1 / \mathrm{O} 2$; and midline sites FZ, CZ, PZ, and OZ. An offline average of the left and right mastoid signals served as the reference. Horizontal eye movements were monitored by electrodes placed on the left and right outer canthi. Vertical eye movements were monitored using an electrode at the inferior orbital ridge and superiorly using FP1. The continuous data was collected using Biosemi ${ }^{\circledR}$ active electrode EEG system, where two extra electrodes, the common mode sense (CMS) and driven right leg (DRL), served as ground electrodes. The signals were band-pass filtered between 0.1 and $100 \mathrm{~Hz}$, and digitized at the rate of $500 \mathrm{~Hz}$. 


\subsubsection{Procedure}

Once the participants were fitted with the electrode capped, they were seated approximately $176 \mathrm{~cm}$ away from a computer screen with a response pad in hand. Once ready, they were given the following instructions:

“Today, you will hear some nonsense words and see some pictures. Each trial will start with a prompt, 'Ready', on the computer screen. Whenever you are ready, press any button on this response pad to start the trial. As soon as you press the button, you will see a plus sign in the middle of the screen and you will hear a nonsense word. Then a picture will appear on the screen for a very short duration. As soon as you see the picture, press the 'Yes' button as quickly as you can if the nonsense word you heard and the name of the picture start with the same sound, or press 'No' as quickly as you can if they don't start with the same sound. Then you will be prompted to name the picture you just saw. After you name the picture, press any button to move on to the next trial. Every ten minutes or so, you will get a break to relax. Let's do a practice set first."

All visual prompts were presented in Arial font as white text against a black background. As illustrated in Figure 2.1, each trial began with a 'Ready?' image presented on the computer screen. When ready, the participant pressed a button on the response pad. The 'Ready' image was replaced by a '+' image to provide a visual focus. The pseudo-word prime was presented through the speaker $1000-1300 \mathrm{~ms}$ after the participant pressed the button. The target picture was then presented on the screen for 
300ms followed by the ' + ' image. From the participant's seated position, the picture was presented at a visual angle of 5.85 degrees horizontally and 5.26 degrees vertically. The stimulus onset asynchrony (SOA) between the prime and target was $800 \mathrm{~ms}$. This SOA was chosen based on cross-modal phonological priming studies that found that the N400 was elicited only when the target was presented at an SOA of $800 \mathrm{~ms}$, but not at $200 \mathrm{~ms}$ or 0ms (Holcomb, Anderson, \& Grainger, 2005; Holcomb \& Anderson, 1993). The participant then pressed the 'Yes' or 'No' button to indicate their response. The participants made button press responses using one finger of each hand for 'Yes' and 'No'. The 'Yes' and 'No' hands for responses were counterbalanced between participants. By pressing 'Yes' or 'No' buttons based on the initial sound of the primetarget pairs, the participants were making phonological judgments. This was also an implicit task for word retrieval, based on the assumption that the participants would have to retrieve conceptual, lemma, and at least partial phonological information of the target picture in order to make phonological judgments regarding the prime and target. After participants pressed the 'Yes' or 'No' buttons, they were prompted to name the picture with a 'Picture name?' image on the screen. Delayed naming was used in the task to avoid artifacts from articulatory planning and execution as a result of immediate naming (see Ganushchak, Christoffels, \& Schiller, 2011, for a review). Following naming, the participants pressed a button to move on to the next trial. 'Ready?' reappeared on the screen and the process was repeated for successive trials. Once the practice was complete, the experiment was initiated. 


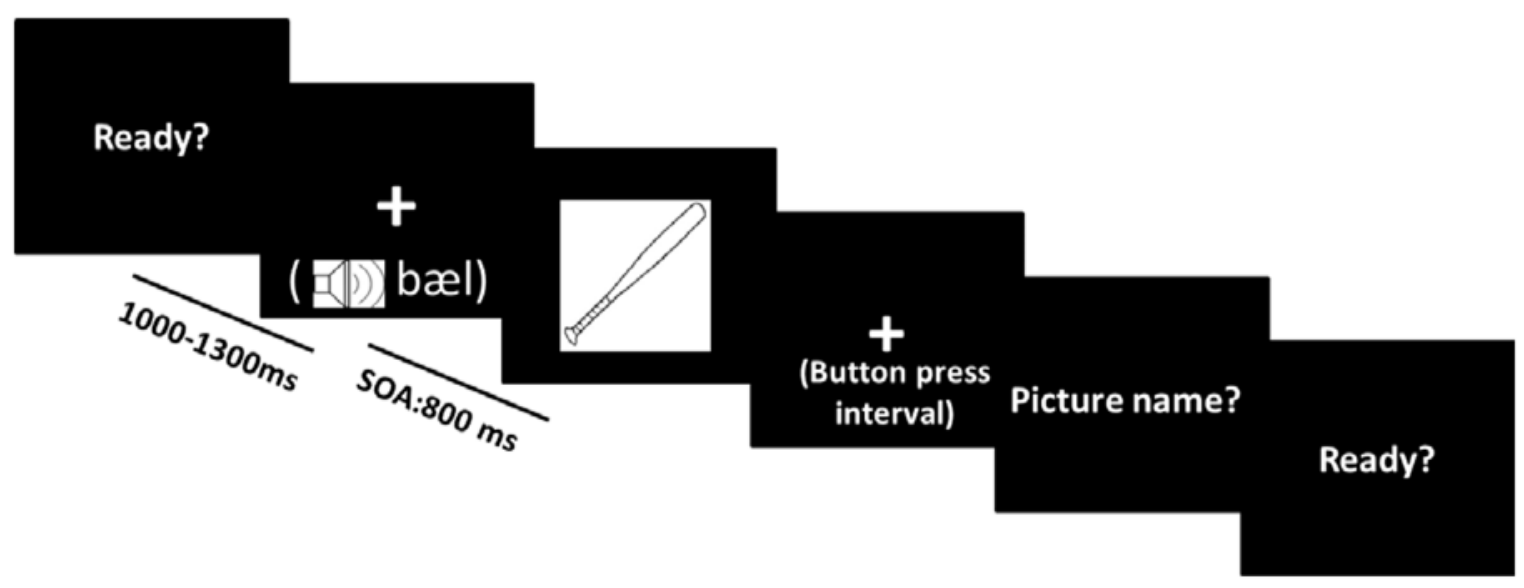

Figure 2.1. Illustration of the ERP experimental procedure.

\subsection{Data Analyses}

\subsubsection{Behavioral Measures from the Naming Task}

Dependent measures for the behavioral naming task were naming accuracy and naming latency. These behavioral measures were analyzed using a Repeated Measures ANOVA that included a between-groups factor (Group: Young, Middle-aged, Older) and a within-subject factor (Word frequency: high, low).

\subsubsection{Behavioral Measures from the ERP Task}

Phonological judgment accuracy and phonological judgment response time (RT) were obtained from the signals generated by the response pad. RT was measured as the time between picture onset and button press, and was calculated only for correct trials. Phonological judgment RT and accuracy were averaged across trials for each participant separately for primed and unprimed conditions for high and low frequency target words. 
Naming accuracy was also noted by the experimenter during the ERP task. The phonological judgment accuracy, RT, and delayed naming accuracy were analyzed using a Repeated measures ANOVA that included a between-groups factor (Group: Young, Middle-aged, Older) and two within-subject factor (Word frequency: high, low; Priming condition: primed, unprimed).

\subsubsection{ERP Measures}

The electrophysiological data were analyzed using EEGLAB and ERPLAB, which are MATLAB ${ }^{\circledR}$ toolboxes, (MathWorks, Natick, MA, USA). The continuous EEG was low-pass filtered at $30 \mathrm{~Hz}$ with a $12 \mathrm{~dB} /$ octave roll-off to eliminate high frequency noise. Eye artifacts were removed from the EEG signal by performing Independent Component Analysis (ICA; EEGLAB). The continuous EEG records were epoched from $100 \mathrm{~ms}$ prior to and $2000 \mathrm{~ms}$ after stimulus onset. The ERP activity occurring $100 \mathrm{~ms}$ prior to the onset of the stimuli (pseudo-word, picture) served as a measure of baseline activity. Automatic voltage-dependent trial rejection was then performed on all the EEG channels. The remaining trials were then averaged by target word frequency and priming condition (primed, unprimed) for each participant and only trials with correct phonological judgment responses were included. There was no difference between the groups in the number of correct trials included for averaging for either target word frequency, $F(2,40)$ $<1$ (High - Mean: 88.76\%, SE: 1.52; Low - Mean: 89.03\%, SE: 1.33), or for either priming conditions, $F(2,40)<1$ (Primed - Mean: 88.32\%, SE: 1.53, Unprimed - Mean: 89.47, SE: 1.49). 
The grand average waveforms for each group displayed two ERP components elicited by the pseudo-word primes (N1 and P2) and four components elicited by the picture targets (N1, P2, N2, and N400). Temporal windows centered around the peaks of each ERP component were used to measure the amplitude and latency of those components. These windows were based on visual inspection of the grand average waveform and checked against the ERP averaged waveforms from each individual participant. Temporal windows selected were as follows: N1 (80-180 ms), P2 (140-240 ms), N2 (220-320 ms), N400 (380-480), and post-N400 window (480-600 ms). Peak amplitudes and peak latencies were measured for the N1 and P2 components since reliable peaks were discernable. Mean amplitudes were measured for the N2 and N400 since the peaks were less reliable across the participants and peak latencies for these components were measured for electrodes with visibly reliable peaks (see Figures 3.9 3.14 in the Results section). The mean amplitude of the averaged ERPs was also measured for the post- N400 window.

Mixed effects repeated measures analysis of variance (ANOVA) was used to compare the ERP measures separately for the high and low frequency targets. The N1 and P2 elicited by the pseudo-word prime were measured at $\mathrm{Cz}$ (Giard et al., 1994; Iragui, Kutas, Mitchiner, \& Hillyard, 1993; Hillyard, Hink, Schwent, \& Picton, 1973). These components are obligatory in nature because they are elicited regardless of participants' attention. The N1 and P2 elicited by the picture target were measured at parietal and parietal-occipital sites (P3, PO3, Pz, P4, and PO4) (Key, Dove, \& Maguire, 2005). The N2, N400, and post-N400 ERPs had broader scalp distributions, consistent 
with previous reports (Kutas \& Hillyard, 1980; Deacon, Breton, Ritter, \& Vaughan, 1991). Preliminary analysis using all the electrode sites revealed that the priming effects were larger over medial and midline sites for each of the groups. Therefore, only medial and midline sites were included for the final analysis. This included a between-group factor (Young, Middle-aged, Older). Within-subject factors included priming condition (primed, unprimed), anterior-to-posterior (AP) scalp distribution (AF and F sites, FC and $\mathrm{C}$ sites, $\mathrm{CP}$ and $\mathrm{P}$ sites, $\mathrm{PO}$ and $\mathrm{O}$ sites) and left-middle-right (LMR) distribution (with 5 sites - two left hemisphere, one midline, and two right hemisphere electrodes - in each of the anterior to posterior clusters) (see Figure 2.2). Hyunh-Feldt (H-F) adjusted $p$-values were used to determine significance with a criterion of $p<0.05$. The effect sizes determining strength of associations, indexed by the partial eta squared statistic $\left(\eta^{2} p\right)$, are reported for all significant effects. Significant group effects were explored using post-hoc Tukey HSD. Significant group x priming interactions were explored using a step-down ANOVA. 


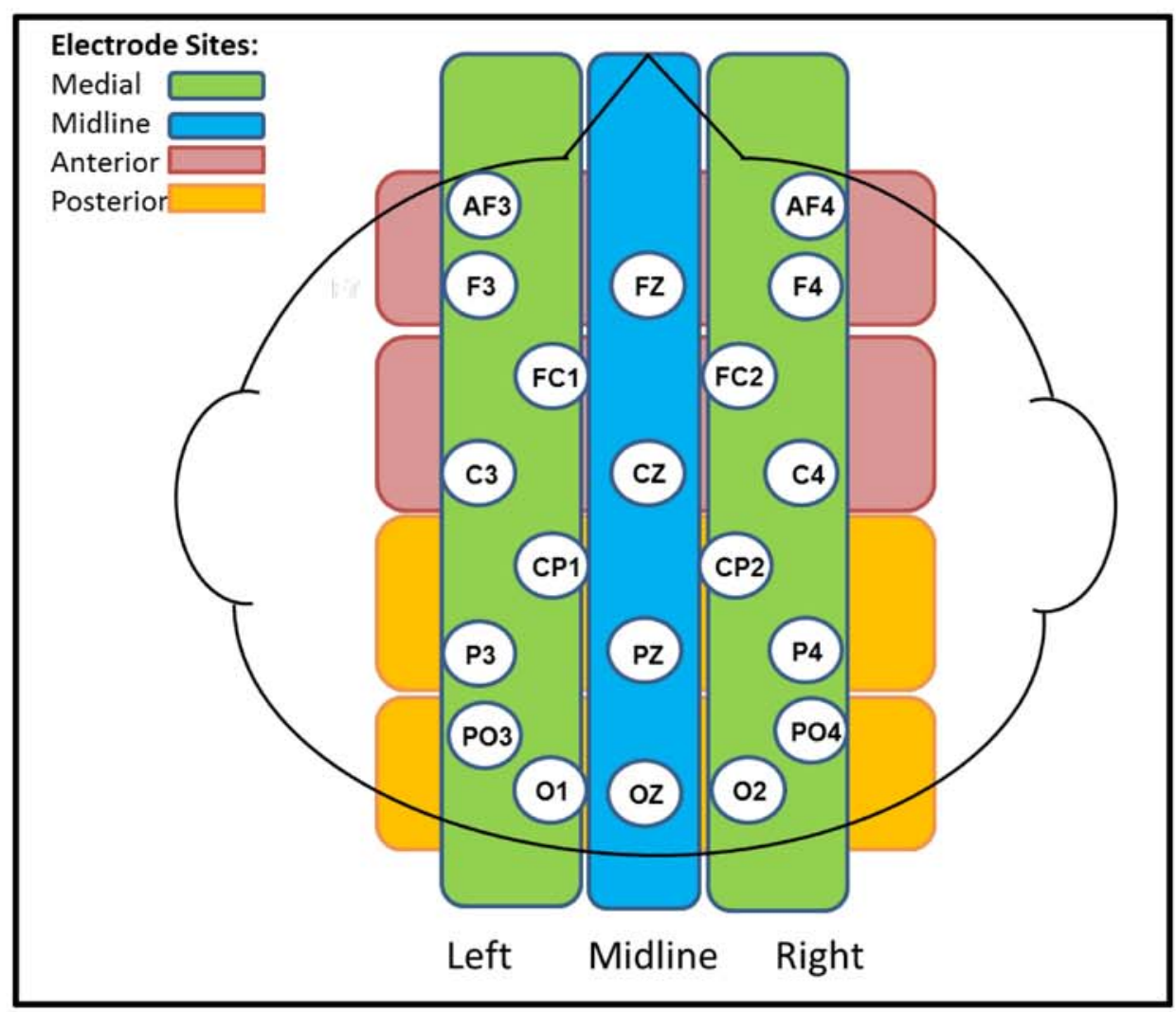

Figure 2.2. Scalp map displaying approximate locations for electrodes included in the analysis.

A hierarchical multiple regression model was used with the purpose of identifying unique determinants of language performance and processing. Only behavioral and ERP measures that revealed a significant group difference were entered into the model. The groups were collapsed for regression analyses, since regression between variables within groups did not reveal significant relationships. 


\section{CHAPTER 3. RESULTS}

\subsection{Results for Cognitive Measures}

Table 3.1 and Figure 3.1 illustrate the performance of each group on the four cognitive assessments. Univariate ANOVAs were performed to compare groups for the cognitive measures. Significant group effects were explored using post-hoc Tukey HSD. Performance on the Digit Span Backwards subtest of the WMS-III did not reveal any group differences, $p=.67$. The Stroop Color-Word Test revealed a group difference, $F$ $(2,40)=28.24, p<.001, \eta_{\mathrm{p}}^{2}=.59$, indicating that young adults scored higher than the middle-aged adults, who in turn scored higher than the older adults $(p<0.001)$. Standardized scores of the PPVT-4 indicated a trend towards significance, $F(2,40)=$ 2.87, $p=.06$. Post-hoc tests revealed that the older adults had significantly higher PPVT4 scores than the young adults, $t(28)=-2.42, p=0.02$, but there were no significant differences between the other groups ( $p>.05$ ). The raw scores of the PPVT-4 also showed a significant group effect, $F(2,40)=8.13, p=.001, \mathrm{\eta}_{\mathrm{p}}{ }^{2}=.59$, and post-hoc tests revealed that the middle-aged and older adults had higher scores than the young adults ( $p$ $<.02)$. Group effects for the standardized scores on the TAWF, $F(2,40)=6.56, p=$ $.004, \eta_{\mathrm{p}}^{2}=.24$, revealed that older adults displayed higher scores than the young adults $(p$ $=.003$ ), indicating that the older adults in the current sample 
performed better on average than the normative means of the TAWF. Raw scores on the TAWF did not reveal group differences $(p=.22)$, indicating that all groups had similar word findings abilities when not corrected for age. As demonstrated in Table 3.2, the performances (raw scores) across the different cognitive tests were not correlated $(r<$ $.29, p>.07)$, except for the significant correlation between raw scores of the PPVT-4 and TAWF.

Therefore, comparison of the raw scores between the groups on the four cognitive measures suggested that inhibition abilities declined with age, as indexed by the Stroop, and vocabulary size increased with age, as indexed by the PPVT-4. The standardized scores on the PPVT and TAWF indicated that the older adults that participated in the current study had larger vocabularies and greater word finding abilities than the mean standard scores from the normative population. It is important to note that while some research indicates that word finding abilities for proper names, common objects, and verbs generally decline with age (Abrams \& Farrell, 2011; Connor, Spiro, Obler, \& Albert, 2004; Kavé, Knafo, \& Gilboa, 2010; Kavé \& Nussbaum, 2012), the performance of the older participants on the TAWF in the present study was matched to the young and middle-aged participants. 
Table 3.1. Means (Standard Error of the Mean) for Age, CLQT Composite, and Cognitive Test Scores.

\begin{tabular}{ccccccccc}
\hline Group & Age & $\begin{array}{c}\text { CLQT } \\
\text { Composite }\end{array}$ & DSB & \multicolumn{2}{c}{$\begin{array}{c}\text { Stroop } \\
\text { Color- }\end{array}$} & $\begin{array}{c}\text { Ptandardized } \\
\text { score }\end{array}$ & Raw Score & \multicolumn{2}{c}{ Standardized } \\
Score & Raw Score \\
\hline Young & $24.73(1.07)$ & $3.96(0.04)$ & $7.60(0.16)$ & $52.87(1.67)$ & $104.87(1.85)$ & $208.2(1.28)$ & $97(1.77)$ & $99.87(0.67)$ \\
Middle & $49.0(1.13)$ & $4.0(0)$ & $7.62(1.15)$ & $44.23(1.37)$ & $108(3.07)$ & $215.54(2.04)$ & $111.54(7.21)$ & $102.54(1.34)$ \\
Older & $66.10(1.09)$ & $4.0(0)$ & $6.73(0.46)$ & $34.93(1.93)$ & $113.33(2.97)$ & $217.8(1.89)$ & $118.87(2.89)$ & $100.93(1.04)$ \\
\hline
\end{tabular}

Note: CLQT = Cognitive Linguistic Quick Test; DSB = Digit Span Backwards; PPVT-4 = Peabody Picture Vocabulary Test,

Fourth Edition; TAWF = Test of Adolescent/Adult Word Finding

Table 3.2. Pearson's Correlations for the Cognitive Test Scores.

\begin{tabular}{|c|c|c|c|c|}
\hline & DSB & $\begin{array}{l}\text { Stroop Color- } \\
\text { Word Test }\end{array}$ & PPVT-4 & TAWF \\
\hline \multirow[t]{2}{*}{ DSB } & & $r=.15$ & $r=.06$ & $r=.19$ \\
\hline & & $p=.34$ & $p=.72$ & $p=.22$ \\
\hline Stroop Color- & & & $r=-.29$ & $r=-.09$ \\
\hline Word Test & & & $p=.06$ & $p=.56$ \\
\hline \multirow[t]{2}{*}{ PPVT-4 } & & & & $r=.74$ \\
\hline & & & & $p<.001 *$ \\
\hline
\end{tabular}

Note DSB = Digit Span Backwards; PPVT-4 = Peabody Picture Vocabulary Test, Fourth Edition; TAWF = Test of Adolescent/Adult word Finding; * indicates significant correlation 

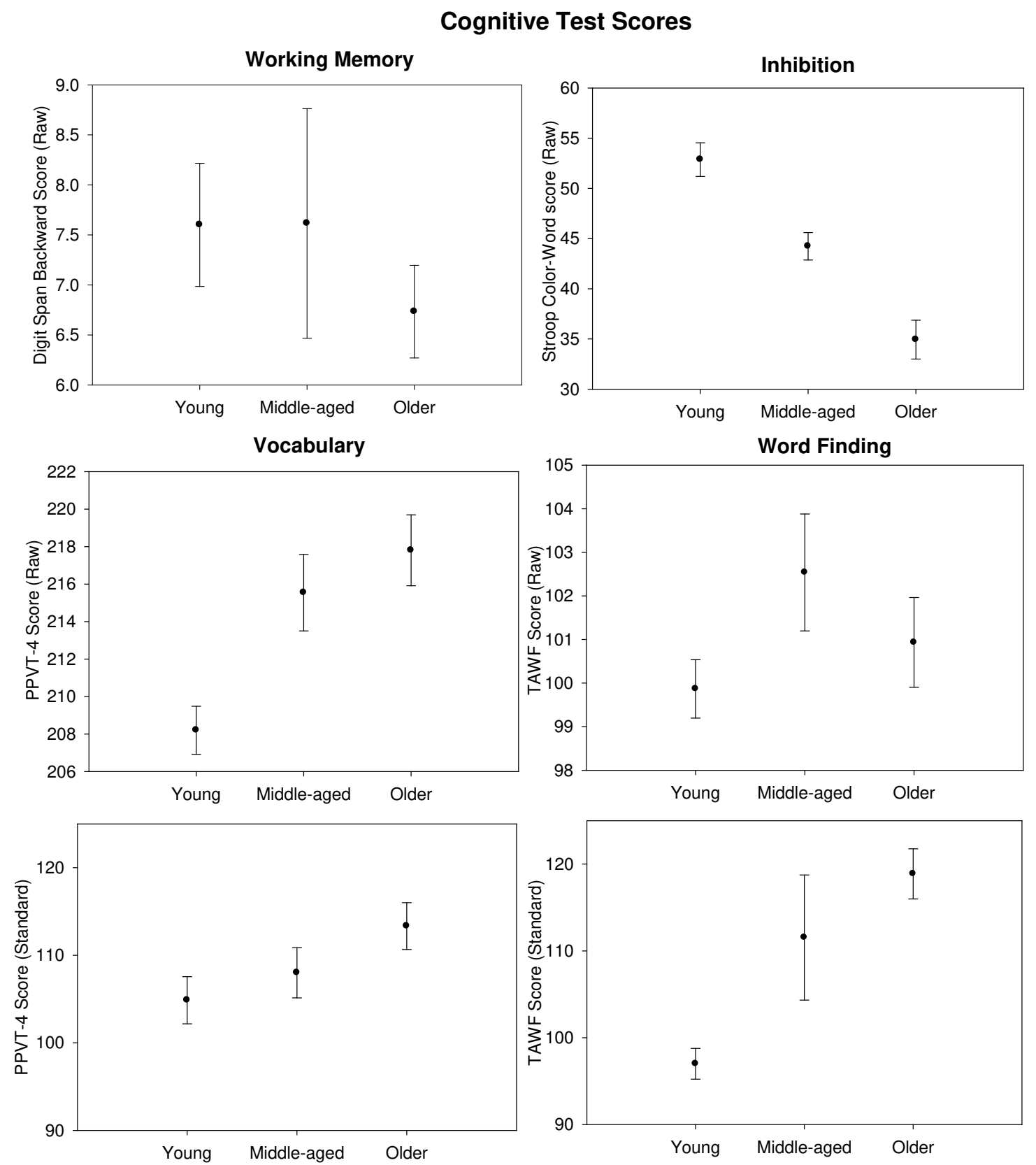

Figure 3.1. Mean Cognitive Test Scores for Young, Middle-Aged, and Older Adults. Bars Represent Standard Error of the Mean. 


\subsection{Results from the Naming Task}

Naming Accuracy: Repeated Measures ANOVA revealed a trend towards a significant frequency effect, $F(1,40)=3.97, p=.053, \eta_{\mathrm{p}}^{2}=.09$, indicating participants named high frequency words $(M=93.72 \%, S E=.84)$ more accurately than low frequency words $(M$ $=91.08 \%, S E=1.09$ ). All participants named the pictures with high accuracy (Young: $M$ $=89.80 \%, S E=1.18$; Middle aged: $M=95.1 \%, S E=1.31$; Older: $M=92 \%, S E=1.57$ ). There was, however, a group effect, $F(2,40)=4.53, p=.02, \mathrm{\eta}_{\mathrm{p}}^{2}=.19$, indicating that the middle-aged adults displayed slightly greater naming accuracy as compared to young adults, $p=.01$ (Figure 3.2).

Naming Latency: Naming latency was analyzed only for correctly named pictures. Repeated-Measures ANOVA revealed a frequency effect, $F(1,40)=59.21, p<.001, \eta_{\mathrm{p}}{ }^{2}$ $=.60$, indicating that participants named pictures of high frequency words faster than those of low frequency words (High frequency: $M=889.55 \mathrm{~ms}, S E=23.29$; Low frequency: $M=984.77 \mathrm{~ms}, S E=24.67)$. There were no significant group effects or group interactions, $\mathrm{F}(2,40)<1$ (Figure 3.2). 

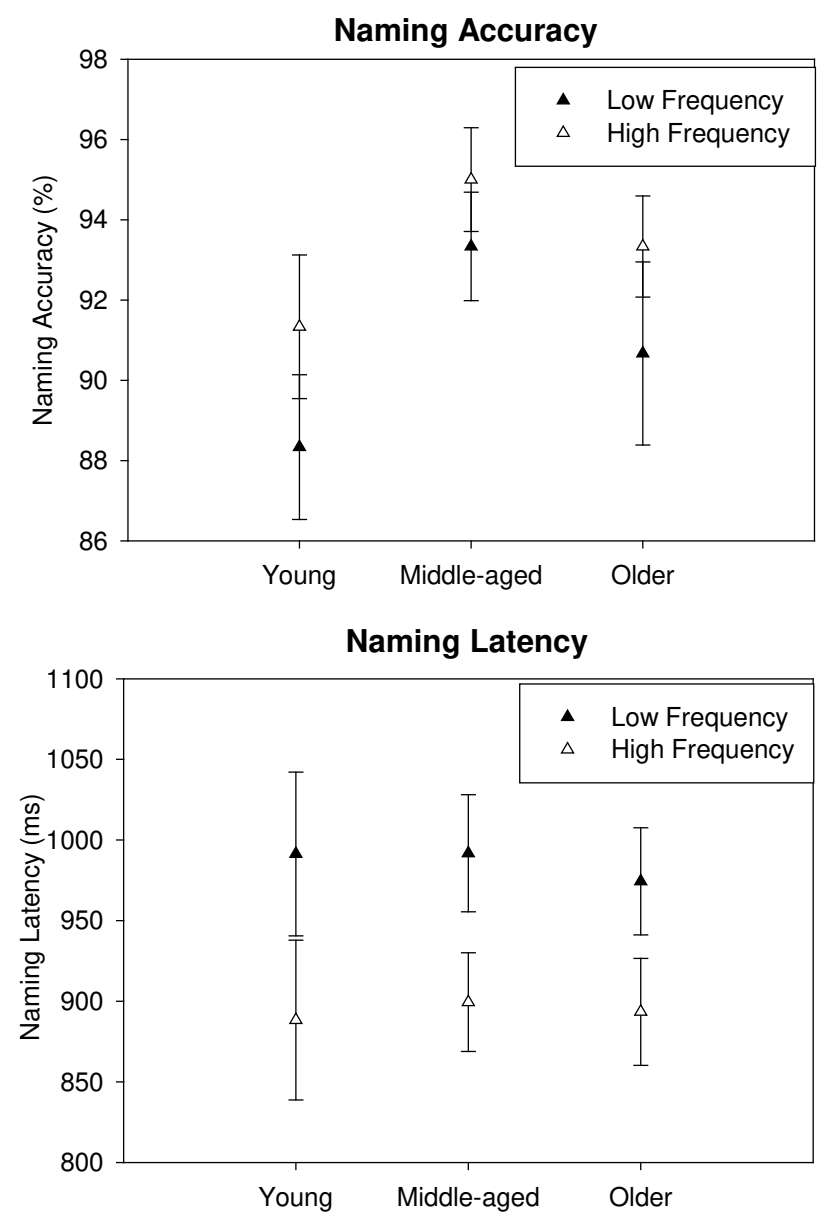

Figure 3.2. Frequency Effect for Naming Accuracy and Naming Latency in Young, Middle-Aged, and Older Adults. Bars Represent Standard Error of the Mean.

\subsection{Results from the ERP Task}

\subsubsection{Behavioral Measures}

Phonological Judgment Accuracy: Participants' phonological judgment accuracy was similar for high and low frequency targets, $p=.12$. As illustrated in Figure 3.3, participants were more accurate in making phonological judgments for unprimed pictures than primed pictures (Primed: $M=89.54 \%, S E=1.16$; Unprimed: $M=95.65 \%, S E=.57$; 
$\left.F(1,40)=22.95, p<.001, \mathrm{\eta}_{\mathrm{p}}^{2}=.37\right)$. Although all the participants were highly accurate in their phonological judgments, a group effect, $F(2,40)=4.29, p=.02, \eta_{\mathrm{p}}{ }^{2}=.18$, indicated that middle-aged adults displayed slightly higher phonological judgment accuracy as compared to the older adults $(p=.02)$, but did not differ from the young adults. There were no significant group interactions, $\mathrm{F}(2,40)<1.32$.

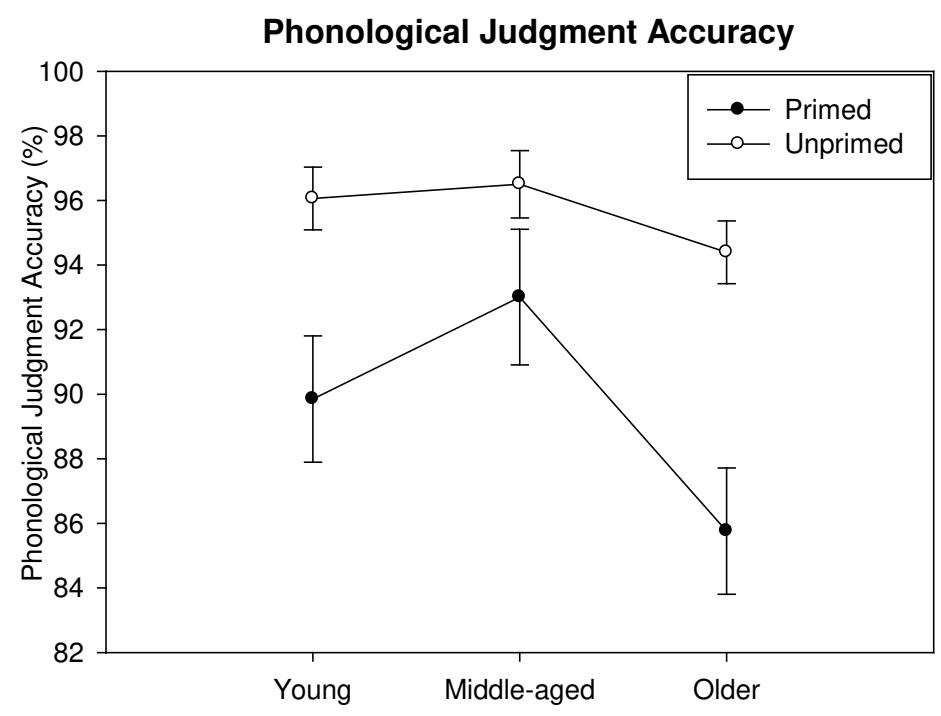

Figure 3.3. Priming Effect for Phonological Judgment Accuracy in Young, Middle-Aged, and Older Adults.

Phonological Judgment RT: RTs were compared only for the correct trials. RTs were shorter for high frequency words as compared to low frequency words (High frequency: $M=1165.56 \mathrm{~ms}, S E=38.29 ;$ Low frequency: $M=1229.21 \mathrm{~ms}, S E=39.79 ; F(1,40)=$ $\left.43.39, p<.001, \mathrm{\eta}_{\mathrm{p}}^{2}=.52\right)$. RTs were also shorter for primed targets in comparison to those that were unprimed (Primed: $M=1136.79 \mathrm{~ms}, S E=38.53$; Unprimed: $M=$ $\left.1257.99, S E=42.28 ; F(1,40)=27.27, p<0.001, \eta_{\mathrm{p}}{ }^{2}=.41\right)$. A group effect, $F(2,40)=$ 
$13.17, p<0.001, \mathrm{\eta}_{\mathrm{p}}^{2}=.40$, and a follow-up post-hoc test revealed significant differences between all three groups, $p<0.05$ (Young: $M=955.63 \mathrm{~ms}, S E=39.25$; Middle-aged: $M$ $=1200 \mathrm{~ms}, S E=61.58 \mathrm{~ms}$; Older: $M=1442.44 \mathrm{~ms}, S E=97.66)$, indicating that phonological judgment RTs increased linearly with age (young $<$ middle-aged $<$ older; Figure 3.4). There were no significant group interactions, $\mathrm{F}(2,40)<0.56$.

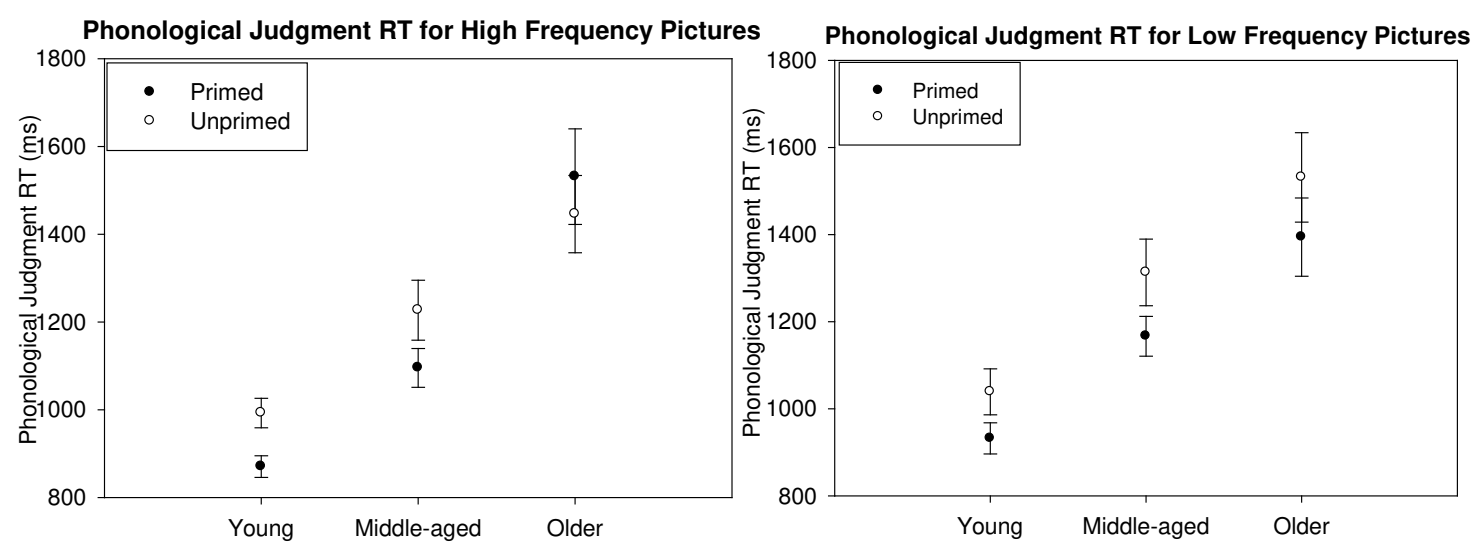

Figure 3.4. Priming effect and Frequency Effect for Phonological Judgment Response Time (RT) in Young, Middle-Aged, and Older Adults

Delayed Naming Accuracy: Participants named pictures of high frequency words with slightly greater accuracy than low frequency words, (High frequency: $M=96.57 \%, S E=$ .47 ; Low frequency: $\left.M=95.25 \%, S E=.51 ; F(1,40)=8.89, p=.005, \eta_{\mathrm{p}}^{2}=.18\right)$, but the difference between the means for naming accuracy between high and low frequency words was only about $1 \%$. As can be seen in Figure 3.5, primed pictures were named more accurately than unprimed pictures (Primed: $M=97.5 \%, S E=.39$; Unprimed: $M=$ $\left.94.29 \%, S E=.57 ; F(1,40)=55.89, p<0.001, \eta_{\mathrm{p}}{ }^{2}=.58\right)$. Although all participants named the pictures in the ERP task with high accuracy, a group effect, $F(2,40)=3.69, p$ 
$=.03, \mathrm{\eta}_{\mathrm{p}}^{2}=.16$, indicated that the middle-aged adults displayed slightly greater accuracy as compared to the older adults $(p=.03)$, but did not differ from the young adults. There were no significant group interactions, $\mathrm{F}(2,40)<2.66$.

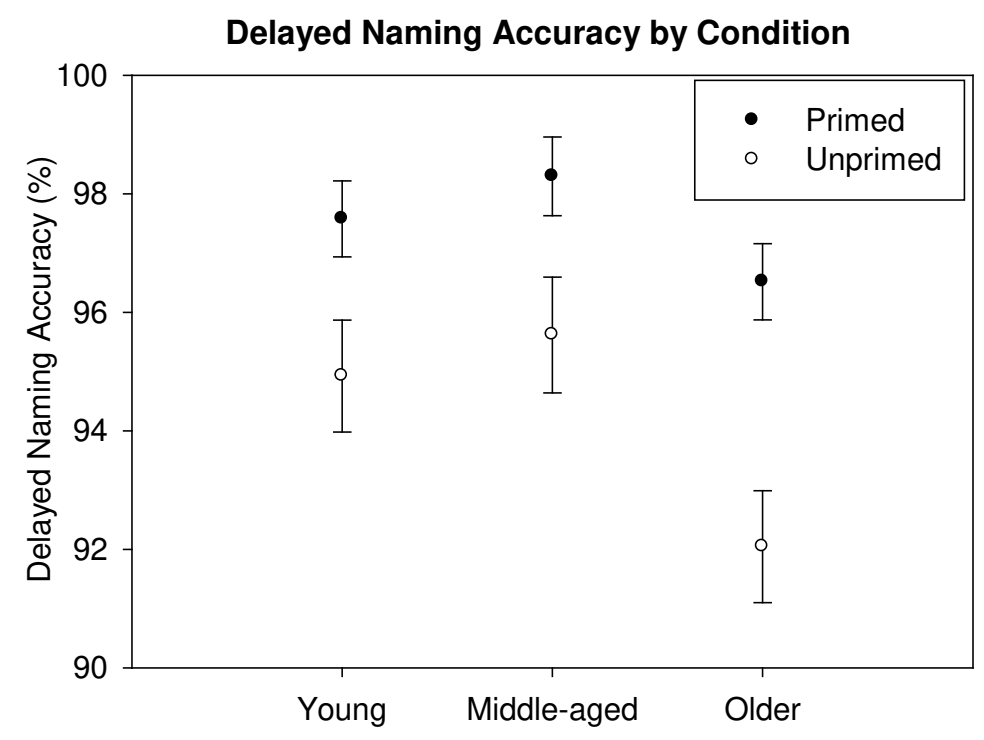

Figure 3.5. Priming Effect for Naming Accuracy in the ERP task for Young, MiddleAged, and Older Adults

To summarize the results of the behavioral variables measured during the ERP task, participants made faster phonological judgments for high frequency pictures as compared to low frequency pictures. Primed pictures had a facilitative effect on phonological judgment RTs and naming accuracy as compared to unprimed pictures. There was an incremental increase in RTs with age. Middle-aged adults showed greater phonological judgment accuracy and naming accuracy as compared to the older adults, however, all participants performed the tasks near ceiling. 


\subsubsection{ERP Measures}

\subsubsection{Prime (Auditory Pseudo-Word)}

The grand average waveform of the ERPs elicited by the primes in each group is shown in Figures 3.6 - 3.8.

N1 (80-180ms) \& P2 (140-240ms): The N1 and P2 peak amplitudes elicited by the pseudo-word primes at $\mathrm{Cz}$ did not reveal group differences, $F(2,40)<1.05, p>.36$.

There were, however, differences between groups for the peak latencies of the N1 and P2 components elicited by the primes, $F(2,40)>3.78, p<0.03$, revealing that older adults exhibited greater latencies of the $\mathrm{N} 1$ and $\mathrm{P} 2$ components as compared to the young adults, $p<0.03$, on the order of $14 \mathrm{~ms}$ for $\mathrm{N} 1$ and $26 \mathrm{~ms}$ for the $\mathrm{P} 2$. The peak latencies for these components for the middle-aged adults did not differ from either the young or older groups. 


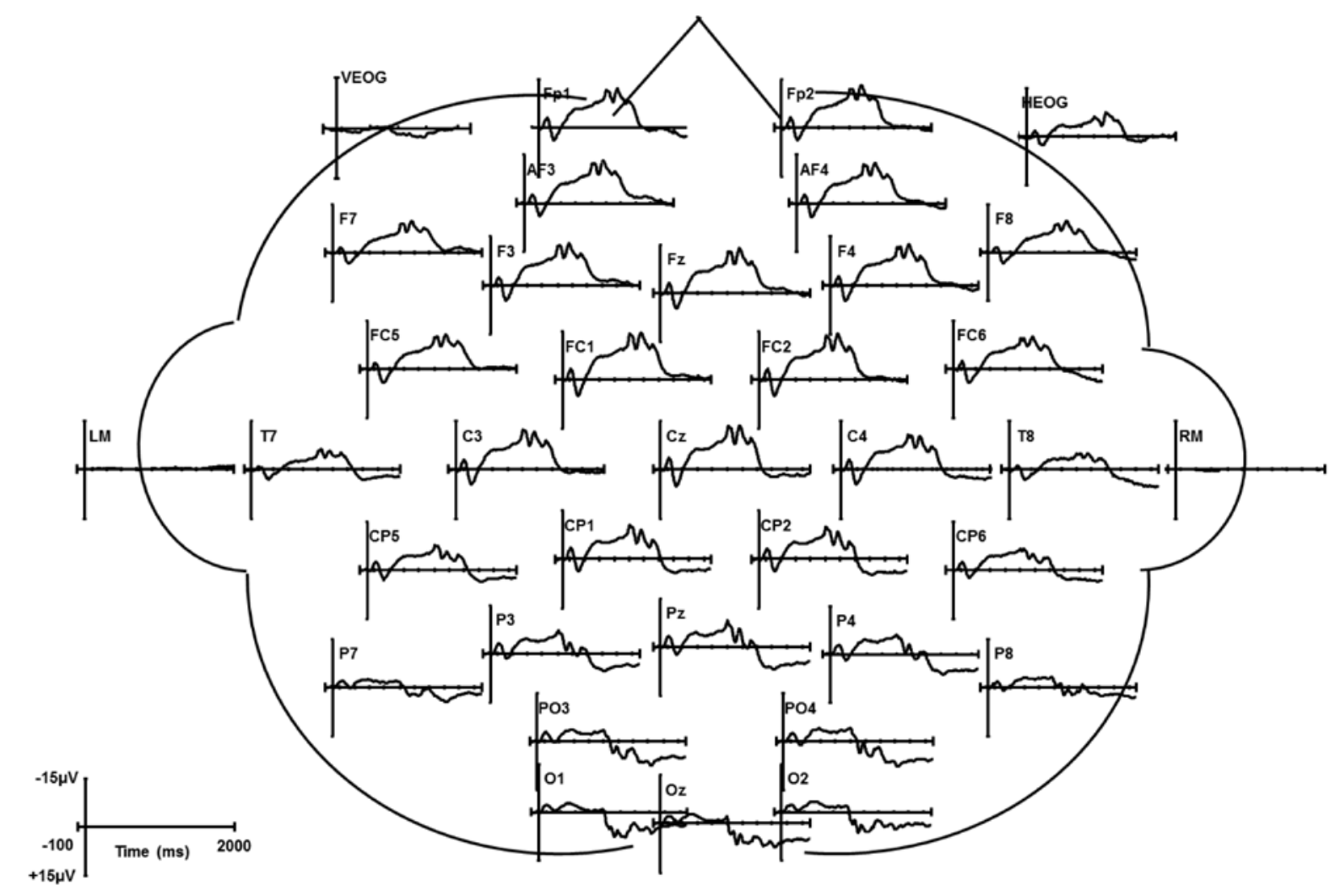

Figure 3.6. Grand average waveforms of the ERPs elicited by pseudo word primes in Young adults. 


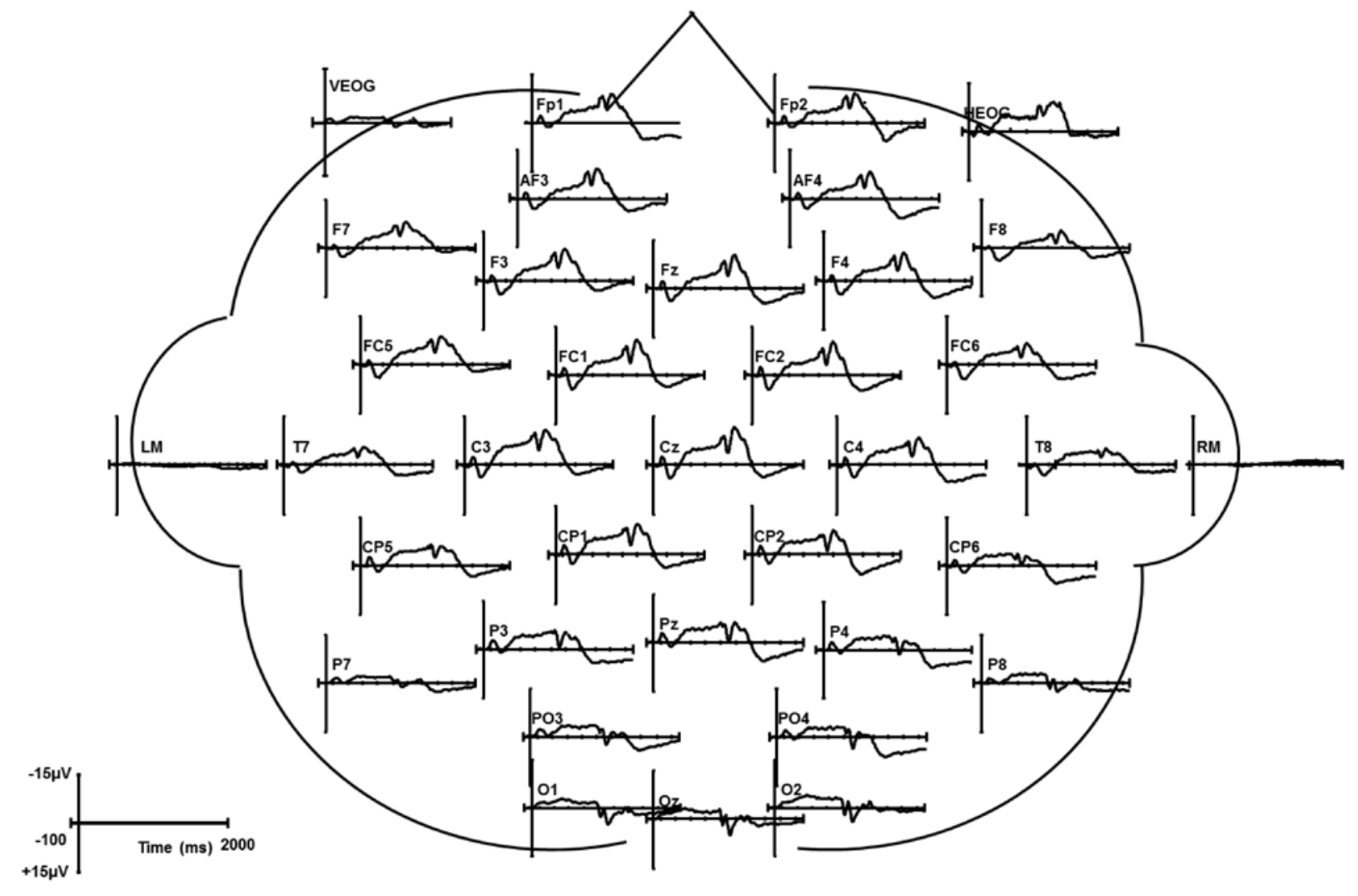

Figure 3.7. Grand average waveforms of the ERPs elicited by pseudo word primes in Middle-aged adults. 


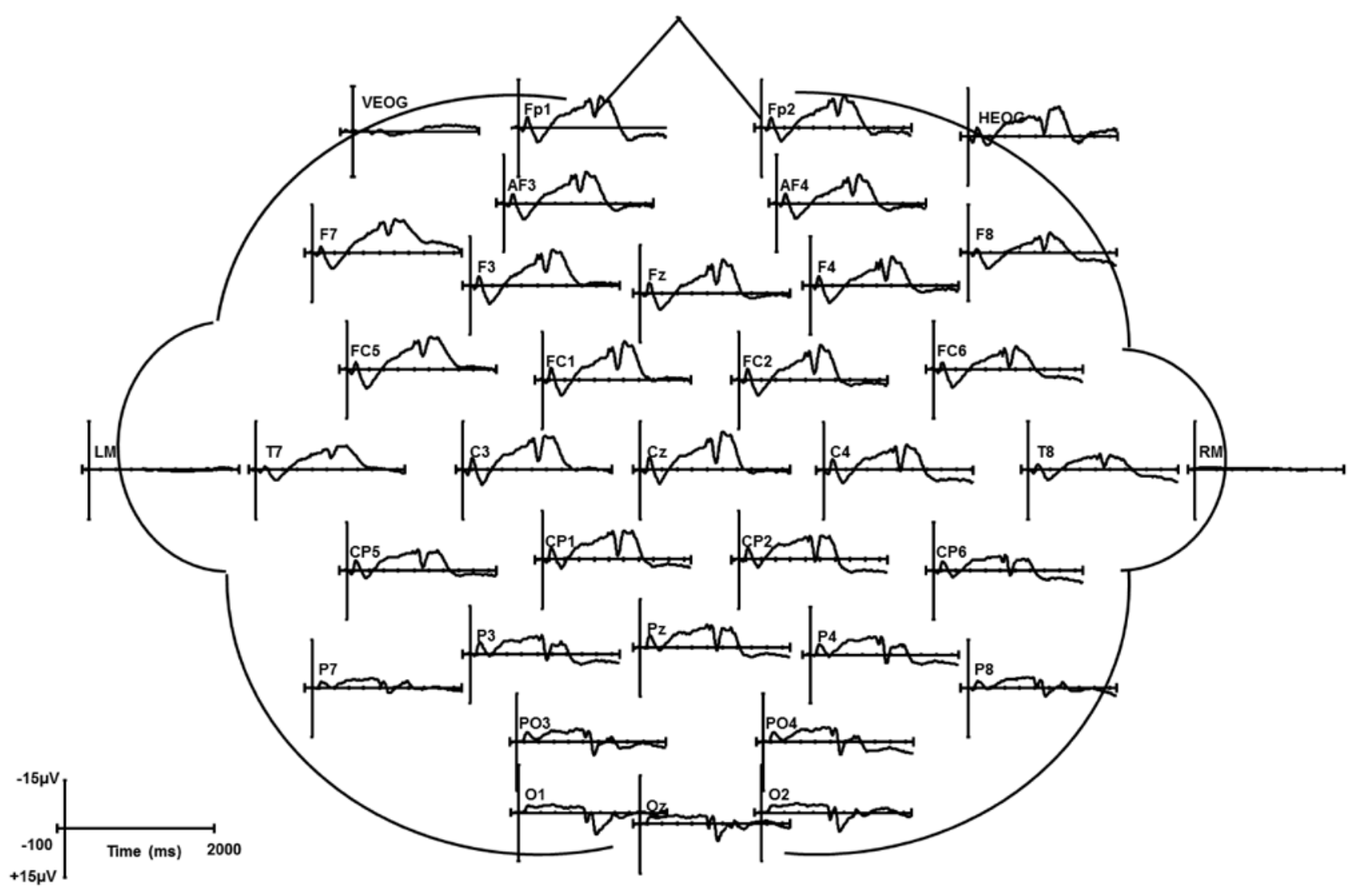

Figure 3.8. Grand average waveforms of the ERPs elicited by pseudo word primes in Older adults. 


\subsubsection{Target (Picture)}

The grand average waveforms of the ERPs elicited by the high and low frequency target pictures in each group are illustrated in Figures 3.9 - 3.14. 


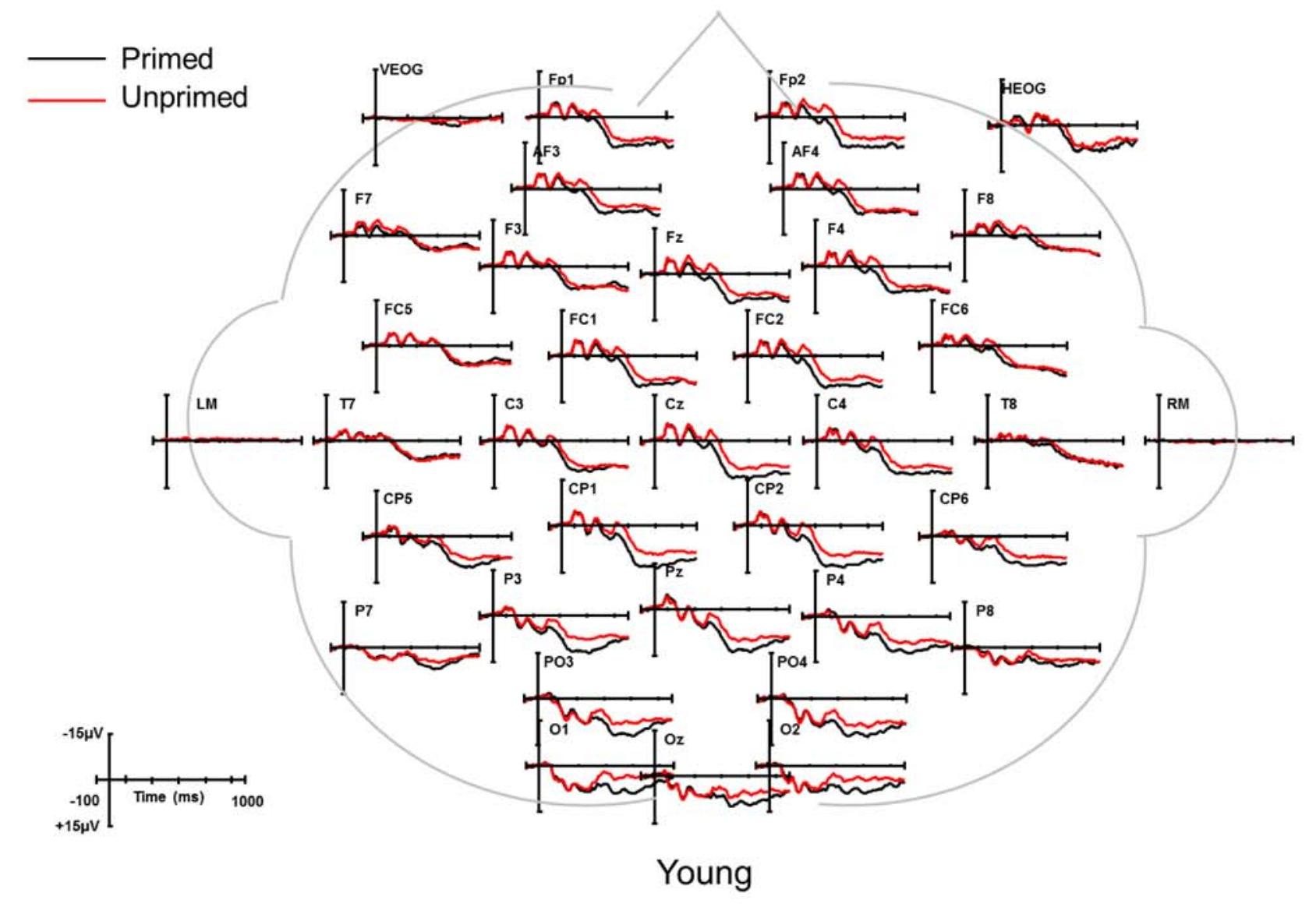

Figure 3.9. Grand average waveforms of the ERPs elicited by high frequency pictures in Young adults. 


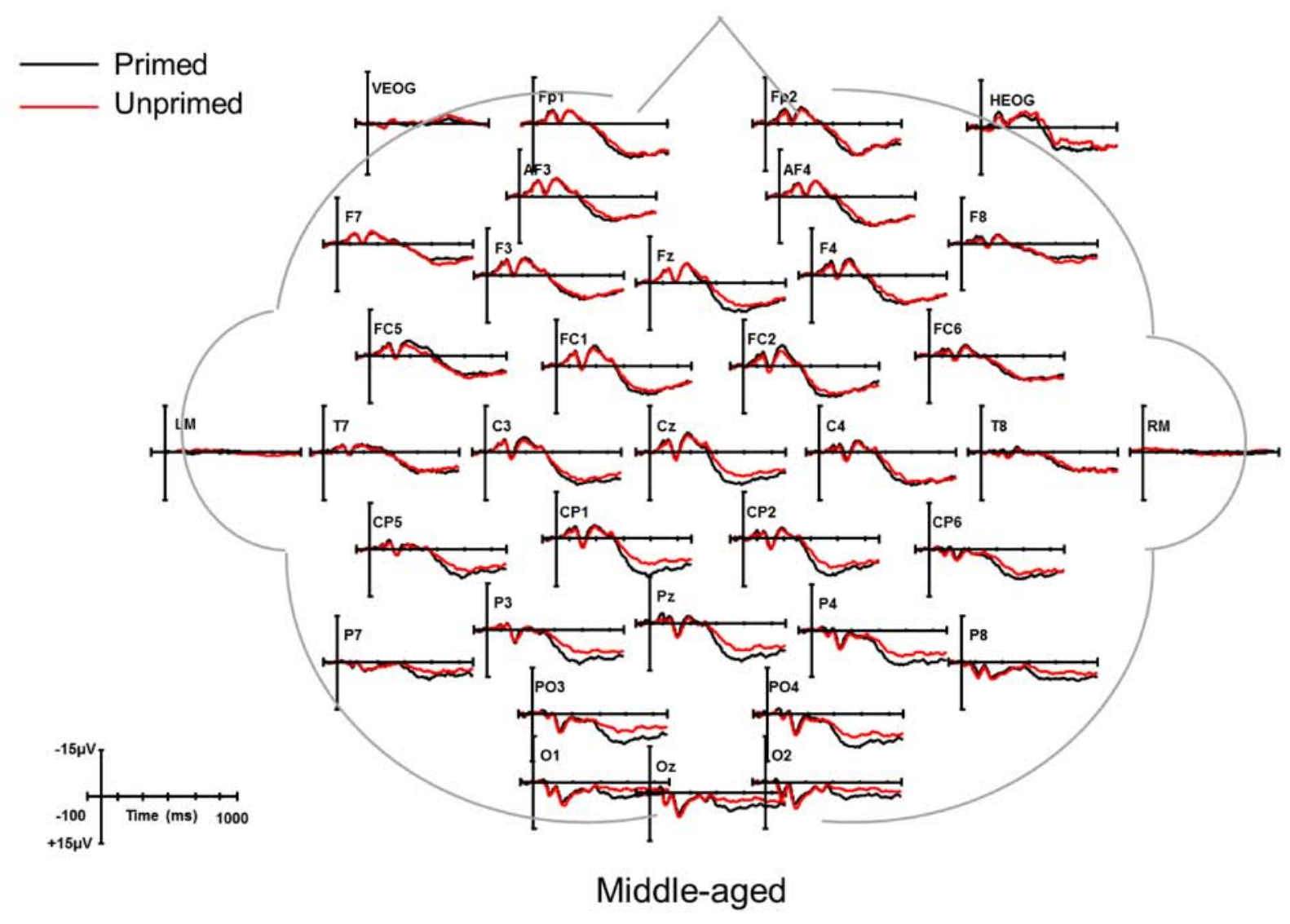

Figure 3.10. Grand average waveforms of the ERPs elicited by high frequency pictures in Middle-aged adults. 


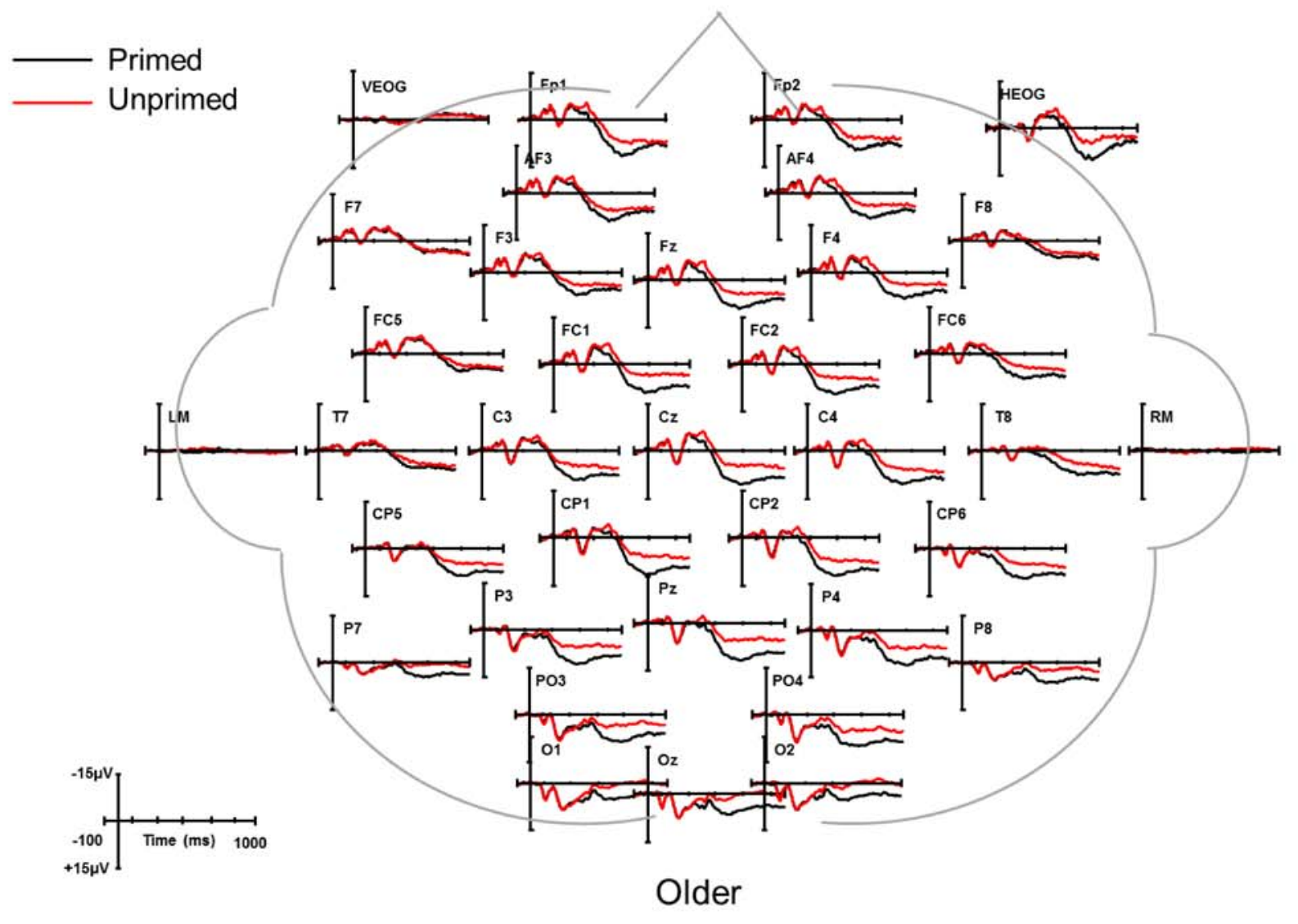

Figure 3.11. Grand average waveforms of the ERPs elicited by high frequency pictures in Older adults. 


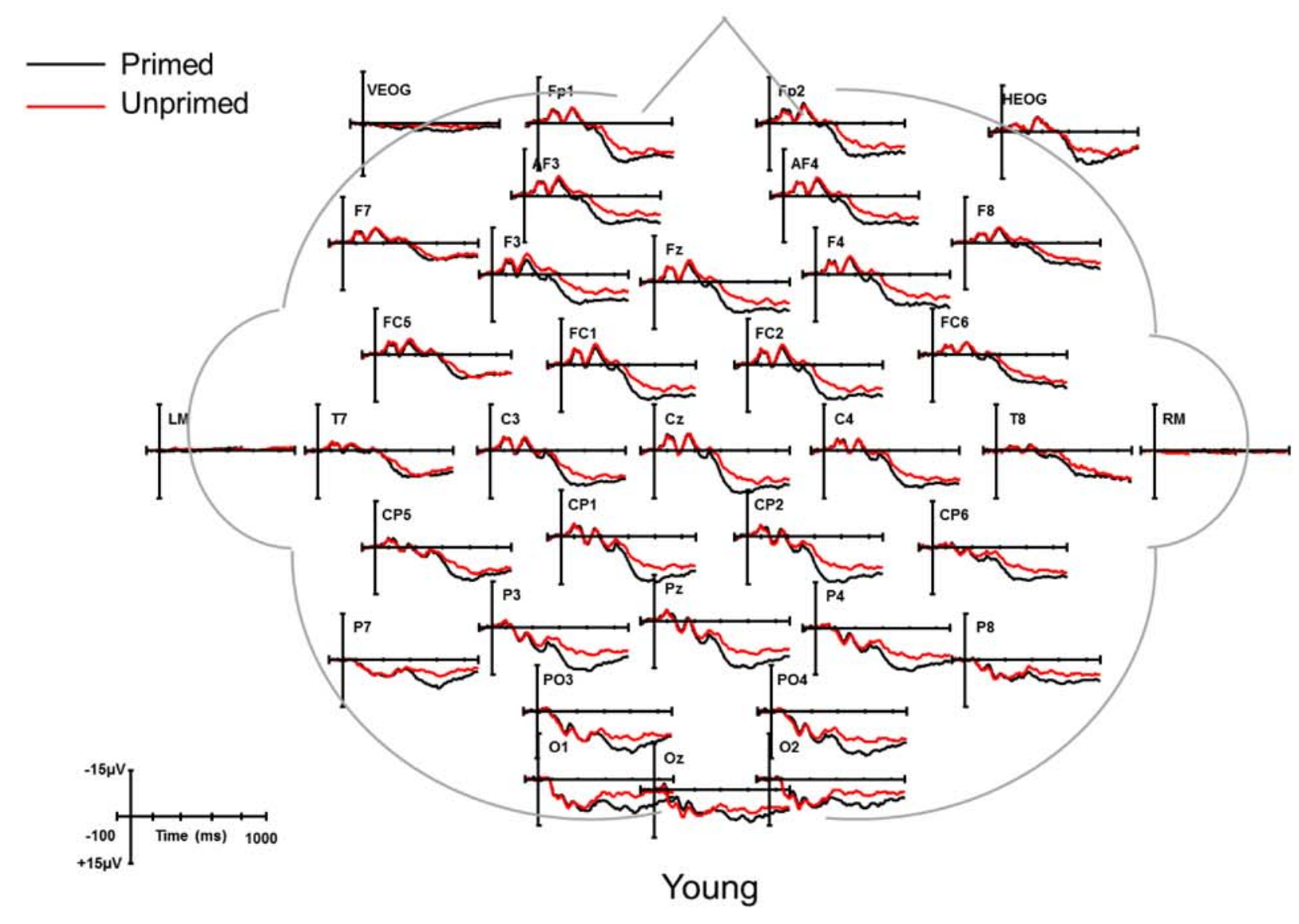

Figure 3.12. Grand average waveforms of the ERPs elicited by low frequency pictures in Young adults. 


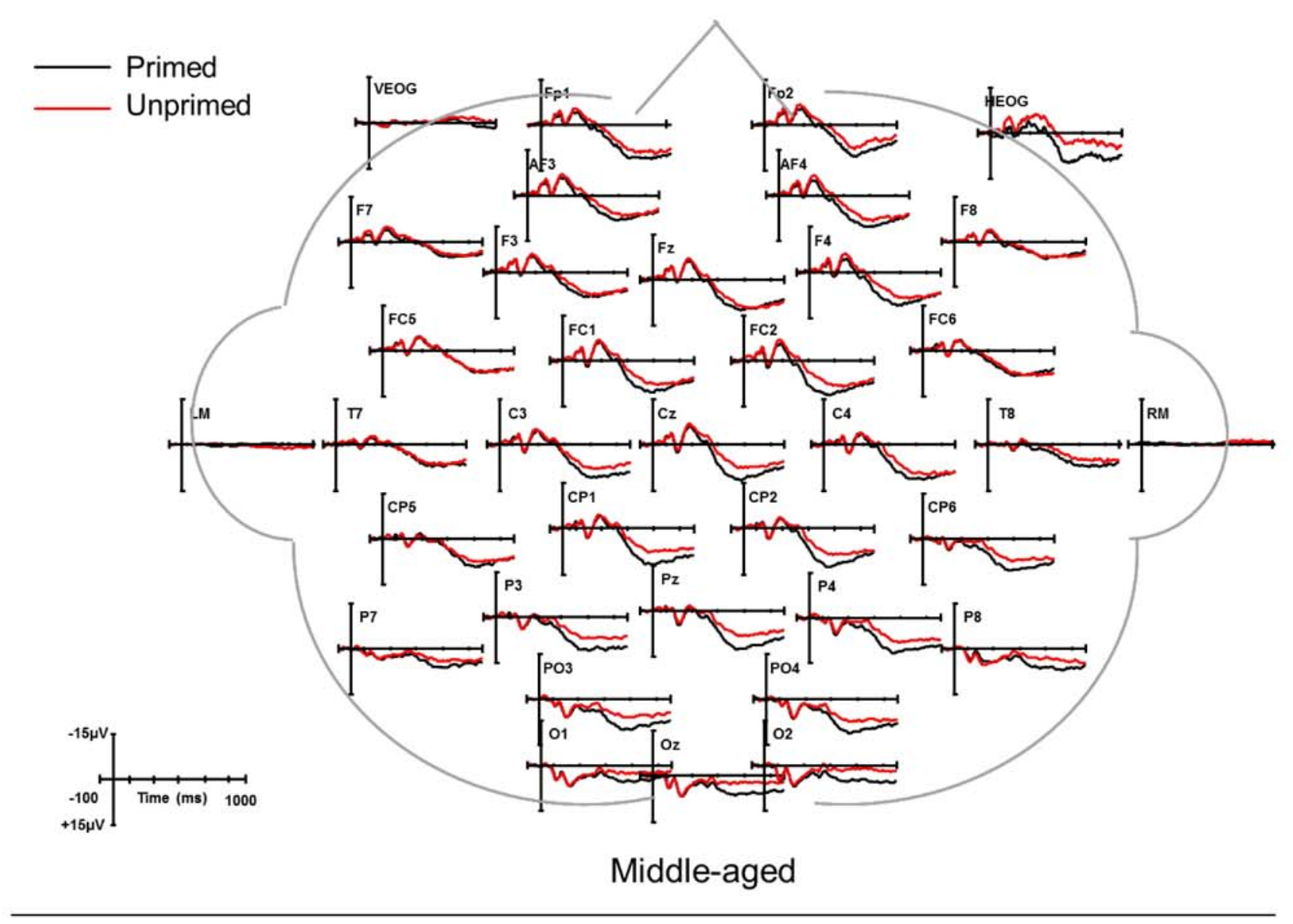

Figure 3.13. Grand average waveforms of the ERPs elicited by low frequency pictures in Middle-aged adults. 


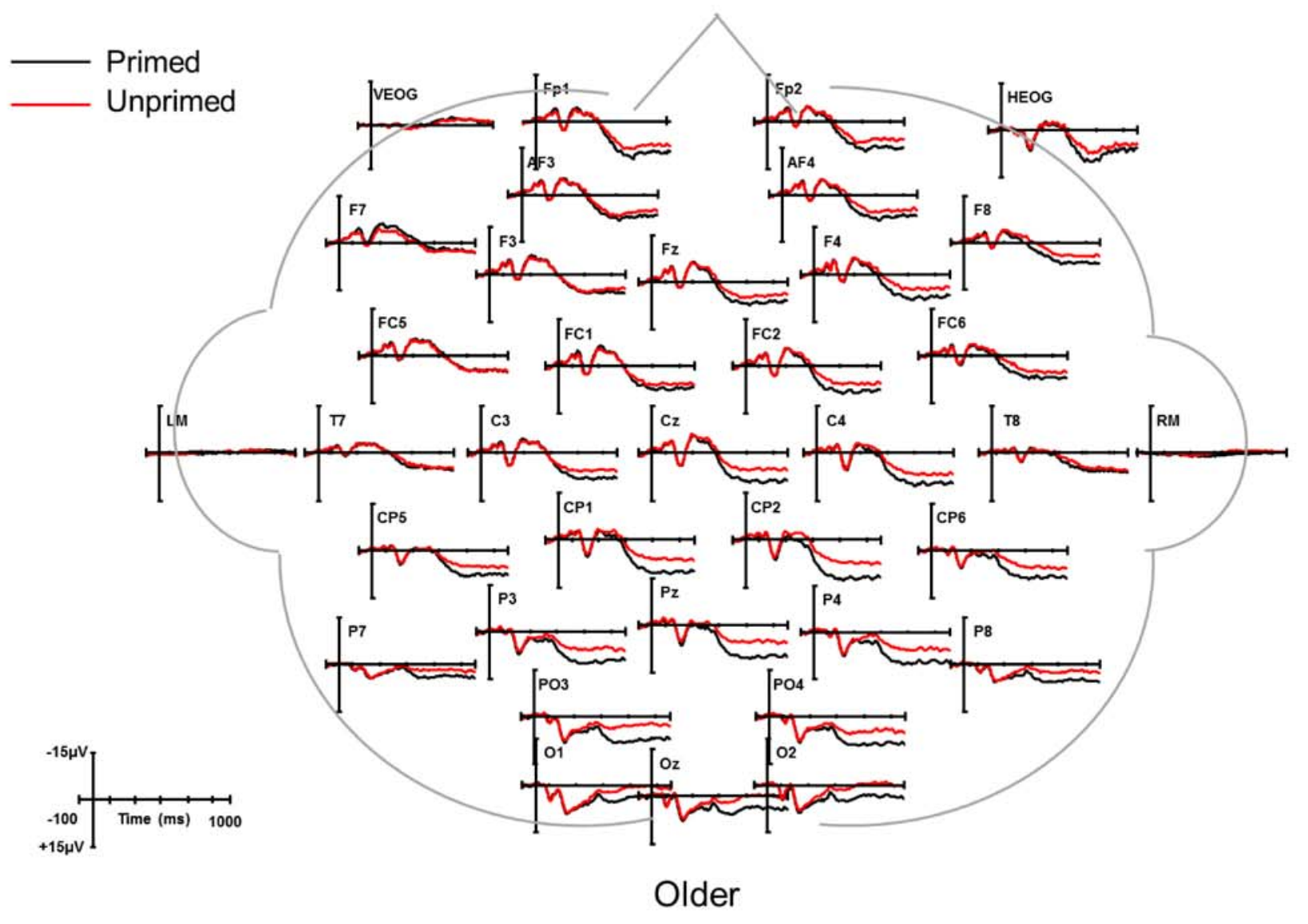

Figure 3.14. Grand average waveforms of the ERPs elicited by low frequency pictures in Older adults. 
N1 (80-180ms) \& P2 (140-240ms): The peak amplitudes of the N1 and P2 elicited by the target pictures were similar across the groups, $F(2,40)<1.84, \mathrm{p}>.17$, and between priming conditions, $F(2,40)<2.95, p>.93$. The peak latencies of the $\mathrm{N} 1$ and $\mathrm{P} 2$ elicited by the high and low frequency pictures, however, displayed a group difference, $F(2,40)$ $>3.89, p<.03$, indicating that, similar to the $\mathrm{N} 1$ and $\mathrm{P} 2$ elicited by auditory prime, the older adults displayed delayed sensory processing for the pictures compared to the young adults, $p<0.05$, on the order of approx. 19ms for the N1 and approx. 15ms for P2. Therefore, older adults exhibited a relative delay in early auditory and visual sensory processing as compared to young adults. The means and standard errors of the peak latencies of the N1 and P2 elicited by targets are shown in Table 3.3.

N2 mean amplitude (220-320 ms): The amplitudes of the N2 were similar for primed and unprimed target pictures, high and low frequency words, and across groups $(p>.19)$. There were no significant group interactions, $F(2,40)<12.36, p>.10$.

N2 peak latency (220-320 ms): Based on distribution of the N2 grand average waveforms and previous reports of the distribution of the N2 (Eimer, 1993; Neumann et al., 2009; Tachibana et al., 1996), the peak latency of the N2 was measured at frontal-central electrode sites (AF3/4, F3/4, Fz, FC1/2, C3/4, Cz). There were no priming effects for high frequency $(p=.77)$ or low frequency pictures $(p=.72)$. However, there were group effects for the peak latency of the N2 elicited by both high frequency, $F(2,40)=21.78, p$ $<0.001, \mathrm{\eta}_{\mathrm{p}}^{2}=.52$, and low frequency words, $F(2,40)=22.84, p<0.001, \mathrm{\eta}_{\mathrm{p}}^{2}=.53$. For both high and low frequency pictures, post-hoc tests revealed that all three groups differed from each other $(p<0.05)$, such that the N2 peaked earliest for the young adults, 
followed by the middle-aged adults and later for the older adults (Table 3.3 and Figure

\section{$3.15)$.}

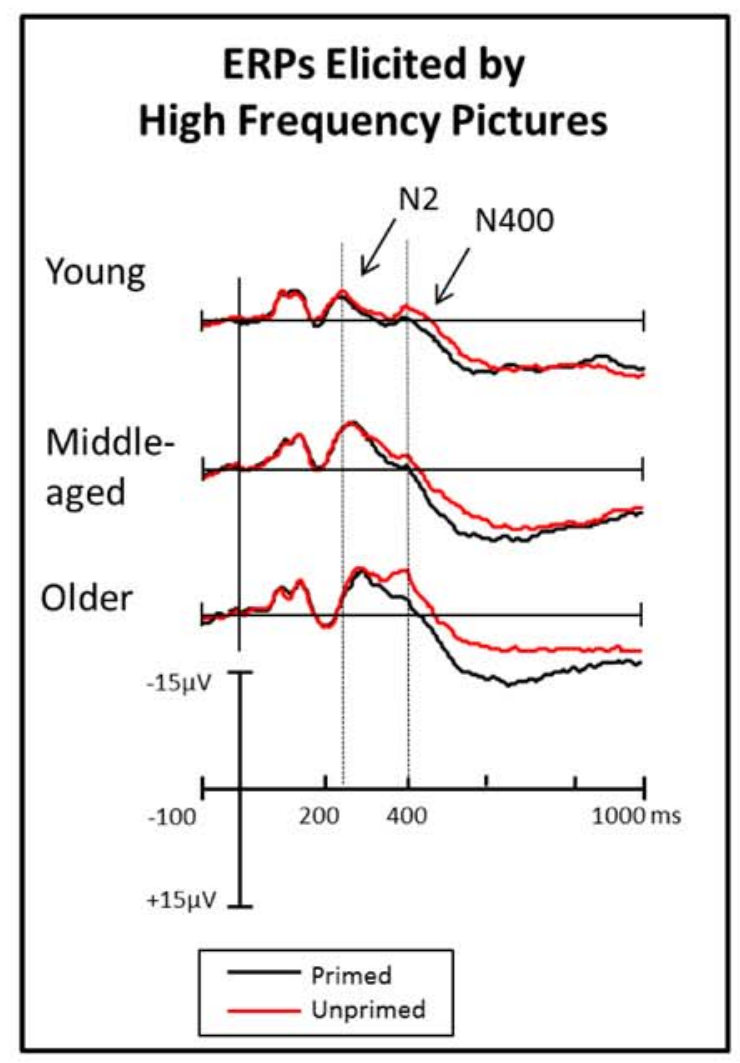

Figure 3.15. A representative figure showing group differences for the peak latency of the $\mathrm{N} 2$ component but not the N400 at Fz. The dashed-line on the left is aligned with the peak of the N2 elicited by the young adults (at approximately $255 \mathrm{~ms}$ ). The dashed-line on the right is aligned at $400 \mathrm{~ms}$ post-stimulus.

N400 mean amplitude (380-480 ms): The mean amplitude of the N400 elicited by the target pictures revealed priming effects for both high frequency, $F(1,40)=34.54, p$ $<0.001, \eta_{\mathrm{p}}{ }^{2}=.46$, and low frequency words, $F(1,40)=29.45, p<0.001, \eta_{\mathrm{p}}{ }^{2}=.42$ (Figures 3.9 - 3.14; and see Figure 3.15 for example). The findings indicated that the 
mean amplitude of the N400 elicited by primed words was smaller than that of the unprimed words for all the groups. In addition, for low frequency words, there was a marginal priming $\mathrm{x}$ group $\mathrm{x}$ LMR interaction, $F(8,160)=2.01, p=.050, \mathrm{\eta}_{\mathrm{p}}^{2}=.09$. As illustrated in Figures 3.12 - 3.14, the priming effect was broadly distributed for the young adults, whereas the middle-aged and older adults displayed a priming effect only at midline and right hemisphere sites, indicating a more restricted distribution of the priming effect.

In summary, all three groups showed priming effects for both high and low frequency words. For low frequency words, young adults showed a broad distribution of the priming effect, while middle-aged and older adults showed a greater right lateralized priming effect.

N400 peak latency (380-480 ms): The peak latency of the N400 elicited by high frequency words and low frequency words was measured at central-parietal sites (FC1/2, $\mathrm{C} 3 / 4, \mathrm{Cz}, \mathrm{CP} 1 / 2, \mathrm{P} 3 / 4, \mathrm{Pz})$, based on distribution of the $\mathrm{N} 400$ in the grand average waveforms and based on previous studies that have also observed the greatest amplitude of the N400 at central-parietal sites (Connolly \& Phillips, 1994; Federmeier, 2014; Kutas \& Hillyard, 1980; Kutas \& Petten, 1988; Kutas \& Iragui, 1998). There were no priming, group, or priming by group interactions for the peak latency of the $\mathrm{N} 400, F(2,40)<$ $2.65, p>.08$

Post-N400 mean amplitude (480-600 ms): Priming effects were seen for the temporal window following the N400 for both high frequency, $F(1,40)=102.45, p<0.001, \mathrm{\eta}_{\mathrm{p}}^{2}=$ .72 , and low frequency words, $F(1,40)=53.85, p<0.001, \eta_{\mathrm{p}}{ }^{2}=.57$. Additionally, for 
the low frequency words, a priming $\mathrm{x}$ group $\mathrm{x}$ LMR interaction was noted, $F(8,160)=$ 2.89, $p=0.006, \eta_{\mathrm{p}}^{2}=.13$. A step-down ANOVA performed to explore this interaction revealed a priming effect for both the young adults, $F(1,14)=19.11, p=.001, \mathrm{\eta}_{\mathrm{p}}^{2}=.58$, and the middle-aged adults, $F(1,14)=28.54, p<.001, \mathrm{\eta}_{\mathrm{p}}^{2}=.67$, and no interaction with LMR. In contrast, the older adults exhibited a priming effect only at midline and right hemisphere sites, $F(4,56)=5.45, p=.002, \mathrm{\eta}_{\mathrm{p}}{ }^{2}=.28$. These findings indicate a more restricted distribution of priming effects for the older adults. There were no overall group effects, $F(2,40)<2.6$. 
Table 3.3. Mean (Standard Error) of the Peak Latency of the ERP Components Elicited by the Target Pictures.

\begin{tabular}{ccccccccc}
\hline Group & \multicolumn{3}{c}{ N1 } & \multicolumn{2}{c}{ P2 } & \multicolumn{2}{c}{ N2 } & \multicolumn{2}{c}{ N400 } \\
\hline & High & Low & High & Low & High & Low & High & Low \\
\hline Young & 113.75 & 116.54 & 201.33 & 202.19 & 255.51 & 258.46 & 420.27 & 417.93 \\
& $(5.74)$ & $(4.71)$ & $(5.52)$ & $(4.63)$ & $(3.07)$ & $(3.69)$ & $(10.88)$ & $(17.42)$ \\
Middle- & 131.55 & 123.41 & 205.65 & 201.56 & 274.81 & 270.34 & 415.69 & 417.14 \\
Aged & $(6.65)$ & $(6.37)$ & $(3.19)$ & $(3.78)$ & $(4.88)$ & $(5.16)$ & $(11.13)$ & $(11.41)$ \\
Older & 139.97 & 127.86 & 218.39 & 214.79 & 291.68 & 294.25 & 416.69 & 417.69 \\
& $(3.82)$ & $(5.71)$ & $(2.63)$ & $(2.86)$ & $(3.98)$ & $(2.82)$ & $(15.77)$ & $(18.96)$ \\
\hline
\end{tabular}




\subsection{Multiple Regression}

Regression coefficients were computed between cognitive variables (raw scores obtained on the Stroop Color-Word test and PPVT-4) as independent variables, and behavioral measures (naming accuracy and phonological judgment RT) and ERP measures (peak latency of the N2) as outcome variables.

The performance on the PPVT-4 was related to the naming accuracy for high frequency pictures, $R^{2}=.21, F(1,41)=10.85, p=.002$, and low frequency pictures, $R^{2}=$ $.10, F(1,41)=4.75, p=.035$. This indicated that $21 \%$ of the variance in naming high frequency words and $10 \%$ of the variance in naming low frequency pictures could be accounted for by the vocabulary size of the participants. Stroop Color-Word test scores were significantly associated with the phonological RTs (high and low frequency), $R^{2}$ $>.44, F(1,41)>31.98, p<.001$, indicating that $44 \%$ of the variance in phonological judgment RTs were associated with inhibition abilities.

The Stroop Color-Word test was uniquely related to the peak latency of the N2 elicited by high frequency pictures, $R^{2}=.52, F(1,41)=44.29, p<.001$, indicating that about $50 \%$ of the variance in the $\mathrm{N} 2$ peak latency could be accounted for by inhibition abilities of the participants. For low frequency pictures, the Stroop Color-Word test and the PPVT-4 together accounted for $52 \%$ of the variance in the peak latency of the $\mathrm{N} 2, R^{2}$ $=.52, F(1,41)=21.63, p<.001$, and the Stroop Color-Word test scores alone accounted for about $47 \%$ of the variance in N2 peak latency, $R^{2}=.47, F(1,41)=36.07, p<.001$. These findings indicate that approximately half of the variance in the peak latency of the N2 was accounted for by inhibition abilities as indexed by Stroop Color-Word Test. 


\section{CHAPTER 4. DISCUSSION}

The primary aim of the present study was to examine age-related changes in the neural correlates of phonological priming and word retrieval in healthy adults. We also assessed the relationship between cognitive proficiencies and the behavioral and neural functions mediating word retrieval. We measured naming accuracy and naming latency, phonological judgment accuracy and RTs, and ERPs elicited by phonological priming and word retrieval. Participants in all the groups benefitted from phonological priming, evidenced by shorter phonological judgment RTs, greater naming accuracy, and smaller mean amplitudes of the $\mathrm{N} 400$ during retrieval of primed pictures as compared to unprimed pictures. There were no group differences in the peak latencies of the N400. There were, however, incremental age-related increases in phonological judgment RTs and the peak latency of the $\mathrm{N} 2$ elicited by the pictures, both of which were related to inhibition abilities indexed by the Stroop Color-Word test. Taken together, these findings indicate that facilitative effects of phonological priming may operate similarly across the lifespan until the mid-70s but healthy aging may be associated with delays in inhibitory processes underlying phonological priming.

Although older adults above the age of 60 report and display increased word retrieval difficulties and TOTs (Lovelace \& Twohig, 1990; Ossher, Flegal, \& 
Lustig, 2013; Salthouse \& Mandell, 2013), standardized naming tests don't reveal naming difficulties until the late 70's (Albert, Heller, \& Milberg, 1988; Zec at al., 2005, 2007). Consistent with these studies, the older adults in the present study who were below the age of 75 years, named the targets with high accuracy and with equivalent naming latency as the young and middle-aged adults. These older adults also reported that they seldom had word finding difficulties, and exhibited greater vocabulary size and word finding skills compared to their peers, as indexed by standardized measures on the PPVT and TAWF. The tendency for middle and older adults to show naming responses similar to young adults was closely related to vocabulary size, indicating that vocabulary and naming skills were highly interrelated. Naming difficulties in middle-aged and older adults may have been offset by greater word knowledge and a lifetime of practice accessing words from the lexicon. (Kavé et al., 2010; Kavé, 2015)

\subsection{Word Frequency Modulated Naming Latency and Phonological Judgment}

According to TD model, infrequently used words or low frequency words with fewer interconnected nodes will result in greater retrieval failures (Harley \& Bown, 1998; White \& Abrams, 2002). While this theory is consistent with the marginal effects of frequency on naming accuracy in the present study, word frequency had greatest impact on speed of retrieval i.e. participants named high frequency words faster and made faster phonological judgments about high frequency targets compared to low frequency targets. Facilitative effects of high frequency words on naming latency have been documented since Oldfield \& Wingfield's 1965 picture naming study (Brysbaert, 1996; Meschyan \& Hernandez, 2002). However, it is still unclear whether lexical 
frequency of the word influences semantic retrieval (Almeida, Knobel, Finkbeiner, \& Caramazza, 2007; Balota \& Abrams, 1995; Carmazza, Costa, Miozzo, \& Bi, 2001; Dell, 1990; Laganaro, Morand, Schwitter, Zimmermann, Camen \& Schnider, 2009), or phonological retrieval (Harley \& Bown, 1998; Jescheniak \& Levelt, 1994; Manoiloff, Segui, and Halle, 2013; Strijkers, Costa, \& Thierry, 2010) during picture naming. These studies differed in the type of stimulus (pictures, homophone words), task (lexical decision, cueing) as well as methods (behavioral vs ERP) used to identify the locus of frequency effects. Since the present study was not designed to delineate the locus of the frequency effects, we cannot make specific interpretations from our behavioral results. Shorter naming latencies and phonological judgment RTs for high frequency words could have been a result of faster activation of the semantic representation of the picture or faster retrieval of phonological features.

Electrophysiological studies that looked at the time course of word frequency effects during picture naming also reveal variable explanations. For example, Strijkers, Costa, and Thierry (2010) observed an early divergence of the ERPs elicited by high- and low-frequency words in bilinguals at $150-200 \mathrm{~ms}$ post-stimulus and concluded that the frequency effect was at the stage of lemma (semantic and syntactic information) retrieval. Laganaro et al. (2009) also concluded that frequency affected lemma retrieval stages of word production. However, their ERP findings differed from those of Strijkers et al. (2010) in that the ERP waveforms for high and low frequency words diverged at 270$330 \mathrm{~ms}$ post-stimulus onset. In the present study, we did not observe any effects of frequency on the mean amplitudes or peak latencies of the ERPs elicited by the pictures. 
It is difficult to make direct comparisons with the above two ERP studies for various reasons: the stimuli were not in English (French in Laganaro et al., Spanish-Catalan bilinguals in Strijkers et al.) and the tasks did not include priming. Since frequency effects were not observed in the ERP waveforms measured until $600 \mathrm{~ms}$ post-picture onset, but did influence phonological judgment RTs and naming latency, it may be that word frequency influenced post-lexical stages of word retreival.

More relevant to the present study, we did not observe any interactions between word frequency and age for the behavioral and neural measures. This is in contrast to Spieler and Balota (2000), who found that although both young and older adults showed a frequency effect, frequency was a greater predictor of naming latencies in the older adults. The study, however, used word naming/reading latencies as the dependent variable rather than pictures, and log frequency as the independent variable rather than absolute frequency of occurrence. Vitevitch \& Sommers (2003) reported that words with low phonological neighborhood density (number of words that are phonologically related to the target) and low neighborhood frequency (lexical frequency of the words that are phonologically related to the target) produced more tip-of-thetongue states among older adults than target words with low lexical frequency. This finding is consistent with interactive activation models of speech production in that a target word will have stronger activation if there are many similar sounding high frequency words that contribute to the activation of the shared phonological nodes. The pictures used as targets in the present study were highly familiar, common nouns and the two lists were matched for phonological neighborhood density and phonological 
neighborhood frequency. It may be that lexical frequency alone is insufficient to produce significant age differences in naming latencies, phonological judgment RTs and ERP measures of word retrieval. In addition, the older adults in the present study displayed very high vocabulary and word finding skills as compared to the larger population of

older adults. These factors may have accounted for the equivalent frequency effects and similar naming latencies observed across the groups. Future studies that manipulate factors such as phonological neighborhood density, phonological neighborhood frequency, syllable frequency, and phonotactic probability are required to assess specific effects on word retrieval and aging.

\subsection{Phonological Priming Facilitated Word Retrieval Similarly Across Groups}

The present study involved a phonological priming paradigm with an internal phoneme monitoring task. Participants had to make phonological judgments about the target picture's name before overtly naming it, implicitly orienting their attention towards a phonological level of representation. We found that priming had positive effects on phonological judgment RTs and naming accuracies, consistent with previous findings (Ferrand, Grainger, \& Segui, 1994; Grainger, Diependaele, Spinelli, Ferrand, \& Farioli, 2003; James \& Burke, 2000; Schriefers, Meyer, \& Levelt, 1990; Taylor \& Burke, 2002; White \& Abrams, 2002). In the present paradigm, the phonologically related primes shared consonantal onset and vowel with the target picture's name and therefore facilitated word retrieval by raising the excitation levels of the target's phonological representation (Grainger \& Ferrand, 1996; Schiller, 2008). The subsequent easier activation of the target's phonological representation upon presentation of the picture 
explains the faster phonological judgment RTs and higher naming accuracy for the primed pictures as compared to unprimed pictures.

Contrary to our expectations, the participants were less accurate in making phonological judgments about primed picture names than unprimed picture names, i.e. participants were less accurate when they had to press the 'Yes' button, indicating that the prime and target started with the same sound, as compared to when they had to press the 'No' button. Previous analyses of two-choice decision tasks identify three components that affect the behavioral data - relative proportion of the stimulus requiring either choice, task instructions that emphasize speed or accuracy of response, and stimulus difficulty (Ratcliff \& McKoon, 2008; Standage, Wang, Heitz, \& Simen, 2015). Since the probability of 'Yes' and 'No' responses corresponding to primed and unprimed conditions was equal, this cannot explain the bias towards a 'No' response. Since the task insisted on speeded responses, our finding may be explained by speed-accuracy tradeoffs, indicating that participants made responses before enough evidence for a decision was available (Bogacz, Wagenmakers, Forstmann, \& Nieuwenhuis, 2010; Ratcliff, 1985). An additional explanation for our finding could be related to the stimulus characteristics of the prime. The primes were monosyllabic pseudo words, with short durations of about $510 \mathrm{~ms}$ and targets were only presented for $300 \mathrm{~ms}$. While previous research has indicated that these durations of stimulus presentation are sufficient for accurate perception (Chauncey et al., 2009; Dufour \& Peereman, 2003), if the participants in the present study did not accurately perceive the prime or were unsure of the phonological 
relationship between the prime and target, they may have been inclined to respond 'No' . Subsequently, the accuracy for 'Yes' responses (Primed condition) decreased.

Consistent with our hypothesis, there were no age differences in behavioral measures of priming. White and Abrams (2002) found that shared first syllable primes resolved TOTs in young and older adults, but did not benefit older adults 73-83 years of age. While priming effects were age invariant, there were incremental age effects in phonological judgment RTs. The older adults' RTs were longer than the middle-aged adults' by $242 \mathrm{~ms}$ and middle-aged adults' RTs were longer than the young adults' by $245 \mathrm{~ms}$. The increase in phonological judgment RTs with age may be related to agerelated motor delays, or delays in the cognitive mechanisms underlying the judgment task, or a combination of the two. Previous reports of performance on simple visual and auditory reaction time tasks indicate a difference of about $50 \mathrm{~ms}$ between young and older adults (Cerella, 1985; Liu, 2001; Welford, 1984; and see Ketcham \& Stelmach, 2004 for review). Therefore, age differences in sensorimotor factors such as response initiation, movement speed, force, or coordination can only account for about 50ms of the delay between groups for phonological judgment RTs.

To our knowledge, the only study that compared phoneme judgment times between young and older adults was the one by Neumann et al. (2009). In a Go/No-Go paradigm, healthy young (mean age: 28.3 years) and older adults (mean age: 73.3 years) were required to make decisions about the ending phoneme of a picture name (phoneme monitoring) or whether the name ended with one or two syllables. Mean reaction times between young and older adults differed by about $100 \mathrm{~ms}$ for both tasks. In the present 
study, mean phonological judgment reaction times between young and older adults differed by about $487 \mathrm{~ms}$. While the experiment in Neumann et al. (2009) and the present study both involved retrieving the semantic and phonological representations of the target picture in order to make phonological judgments, there are fundamental differences between the two studies that may explain the larger age-related RT differences in the present study. Firstly, the Neumann et al study did not involve a priming paradigm. Participants only made judgments about the target picture's phonologic/syllabic representation. Our experiment included not only retrieving the phonological features of the picture name, but also comparing it to phonological features of the prime. This task, therefore, inherently involved more processing demands and/or additional stages of processing. In fact, the greater cognitive demands in our study is also evident by the greater RTs for young adults in the present study $($ Mean $=955 \mathrm{~ms})$ as compared to the RTs of young adults in Neumann et al. (Mean $=663 \mathrm{~ms})$. Additionally, although the elderly participants in the Neumann et al. study were older than the elderly participants in our study (73.3 years vs 66.1 years), they displayed shorter phoneme monitoring response times (759ms vs $1442 \mathrm{~ms})$, suggesting that the task in the present study involved greater demands. Secondly, the pictures in Neumann et al were familiarized before the experiment and each picture was repeated ten times within each task (phoneme and syllable monitoring), increasing the ease of picture recognition and word retrieval with every repetition. The participants in the present study were not familiarized to the pictures and the pictures were only repeated once in the experiment. Therefore, the lack of familiarization, minimal repetition, and greater task demands may be attributed to the overall longer RTs reported in our study. Note that task demand and the absence of 
familiarization only affected processing speed, but did not affect phonological judgment accuracy or naming accuracy, since both these measures in older and middle-aged adults were similar to those of the young adults.

Therefore, the age effects observed in phonological judgment RTs in our experiment are most likely explained by a combination of sensorimotor and cognitive delays, with a greater proportion of delay in the cognitive processes underlying phonological judgment. Which stage of cognitive processing involved in the present task - conceptual processing, semantic access, phonological access, comparison between phonological features of the prime and target (Praamstra \& Stegeman, 1993)- may be associated with the age-related RT delays? Evidence from naming latencies, as measured using the VoiceKey, provides indirect evidence that the time course of access to conceptual, semantic, and phonological representation of the target picture names is similar across the ages. This indicates that the linear increase in phonological judgment times were most likely related to the cognitive process underlying matching phonological features of the prime and target and not to overall lexical or phonological retrieval. The ERP components elicited by the prime and pictures, as discussed below, will provide greater insights into the time course of processing most sensitive to aging.

\subsection{Neural Indices of Word Retrieval Reveal Age Invariance in Phonological Priming}

Phonological priming modulated the N400 in the present study, revealing smaller amplitudes in the primed condition as compared to the unprimed condition. This is consistent with our hypothesis and the premise that N400 amplitude is inversely related to the excitation levels emerging from priming contexts (Connolly \& Phillips, 1994; 
Jescheniak et al., 2002; Praamstra et al., 1994; Van Petten \& Kutas, 1990), and is sensitive to the interactivity between phonological and lemma representations (Holcomb \& Grainger, 2006). The greater ease of integration of phonologically primed picture labels can be explained through interactive vertical and lateral spread of activations. On presentation of the auditory pseudo word, priming or subthreshold excitation spreads to phonologically related word forms, preparing them for possible activation. Presentation of the target picture then triggers top-down spreading of activation from conceptual, to phonological nodes. If the target phonological node was not excited by the prime (the unprimed condition), activation of these nodes is reflected by greater N400 amplitude. If the target phonological node's excitation level had already been raised by the prime, activation of these nodes is easier, as reflected by smaller N400 amplitude. In this way, the prime modulates the activation of the picture's label (Jescheniak et al., 2002). Importantly, the priming effects were also sustained in the post-N400 window for all the groups. Note that the effect in this temporal window does not represent a distinct cognitive process relative to the N400, but represents sustained effects of phonological priming in the word retrieval process (Halgren, 1990).

There were no peak latency differences in the elicited N400 between either priming conditions or for any of the groups, indicating that phonological priming and aging did not affect the timing of activation of target words. Delayed N400 in older adults has been previously reported only for processing of semantic context or semantic incongruity while reading sentences or words (Gunter, Jackson, \& Mulder, 1992; Harbin, marsh, \& Harvey, 1984; King \& Kutas, 1995 also for review). Also contrary to 
predictions, there were no interactions between frequency, priming, and age. Marginal evidence for such interactions were observed in the distribution of the priming effects for low frequency words; while young adults exhibited a broad distribution of the N400 priming effect for high and low frequency targets, priming effects for middle-aged and older adults were limited to midline and right medial electrode sites. This is consistent with the finding of reduced left insula activity, a region associated with phonological retrieval, during TOTs for older adults compared to young adults (Shafto et al., 2010; Shafto \& Tyler, 2014), indicating differential ability of young and older adults to modulate neural response during difficult retrieval and in our case, during retrieval of low frequency words.

Therefore, all the participants in the present study, including the healthy older adults, demonstrated equivalent facilitation of target retrieval by the priming context, as evidenced by similar modulation of the N400. There were, however, age differences in the behavioral measures associated with making phonological judgments about the prime and target name and an age-related increase in the peak latency of the N2, which will be discussed in the next section.

\subsection{Inhibitory Processes Associated with Target Activation Show Age Differences}

The most significant finding in the present study was the increase in the peak latency of the $\mathrm{N} 2$ with age. There are a few possibilities for these aging effects. The first possibility is the cascading effects of delayed visual processing on the subsequent components. The N1 and $\mathrm{P} 2$ have been reported to be delayed in older relative to young adults (Anderer, Semlitsch, \& Saletu, 1996; Dushanova \& Christov, 2013; Finnigan, et 
al., 2011). This interpretation would suppose that delays in early visual processing will delay all subsequent processing stages, presumably with similar magnitude. This was, however, not the case: the delay in latency between older and young adults for N1 (approx. 19ms) and P2 (approx. 15ms) was smaller than for $\mathrm{N} 2$ (approx. 37ms) and there were no latency differences between groups for N400. Additionally, the middle-aged adults did not differ from young adults for early visual processing, but they differed from both young and older adults in the peak latency of the N2. The possibility that the age effects for peak latency of the $\mathrm{N} 2$ were related to delays in early stimulus processing is therefore, not likely.

The second interpretation relates to the cognitive process underlying the $\mathrm{N} 2$ that peaked at $255 \mathrm{~ms}$ for the young adults. As described in the introduction, previous researchers using different types of stimuli and experimental paradigms have observed negative potentials that co-occurs with the $\mathrm{N} 400$ - the N250, N270, N280, and the N300. While there are obvious differences between our study and some of the studies mentioned above in the peak latency of the relevant component $(255 \mathrm{~ms}$ in ours versus $270 / 280 / 300 \mathrm{~ms}$ ), the primary difference is that the N2 amplitude reported by previous studies is modulated by the priming conditions. In contrast, the absence of priming effects for the amplitude and latency of the N2 for all the groups in our study suggest that the $\mathrm{N} 2$ most likely indexes a unique cognitive process, unrelated to phonological-lexical integration mediating the $\mathrm{N} 400$.

Forty-seven percent of the variation in peak latency of the $\mathrm{N} 2$ was related to scores on the Stroop test in the present study, suggesting that the N2 may be related to 
inhibition. Indeed, efficient retrieval of the target requires simultaneous activation of target nodes and inhibition/deactivation of incompatible neighbors (Berg \& Schade, 1992). Analysis of errors during speech production, including perseverative errors in speech of some persons with aphasia (Martin \& Dell, 2004), letter perseverations in acquired dysgraphia (Fischer-Baum \& Rapp, 2014), and reports of persistent alternates in young and older adults experiencing TOTs provide evidence for the need to inhibit previously activated nodes for efficient speech production. In the case of priming, this inhibition process may have to be up-regulated as multiple incompatible neighbors that have received partial activation from the prime have to be deactivated. The N2 elicited in the present study may reflect inhibition of neighbors in the lexicon that were not relevant to target processing. Importantly, even if the prime's phonological form is unrelated to the target, the incompatible nodes, including the prime have to be inhibited. Based on our interpretation that the N2 may be related to inhibition of incompatible lexical neighbors, we would not expect the amplitude of the N2 in the present study to be modulated by priming effects. Both phonologically related and unrelated pseudo words would prime a large network of related nodes. Processing the picture would entail selection of nodes at each level of representation (conceptual, lemma, phonological word form, phonemes), inherently inhibiting nodes that were primed by the preceding context but not selected as the target. For example, presentation of the pseudo word /keb/ will prime phonological representations for cane, cake, come, babe, etc. A picture of cake will activate its conceptual representations, cake(noun) at the lemma level, and its phonological word form $/ \mathrm{kek} /$. Activation of $/ \mathrm{kek} /$ that is most compatible with the picture would be accompanied by inhibition/deactivation of cane, come, babe, and other primed neighbors. 
Previous studies assessing phonological priming on target word processing reported priming effects on the N400, but did not report an analysis of the N2 (Blackford et al., 2012; Praamstra et al., 1994). Visual inspection of the waveforms in these publications reveals a negative peak prior to the N400 at about 200ms (Praamstra et al., 1994) and 250ms (Blackford et al., 2012) whose amplitude was unaffected by priming condition. The presence of this peak was probably not discussed as the purpose of these studies was to identify the temporal onset of priming effects and ERP components prior to priming effects were not measured. It is possible however, that these peaks also reflect the cognitive process underlying inhibition of primed neighbors.

In the present study, we were in a unique position to interpret the cognitive process mediating the $\mathrm{N} 2$ since the peak latency of the $\mathrm{N} 2$ distinguished age groups and because it was highly correlated with Stroop scores. Low scores on the Stroop ColorWord Test fit with theories that suggest older adults show deficits in inhibition abilities (Hasher et al., 2007). The age-related differences in the peak latency of the N2 may reflect age-related inability to inhibit incompatible primed neighbors during word retrieval. While Stroop scores accounted for a large proportion (47\%) of the variability in N2 latency, the combination of Stroop and PPVT-4 scores accounted for a greater $(52 \%)$ of the variability. This is also in line with the possibility that greater vocabulary size in older adults would be associated with greater number of lexical competitors requiring inhibition (Sommers \& Danielson, 1999; Taler, Aaron, Steinmetz, \& Pisoni, 2010). Interestingly, both the middle-aged and older adults showed delays in the latency of the $\mathrm{N} 2$, indicating that underlying deficits in inhibiting primed neighbors may be exhibited as 
early as middle age. Most studies investigating aging effects during word retrieval have only compared young and older adults, limiting the potential to extrapolate the findings to other age groups and misleading interpretations as changes only seen in individuals over 60 years. Including a third age group between young and older adults in the present study provided the opportunity to assess the trajectory of age-related changes in language processing. While lexical integration by priming contexts is relatively intact at least until the mid-70s, inhibition of partially activated neighbors is slower even in adults in their 40s.

Along with latency of the N2, a large part of the variance in phonological judgment RTs was accounted for by inhibition abilities, indicating that the three measures may be related. Increased latency in RTs with age may be partially related to delays in making accurate phonological judgments about the prime and target until lexical and phonological competitors had been deactivated.

\subsection{Conclusion and Implications}

The present study adds to the growing literature that aging is a dynamic process of domain-specific asymmetries in language processing. Identifying neural correlates of word retrieval in a phonological priming paradigm revealed important information about cognitive aging beyond that revealed by behavioral results alone. In addition, characterizing the relationship between clinical measures of cognition and language known to change with age and the electrophysiological and behavioral measures of naming allowed us to better interpret age-related changes in word retrieval. These findings suggest that age differences in the various word retrieval processes are at 
least in part determined by supporting cognitive mechanisms. This also raises important questions about the relationship between cognitive measures and neural correlates of word retrieval during other types of priming, including semantic and syntactic priming.

A crucial contribution of the present study is the characterization of the N2N400 complex in priming paradigms. The N2 elicited by picture targets may underlie the process of inhibiting primed neighbors that are incompatible with target representations, while the N400 indexes ease of lexical activation by the priming context. Although greater vocabulary and intact naming skills may offset age effects for behavioral and neural measures of phonological priming and word retrieval, lower inhibition skills in healthy aging as indexed by clinical measures may be associated with deficits in inhibiting incompatible neighbors during word retrieval, as evidenced by increased latency of the N2. Delay in inhibiting neighbors had negative consequences for phonological judgment response times as well. Importantly, delayed peak latency of the $\mathrm{N} 2$ and phonological judgment RTs indicated reduced inhibition of primed neighbors early in the aging process. This finding justifies the need to investigate aging from a lifespan perspective. Since most studies attempt to understand age-related language processing by comparing only young and older adults, crucial information about the onset of such processing deficits is missed. The present study adds important information to the literature about the age trajectory of word retrieval processes; future cross-sectional studies comparing age groups across multiple decades are needed to identify potential onset of inhibitory processing delays. 
The present study is a first attempt to explore neural correlates of phonological priming and word retrieval in healthy older adults. We found that phonological priming operates similarly across the lifespan for healthy adults between 20-75 years. Based on the finding that clinical tests reveal naming difficulties only for adults over the age of 75 , future studies investigating neural correlates of phonological priming in older adults above the age of 75 will shed more light on age-related phonological retrieval deficits. We strictly controlled many variables and matched the groups in the present study on several factors such as education, SES, hearing and vision, and reports of word retrieval abilities, increasing our confidence that age differences observed in the healthy adults were specific to the task-related language and cognitive processes. Findings from the current study, therefore, provide a strong foundation to study neural correlates of word retrieval in those displaying varying degrees of word finding difficulties, including individuals with aphasia and dementia. 


\section{REFERENCES}




\section{REFERENCES}

Abrams, L., \& Farrell, M. T. (2011). Language Processing in Normal Aging. The Handbook of Psycholinguistic and Cognitive Processes: Perspectives in Communication Disorders, (352), 1-47.

Abrams, L., White, K. K., \& Eitel, S. L. (2003). Isolating phonological components that increase tip-of-the-tongue resolution. Memory and Cognition, 31(8), 1153-1162.

Acheson, D. J., \& MacDonald, M. C. (2009). Verbal working memory and language production: Common approaches to the serial ordering of verbal information. Psychological Bulletin, 135(1), 50-68.

Albert M. S., Heller, H. S., Milberg, W. (1988). Changes in naming ability with age. Psychology \& Aging, 3(2), 173-8.

Allen, P. A., Madden, D. J., \& Crozier, L. C. (1993). Adult age differences in letter-level and word-level processing. Psychology and Aging, 6, 261-271.

Allen, P. A., Sliwinski, M., \& Bowie, T. (2002). Differential age effects in semantic and episodic memory, Part II: Slope and intercept analyses. Experimental Aging Research, 28, 111-142.

Almeida, J., Knobel, M., Finkbeiner, M., \& Caramazza, A. (2007). The locus of the frequency effect in picture naming: when recognizing is not enough. Psychonomic Bulletin \& Review, 14(6), 1177-1182.

Anderer, P., Semlitsch, H. V., \& Saletu, B. (1996). Multichannel auditory event-related brain potentials: effects of normal aging on the scalp distribution of N1, P2, N2 and P300 latencies and amplitudes. Electroencephalography and Clinical Neurophysiology, 99(5), 458-472.

Archibald, L. M. D., \& Joanisse, M. F. (2012). Atypical neural responses to phonological detail in children with developmental language impairments. Developmental Cognitive Neuroscience, 2(1), 139-151. 
Babcock, R. L., Salthouse, T. A. (1990). Effects of increased processing demands on age differences in working memory. Psychology \& Aging, 5(3), 421-428.

Balota, D. A. \& Abrams, R. A. (1995). Mental chronometry: Beyond onset latencies in the lexical decision task. Journal of Experimental Psychology: Learning, Memory, and Cognition, 21, 1289-1302.

Barnes, C. A. (1990). Effects of aging on the dynamics of information processing and synaptic weight changes in the mammalian hippocampus. Progress in Brain Research, 86, 89-104.

Barrett, S. E., \& Rugg, M. D. (1990). Event-related potentials and the semantic matching of pictures. Brain and Cognition, 14(2), 201-212.

Bartrés-Faz, D., and Arenaza-Urquijo, E. M. (2011). Structural and functional imaging correlates of cognitive and brain reserve hypotheses in healthy and pathological aging. Brain Topography, 24, 340-357.

Beier, M. E. \& Ackerman, P. L. (2001). Current events knowledge in adults: An investigation of age, intelligence and non-ability determinants. Psychology and Aging, 16, 615-628.

Berg, T. \& Schade, U. (1992). The role of inhibition in a spreading-activation model of language production. I. The psycholinguistic perspective. Journal of Psycholinguistic Research, 21(6), 405-434.

Bialystok E., Craik F. I., Freedman M. (2007). Bilingualism as a protection against the onset of symptoms of dementia. Neuropsychologia, 45, 459-464.

Blackford, T., Holcomb, P. J., Grainger, J., \& Kuperberg, G. R. (2012). A funny thing happened on the way to articulation: N400 attenuation despite behavioral interference in picture naming. Cognition, 123(1), 84-99.

Blazer, D. G. (2006). Cognitive Neuroscience of Aging: Linking Cognitive and Cerebral Aging. American Journal of Psychiatry, 163(3), 560-561.

Blazer, D. G., Yaffe, K., \& Karlawish, J. (2015). Cognitive aging: A report from the Institute of Medicine. Journal of the American Medical Association, 313 (21), 2121-2122.

Bogacz, R., Wagenmakers, E. J., Forstmann, B. U., \& Nieuwenhuis, S. (2010). The neural basis of the speed-accuracy tradeoff. Trends in Neuroscience, 33(1), 10-16. 
Bokura, H., Yamaguchi, S., Matsubara, M., Kobayashi, S. (2002) Frontal lobe contribution to response inhibition process - an ERP study and aging effect. International Congress Series, 1232, 17-20.

Bondareff, W. (1985). The neural basis of aging. In J. E. Birren \& K. W. Schaie (Eds.), Handbook of the psychology of aging (2nd ed., pp. 95-112). New York: Van Nostrand Reinhold Company.

Bopp, K. L., \& Verhaeghen, P. (2005). Aging and verbal memory span: a meta-analysis. Journal of Gerontology B - Psycholological Sciences and Social Sciences, 60(5), 223-233.

Bowles, R. P., \& Salthouse, T. A. (2008). Vocabulary test format and differential relations to age. Psychology and Aging, 23(2), 366-376.

Braver, T. S. \& West, R. (2008). Working memory, executive control, and aging. In: Craik FIM, Salthouse TA, editors. The Handbook of Aging and Cognition (3rd ed. pp. 311-372) Psychology Press; New York, USA.

Brennen, T. J., Baguley, T., Bright, J., \& Bruce, V. (1990). Resolving semantically induced tip of the tongue states for proper nouns. Memory and Cognition, 18, 339-347.

Brown, A. S. (1991).The tip-of-the-tongue experience: A review and evaluation. Psychological Bulletin, 10, 204-223.

Brown, C. \& Hagoort, P. (1993). The processing nature of the N400: evidence from masked priming. Journal of Cognitive Neuroscience, 5(1), 33-44.

Brysbaert, M. \& New, B. (2009) Moving beyond Kucera and Francis: A critical evaluation of current word frequency norms and the introduction of a new and improved word frequency measure for American English. Behavior Research Methods, 41: 977-990.

Brysbaert, M. (1996). Word frequency affects naming latency in Dutch when age of acquisition is controlled. European Journal of Cognitive Psychology, 8(2), 185194.

Bullmore, E. \& Sporns, O. (2009). Complex brain networks: graph theoretical analysis of structural and functional systems. Nature Reviews Neuroscience, 10(3), 186-198.

Burke, D. M. \& Shafto, M.A. (2008). Language and aging. In F.I.M. Craik \& T.A. Salthouse (Eds.), The handbook of aging and cognition (pp.373-443). New York: Psychology Press. 
Burke, D. M., MacKay, D. G., \& James, L. E. (2000). Theoretical approaches to language and aging. In T. J. Perfect \& E. A. Maylor (Eds.), Models of cognitive aging (pp. 204-237). New York: Oxford University Press.

Burke, D.M., Austin, A., \& Kester, J. (1998). Repetition priming with homographs: Age interactions in production of proper names. Paper presented at the Seventh Cognitive Aging Conference, Atlanta.

Burke, D.M., MacKay, D.G., Worthley, J.S., \& Wade, E. (1991). On the tip of the tongue: What causes word finding failures in young and older adults. Journal of Memory and Language, 30, 542-579.

Cabeza, R. (2002). Hemispheric asymmetry reduction in older adults: the HAROLD model. Psychology \& Aging, 17(1), 85-100.

Cabeza, R., Daselaar, S. M., Dolcos, F., Prince, S. E., Budde, M., \& Nyberg, L. (2004). Task-independent and task-specific age effects on brain activity during working memory, visual attention and episodic retrieval. Cerebral Cortex, 14, 364-375.

Caramazza, A., Costa, A., Miozzo, M., \& Bi, Y. (2001). The specific-word frequency effect: Implications for the representation of homophones. Journal of Experimental Psychology: Learning, Memory, and Cognition, 27,1430-1450.

Cavanaugh, J. C. \& Blanchard-Fields, F. (2006). Adult development and aging ( $\left.5^{\text {th }} \mathrm{Ed}.\right)$. Belmont: Thomson Wadsworth.

Cerella, J. (1985). Information processing rates in the elderly. Psychological Bulletin, 98(1), 67-83.

Cerella, J. (1990). Aging and information-processing rate. In J. E. Birren \& K. W. Schaie (Eds.), Handbook of the Psychology of Aging (3rd ed., pp. 201-221). San Diego, CA: Academic Press, Inc.

Chauncey, K., Holcomb, P., \& Grainger, J. (2009). Primed picture naming within and across languages: An ERP investigation. Cognitive, Affective, \& Behavioral Neuroscience, 9(3), 286-303.

Cohen, G. (1979). Language comprehension in old age. Cognitive Psychology, 11, 412429.

Cohen, J. E. (2003). Human population: the next half century. Science, 302(5648), 117275. 
Connolly, J. F., \& Phillips, N. A. (1994). Event-Related Potential Components Reflect Phonological and Semantic Processing of the Terminal Word of Spoken Sentences. Journal of Cognitive Neuroscience, 6(3), 256-266.

Connor, L.T., Spiro, A., Obler, L.K., \& Albert, M.L. (2004). Change in object naming during adulthood. Journal of Gerontology: Psychological Sciences, 59(5), 203209.

Craik F. I., Bialystok E., Freedman M. (2010). Delaying the onset of Alzheimer disease: bilingualism as a form of cognitive reserve. Neurology, 75, 1726-1729.

Cross, E. S., \& Burke, D. M. (2004). Do alternative names block young and older adults' retrieval of proper names? Brain and Language, 89(1), 174-181.

Cui, L., Wang, Y., Wang, H., Tian, S., \& Kong, J. (2000). Human brain sub-systems for discrimination of visual shapes. NeuroReport, 11, 2415-2418.

Davis, S. W., Dennis, N. A, Daselaar, S. M., Fleck, M. S., Cabeza, R. (2008). Que pasa? The posterior-anterior shift in aging. Cerebral Cortex, 18, 1201-1209.

De Sanctis, P., Katz, R., Wylie, G. R., Sehatpour, P., Alexopoulos, G. S., \& Foxe, J. J. (2008). Enhanced and bilateralized visual sensory processing in the ventral stream may be a feature of normal aging. Neurobiology of Aging, 29, 1576-1586

De Sanctis, P., Ritter, W., Molholm, S., Kelly, S. P., \& Foxe, J. J. (2008). Auditory Scene Analysis: the interaction of stimulation rate and frequency separation on preattentive grouping. The European Journal of Neuroscience, 27(5), 1271-1276.

Deacon, D., Breton, F., Ritter, W. and Vaughan, H. G. (1991). The Relationship between N2 and N400: Scalp distribution, stimulus probability, and task relevance. Psychophysiology, 28, 185-200.

Dell, G. S. (1986). A spreading-activation theory of retrieval in sentence production. Psychological Review, 93, 283-321.

Dell, G. S. (1990). Effects of frequency and vocabulary type on phonological speech errors. Language and Cognitive Processes, 5, 313-349.

Dell'Acqua, R., Sessa, P., Peressotti, F., Mulatti, C., Navarrete, E., \& Grainger, J. (2010). ERP Evidence for Ultra-Fast Semantic Processing in the Picture-Word Interference Paradigm. Frontiers in Psychology, 1(October), 1-10.

Demiral, S. B., Malcolm, G. L., \& Henderson, J. M. (2012). ERP correlates of spatially incongruent object identification during scene viewing: Contextual expectancy versus simultaneous processing. Neuropsychologia, 50, 1271-1285. 
Der, G. \& Deary, I. J. (2006). Age and sex differences in reaction time in adulthood: Results from the United Kingdom Health and Lifestyle Survey. Psychology and Aging, 21, 62-73.

Dufour, S., \& Peereman, R. (2003). Inhibitory priming effects in auditory word recognition: When the target's competitors conflict with the prime word. Cognition, 88(3).

Dunn, M., \& Dunn, L. M. (2007). Peabody Picture Vocabulary Test-4. Circle Pines, MN: AGS.

Dushanova, J. \& Christov, M. (2013). Auditory event-related brain potentials for an early discrimination between normal and pathological brain aging. Neural Regeneration Research, 8(15), 1390-1399.

Eimer, M. (1993). Effects of attention and stimulus probability on ERPs in a Go/Nogo task. Biological Psychology, 35, 123-138.

Engle, R. W. (2002). Working memory capacity as executive attention. Current Directions in Psychological Science, 11, 19-23.

Estévez-González, A., García-Sánchez, C., Boltes, A., Otermín, P., Pascual-Sedano, B., Gironell, A., et al (2004). Semantic knowledge of famous people in mild cognitive impairment and progression to Alzheimer's disease. Dementia and Geriatric Cognitive Disorders, 17, 188-195.

Evrard, M. (2002). Ageing and lexical access to common and proper names in picture naming. Brain and Language, 18, 174 -179.

Farrell, M. T., \& Abrams, L. (2011). Tip-of-the-tongue states reveal age differences in the syllable frequency effect. Journal of Experimental Psychology: Learning, Memory, and Cognition, 37, 77-285.

Faustman, A., Murdoch, B. E., Finnigan, S. P. \& Copland, D. A. (2007). Effects of Advancing Age on the Processing of Semantic Anomalies in Adults: Evidence from Event-Related Brain Potentials. Experimental Aging Research, 33(4), 439460.

Federmeier, K. D. (2014). Thirty years and counting: Finding meaning in the N400 component of the event related brain potential (ERP). NIH Public Access, 621-647.

Ferrand, L., Grainger, J., \& Segui, J. (1994). A study of masked form priming in picture and word naming. Memory \& Cognition, 22(4), 431-441. 
Ferreira, V.S. \& Pashler, H. (2002). Central bottleneck influences on the processing stages of word production. Journal of Experimental Psychology: Learning, Memory and Cognition, 28(6), 1187-1199.

Finnigan, S., O'Connell, R. G., Cummins, T. D. R., Broughton, M. and Robertson, I. H. (2011), ERP measures indicate both attention and working memory encoding decrements in aging. Psychophysiology, 48, 601-611.

Fischer-Baum, S. \& Rapp, B. (2014). The analysis of perseverations in acquired dysgraphia reveals the internal structure of orthographic representations. Cognitive Neuropsychology, 31, 237-265.

Fisher, D.L., Fisk, A.D., \& Duffy, S.A. (1995). Why latent models are needed to testhypotheses about the slowing of word and language processes inolder adults. In P.A. Allen \&T.R. Bashore (Eds.), Age differences in word and language processing (pp. 1-29). Amsterdam: Elsevier.

Fjell, A. M. \& Walhovd, K. B. (2010). Structural brain changes in aging: courses, causes and cognitive consequences. Reviews in the Neurosciences, 21 (3), 187-221.

Ganushchak, L. Y., Christoffels, I. K., \& Schiller, N. O. (2011). The use of electroencephalography in language production research: A review. Frontiers in Psychology, 2(SEP), 1-6.

German, J. D. (1990). Test of Adolescent and Adult Word Finding. PRO-ED, Austin, TX.

Giard, M. H., Perrin, F., Echallier, J. F., Thevenet, M., Froment, J. C., \& Pernier, J. (1994). Dissociation of temporal and frontal components in the human auditory N1 wave: a scalp current density and dipole model analysis. Electroencephalography and Clinical Neurophysiology/ Evoked Potentials, 92(3), 238-252.

Goh, J. O. \& Park, D. C. (2009). Neuroplasticity and cognitive aging: The scaffolding theory of aging and cognition. Restorative Neurology and Neuroscience, 27(5), 391-403.

Golden C. J., \& Freshwater, S. M. (2002). The Stroop color and word test: A manual for clinical and experimental uses. Chicago, IL: Stoelting.

Goral, M., Spiro, A. III, Albert, M.L., Obler, L.K., \& Connor, L.T. (2007). Change in lexical skills in adulthood: Not a uniform decline. Mental Lexicon, 2, 215-238. 
Gorus, E., De Raedt, R., Lambert, M., Lemper, J., \& Mets, T. (2008). Reaction times and performance variability in normal aging, mild cognitive impairment, and Alzheimer's disease. Journal of Geriatric Psychiatry and Neurology 21(3): 204219.

Grainger, J., \& Ferrand, L. (1996). Masked orthographic and phonological priming in visual word recognition and naming: Cross-task comparisons. Journal of Memory and Language, 35(5), 623-647.

Grainger, J., Diependaele, K., Spinelli, E., Ferrand, L., \& Farioli, F. (2003). Masked repetition and phonological priming within and across modalities. Journal of Experimental Psychology. Learning, Memory, and Cognition, 29(6), 1256-1269.

Grainger, J., Kiyonaga, K., \& Holcomb, P. (2006). The time course of orthographic and phonological code activation. Psychological Science, 17(12), 1021-1026.

Grainger, J., Lopez, D., Eddy, M., Dufau, S., \& Holcomb, P. J. (2012). How word frequency modulates masked repetition priming: An ERP investigation. Psychophysiology, 49(5), 604-616.

Gunter, T. C., Jackson, J. L. and Mulder, G. (1992). An Electrophysiological Study of Semantic Processing in Young and Middle-Aged Academics. Psychophysiology, 29, 38-54.

Hagoort, P. \& Kutas, M. (1995). Electrophysiological insights into language deficits. In: F. Boller and J. Grafman (Eds.), Handbook of Neuropsychology, Vol. 10, Elsevier Science Publishers B. V., Amsterdam, pp. 105-134.

Halgren, E. (1990). Human evoked potentials. In: Boulton AA, Baker GB, Vanderwolf C, editors. Neurophysiological Techniques -Applications to Neural Systems. Humana; Clifton, NJ.

Hämmerer D, Li SC, Müller V, Lindenberger U (2010) An electrophysiological study of response conflict processing across the lifespan: Assessing the roles of conflict monitoring, cue utilization, response anticipation, and response suppression. Neuropsychologia, 48, 3305-3316.

Hampson, M., Tokoglu, F., Shen, X., Scheinost, D., Papademetris, X., \& Constable, R. T. (2012). Intrinsic Brain Connectivity Related to Age in Young and Middle Aged Adults. PLoS ONE, 7(9), e44067.

Harbin, T.J., Marsh, G.R. and Harvey, M.T. (1984) Differences in the Late Components of the Event-Related Potential Due to Age and to Semantic and Non-Semantic Tasks. Electroencephalography \& Clinical Neurophysiology, 59, 489- 496. 
Harley, T. A., \& Bown, H. E. (1998). What causes a tip-of-the-tongue state? Evidence for lexical neighbourhood effects in speech production. British Journal of Psychology, 89, 151-174.

Hasher, L., Lustig, C., \& Zacks, R. T. (2007). Inhibitory mechanisms and the control of attention. In A. Conway, C. Jarrold, M. Kane, A. Miyake, A., \& J. Towse (Eds.), Variation in working memory. Pp. 227-249. New York: Oxford University Press.

Hebert, L. E., Scherr, P. A., Bienias, J. L., Bennett, D. A., \& Evans, D. A. (2003). Alzheimer disease in the US population: prevalence estimates using the 2000 census. Archives of Neurology, 60(8), 1119-22.

Heine, M. K., Ober, B. A., \& Shenaut, G. K. (1999). Naturally occurring and experimentally induced tip-of-the-tongue experiences in three adult age groups. Psychology and Aging, 14(3), 445-457.

Helm-Estabrooks, N. (2001). Cognitive Linguistic Quick Test. San Antonio, TX: Harcourt Assesment.

Henninger, D. E., Madden, D. J., \& Huettel, A. S. (2010). Processing speed and memory mediate age-related differences in decision making. Psychology \& Aging, 25(2), 262-270.

Hillyard, S. a, Hink, R. F., Schwent, V. L., \& Picton, T. W. (1973). Electrical signs of selective attention in the human brain. Science (New York, N.Y.), 182(108), 177180.

Holcomb, P. J., \& Anderson, J. E. (1993). Cross-modal Semantic Priming: A Timecourse Analysis Using Event-related Brain Potentials. Language and Cognitive Processes, 8(4), 379-411.

Holcomb, P. J., \& Grainger, J. (2006). On the time course of visual word recognition: an event-related potential investigation using masked repetition priming. Journal of Cognitive Neuroscience, 18(10), 1631-43.

Holcomb, P. J., Anderson, J., \& Grainger, J. (2005). An electrophysiological study of cross-modal repetition priming. Psychophysiology, 42(5), 493-507.

Holcomb, P. J., Coffey, S. A., \& Neville, H. J. (1992). Visual and auditory sentence processing: A developmental analysis using event-related brain potentials. Developmental Neuropsychology, 8(2-3), 203-241.

Hollingshead, A. (1975). Four factor index of social status. Yale Journal of Sociology. Retrieved from http://elsinore.cis.yale.edu/sociology/yjs/yjs_fall_2011.pdf\#page=21 
Indefrey, P. \& Levelt. W. J. M. (2004). The spatial and temporal signatures of word production components. Cognition, 92, 101-144.

Iragui, V. J., Kutas, M., Mitchiner, M. R., \& Hillyard, S. A. (1993). Effects of aging on event-related brain potentials and reaction times in an auditory oddball task. Psychophysiology, 30(1), 10-22.

Iragui, V. J., Kutas, M., Mitchiner, M. R., \& Hillyard, S. A. (1993). Effects of aging on event-related brain potentials and reaction times in an auditory oddball task. Psychophysiology, 30(1), 10-22.

James, L. E. (2006). Specific effects of aging on proper name retrieval: Now you see them, now you don't. Journal of Gerontology B: Psychological Sciences and Social Sciences, 61, 180-183.

James, L. E., \& Burke, D. M. (2000). Phonological priming effects on word retrieval and tip-of-the-tongue experiences in young and older adults. Journal of Experimental Psychology: Learning, Memory, and Cognition, 26, 1378-1391.

James, L., \& Burke, D. (2000). Phonological Priming Effects on Word Retrieval and Tipof-the-Tongue Experiences in Young and Older Adults. Journal of Experimental Psychology: Learning, Memory, and Cognition, 26(6), 1378-1391.

Jenkins, L., Myerson, J., Joerding, J. A., \& Hale, S. (2000). Converging evidence that visuospatial cognition is more age-sensitive than verbal cognition. Psychology \& Aging, 15(1), 157-175.

Jescheniak, J. D., Schriefers, H., Garrett, M. F., \& Friederici, A. D. (2002). Exploring the activation of semantic and phonological codes during speech planning with eventrelated brain potentials. Journal of Cognitive Neuroscience, 14(6), 951-64.

Kaplan, E., Goodglass, H., \& Weintraub, S. (1983). The Boston Naming Test. Philadelphia: Lea and Febiger.

Kavé, G. (2015). Doubly Blessed : Older Adults Know More Vocabulary and Know Better What They Know. Psychology and Aging, 30(1), 68-73.

Kavé, G., \& Nussbaum, S. (2012). Characteristics of noun retrieval in picture descriptions across the adult lifespan. Aphasiology, 26(10), 1238-1249.

Kavé, G., Knafo, A., \& Gilboa, A. (2010). The rise and fall of word retrieval across the lifespan. Psychology and Aging, 25(3), 719-724.

Kemper, S., \& Lacal, J. C. (2004). Addressing the communication needs of an aging society. R. W. Pew \& S. B. Van Hemel (Eds.), Technology for adaptive aging (pp. 129-149). Washington, DC: The National Academies Press. 
Kenney, R. A. (1988). Physiology of aging. In B. B. Shadden (Ed.), Communication behavior and aging: A sourcebook for clinicians (pp. 58-78). Baltimore: Williams \& Williams.

Ketcham, C. J. \& Stelmach, G. E. (2004). Movement Control in the Older Adult. In: National Research Council (US) Steering Committee for the Workshop on Technology for Adaptive Aging. Pew RW, Van Hemel SB, editors. Technology for Adaptive Aging. Washington (DC): National Academies Press (US).

Key, A. P. F., Dove, G. O., \& Maguire, M. J. (2005). Linking brainwaves to the brain: an ERP primer. Developmental Neuropsychology, 27(2), 183-215.

King, J. W., \& Kutas, M. (1995). Do the waves begin to waver? ERP studies of language processing in the elderly. Age Differences in Word and Language Processing, Volume 110, 314-344.

Kiyonaga, K., Grainger, J., Midgley, K., \& Holcomb, P. (2007). Masked cross-modal repetition priming: An event-related potential investigation. Language and Cognitive Processes, 22(3), 337-376.

Kong, J., Wang, Y. P., Zhang, W. T., Wang, H. J., Wei, H. F., \& Shang, H. Y. (2000). Event-related brain potentials elicited by a number discrimination task. Neuroreport, 11, 1195-1197.

Kramer A. F., Bherer L., Colcombe S. J., Dong W., Greenough W. T. (2004). Environmental influences on cognitive and brain plasticity during aging. Journal of Gerontology Series A - Biological Sciences and Medical Sciences, 59(A), 940957.

Kramer, A. F., Bherer, L., Colcombe, S. L., Dong, W. \& Greenough, W. T. (2004). Environmental influences on cognitive and brain plasticity during aging. The Journals of Gerontology. Series A. Biological and Medical Sciences, 59(9), 94057.

Kutas, M., \& Hillyard, S. A. (1980). Reading senseless sentences: brain potentials reflect semantic incongruity. Science (New York, N.Y.), 207(4427), 203-205.

Kutas, M., \& Iragui, V. (1998). The N400 in a semantic categorization task across 6 decades. Electroencephalography and Clinical Neurophysiology - Evoked Potentials, 108(5), 456-471.

Kutas, M., \& Petten, C. Van. (1988). Event-related brain potential studies of language. Advances in Psychophysiology, 3, 139-187. 
Laganaro, M., Morand, S., Schwitter, V., Zimmermann, C., Camen, C., \& Schnider, A. (2009). Electrophysiological correlates of different anomic patterns in comparison with normal word production. Cortex, 45(6), 697-707.

Laver,G. D. \& Burke, D. M. (1993). Why do semantic priming effects increase in old age? A meta-analysis. Psychology and Aging, 8(1), 34-43.

Lefebvre, C. D., Marchand, Y., Eskes, G. A., \& Connolly, J. F. (2005). Assessment of working memory abilities using an event-related brain potential (ERP)-compatible digit span backward task. Clinical Neurophysiology, 116, 1665-1680.

Levelt, J. M. (1998). Speaking: From intention to articulation. Cambridge, MA: MIT Press.

Levelt, W. J. M., Roelofs, A., \& Meyer, A. S. (1999). A theory of lexical access in speech production. Behavioral \& Brain Sciences, 22(1), 1-75.

Li, S. C. (2002). Connecting the Many Levels and Facets of Cognitive Aging. Current Directions in Psychological Science, 11(1), 38-43.

Light, L. L. \& LaVoie, D. L. (1993). Direct and indirect measures of memory in old age. In P.Graff, E. Michael, \& J. Masson (Ed), Implicit memory, new directions in cognition, development, and neuropsychology. Mahwah, NJ: Lawrence Erlbaum Associates.

Liu, Y.C. (2001). Comparative study of effects of auditory, visual and multimodality displays on drivers' performance in advanced traveler information systems. Ergonomics, 44(4), 425-442.

Lovelace, E.A., \& Twohig, P. T. (1990). Healthy older adults' perceptions of their memory functioning and use of mnemonics. Bulletin of the Psychonomic Society, $28,115-118$.

Luck, S. J. \& Kappenman, E. S. (2012): The Oxford Handbook of Event-Related Potential Components. New York: Oxford University Press.

MacKay, D. G. \& James, L.E. (2004). Sequencing, speech production, and selective effects of aging on phonological and morphological speech errors. Psychology and Aging, 19, 93-110.

MacKay, D. G., \& Burke, D. M. (1990). Cognition and Aging: a theory of new learning and the use of old connections. Aging and Cognition: Knowledge Organization and Utilization, 213-263. 
Madden, D. J. (2001). Speed and timing of behavioral processes. In J. E. Birren \& K. W. Schaie (Eds.), Handbook of the psychology of aging (5th ed., pp. 288 - 312). San Diego, CA: Academic Press.

Madden, D. J., Bennett, I. J., \& Song, A. W. (2009). Cerebral white matter integrity and cognitive aging: contributions from diffusion tensor imaging. Neuropsychological Review, 19(4), 415-435.

Manoiloff, L., Segui, J., \& Hallé, P. (2015). Subliminal repetition primes help detection of phonemes in a picture: Evidence for a phonological level of the priming effects. The Quarterly Journal of Experimental Psychology, 69(1), 24-36.

Martin, N. \& Dell, G. S. (2004). Perseverations and anticipations in aphasia: Primed intrusions from the past and future. Seminars in Speech and Language, 25(4), 349-362.

Mathalon, D. H., Whitfield, S. L., \& Ford, J. M. (2003). Anatomy of an error: ERP and fMRI. Biological Psychology, 64, 119-141.

McArdle, J. J., Ferrer-Caja, E., Hamagami, F., \& Woodcock, R. W. (2002). Comparative longitudinal structural analyses of the growth and decline of multiple intellectual abilities over the life span. Developmental Psychology, 38(1), 115-142.

McCoy, S. L., Tun, P. A., Cox, L. C., Colangelo, M., Stewart, R. A., \& Wingfield, A. (2005).Hearing loss and perceptual effort: Downstream effects on older adults' memory for speech. The Quarterly Journal of Experimental Psychology, 58A, 2233.

McDowd, J. M. \& Shaw, R. J. (2000). Attention and aging: a functional perspective. In: Craik FIM, Salthouse TA, editors. The Handbook of Aging and Cognition $\left(2^{\text {nd }}\right.$ Ed. p. 221). Erlbaum; Mahwah, NJ.

McPherson, W. B., \& Holcomb, P. J. (1999). An electrophysiological investigation of semantic priming with pictures of real objects. Psychophysiology, 36(01), 53-65.

Meschyan, G., \& Hernandez, A. (2002). Age of acquisition and word frequency: determinants of object-naming speed and accuracy. Memory \& Cognition, 30(2), 262-269.

Meunier, D., Stamatakis, E. A., \& Tyler, L. K. (2014). Age-related functional reorganization, structural changes, and preserved cognition. Neurobiology of Aging, 35 (1), 42-54.

Meyer A. S, Bock J. K. (1992). The tip-of-the-tongue phenomenon: Blocking or partial activation? Memory \& Cognition, 20, 715-726. 
Murphy, D. R., Craik, F. I. M., Li, K. Z. H., \& Schneider, B. A. (2000). Comparing the effects of aging and background noise on short-term memory performance. Psychology and Aging, 15, 323-334.

Myerson, J., Emery, L., White, A. D., \& Hale, S. (2002). Effects of age, domain, and processing demands on memory span: Evidence for differential decline. Aging Neuropsychology and Cognition, 10(1), 20-27.

Naveh-Benjamin, M. \& Craik, F. I. (1995). Memory for context and its use in item memory: comparisons of younger and older persons. Psychology \& Aging, 10(2), 284-293.

Naveh-Benjamin, M. \& Craik, F. I. (1996). Effects of perceptual and conceptual processing on memory for words and voice: different patterns for young and old. Quarterly Journal of Experimental Psychology A, 49(3), 780-796.

Neumann, Y, Obler, L.K., Gomes, H. \& Shafer, V. (2009). Phonological vs. sensory contributions to age effects in naming: An electrophysiological study. Aphasiology, 12, 1028-1039.

Neville, H. J. (1985). Biological constraints on semantic processing: a comparison of spoken and signed languages. Psychophysiology, 22, 576.

Newson, R. S. \& Kemps, E. B. (2006). The nature of subjective cognitive complaints of older adults. International Journal of Aging and Human Development, 63(2), 139151.

Oldfield, R. C., \& Wingfield, A. (1965). Response latencies in naming objects. The Quarterly Journal of Experimental Psychology, 17(4), 273-281.

Ossher, L., Flegal, K. E., \& Lustig, C. (2013). Everyday memory errors in older adults. Aging, Neuropsychology and Cognition, 20(2), 220-242.

Park, C. D. \& Reuter-Lorenz, P. (2009). The adaptive brain: Aging and neurocognitive scaffolding. Annual Review of Psychology, 60, 173-196.

Phillips, N. A., \& Lesperance, D. (2003). Breaking the waves: Age differences in electrical brain activity when reading text with distractors. Psychology and Aging, 18(1), 126-139.

Praamstra, P. \& Stegeman, D. F. (1993). Phonological effects on the auditory N400 event-related brain potential. Cognitive Brain Research, 1(2), 73-86. 
Praamstra, P., Meyer, A. S., \& Levelt, W. J. M. (1994). Neurophysiological

Manifestations of Phonological Processing: Latency Variation of a Negative ERP Component Timelocked to Phonological Mismatch. Journal of Cognitive

Neuroscience, 6(3), 204-219.

Pratarelli, M. E. (1994). Semantic processing of pictures and spoken words: Evidence from event-related brain potentials. Brain and Cognition, 24, 137-157.

Ratcliff, R. (1985). Theoretical interpretations of the speed and accuracy of positive and negative responses. Psychological Review, 92, 212-225.

Ratcliff, R., \& McKoon, G. (2008). The diffusion decision model: theory and data for two-choice decision tasks. Neural Computation, 20(4), 873-922.

Raz, N., Lindenberger, U., Rodrigue, K. M., Kennedy, K. M., Head, D., Williamson, A., Dahle, C., Gerstorf, D., \& Acker, J. D. (2005). Regional brain changes in aging healthy adults: general trends, individual differences and modifiers. Cerebral Cortex, 15(11), 1676-89.

Reuter-Lorenz, P. A. \& Lustig, C. (2005). Brain aging: Reorganizing discoveries about the aging mind. Current Opinion in Neurobiology, 15, 245-251.

Reuter-Lorenz, P. A. \& Park, D. C. (2010). Human neuroscience and the aging mind: a new look at old problems. Journal of Gerontology Series B - Psychological and Social Sciences, 65(4), 405-415.

Reuter-Lorenz, P. A. \& Sylvester, C-Y. C. (2005). The cognitive neuroscience of working memory and aging. In: Cabeza R, Nyberg L, Park D, editors. Cognitive Neuroscience of Aging. Oxford University Press; Oxford.

Reuter-Lorenz, P. A., Jonides, J., Smith, E. E., Hartley, A., Miller, A., Marshuetz, C., et al. (2000). Age differences in the frontal lateralization of verbal and spatial working memory revealed by PET. Journal of Cognitive Neuroscience, 12(1), 174-187.

Riecker, A., Gröschel, K., Ackermann, H., Steinbrink, C., Witte, O., \& Kastrup, A. (2006). Functional significance of age-related differences in motor activation patterns. NeuroImage, 32, 1345 - 1354.

Salthouse, T. A. \& Mandell, A. R. (2013) Do age-related increases in TOT experiences signify episodic memory impairments. Psychological Science, 24(12), 2489_ 2497. 
Salthouse, T. A. (1996). The processing-speed theory of adult age differences in cognition. Psychological Review, 103, 403-428.

Salthouse, T. A. (2000). Aging and measures of processing speed. Biological Psychology, $54,35-54$.

Schaie, K. W. (2005). Developmental influences on adult intelligence: The Seattle Longitudinal Study. New York: Oxford University Press.

Schiller, N. O. (2008). The masked onset priming effect in picture naming. Cognition, 106(2), 952-962.

Schriefers, H., Meyer, A. S., \& Levelt, W. J. M. (1990). Exploring the time course of lexical access in language production: Picture-word interference studies. Journal of Memory and Language, 29(1), 86-102.

Shafto, A. M., Stamatakis, A. E., Tam, P. P., \& Tyler, K. L. (2010). Word retrieval failures in old age: The relationship between structure and function. Journal of Cognitive Neuroscience, 27(7): 1530-40.

Shafto, M. A. \& Tyler, L. K. (2014). Language in the aging brain: The network dynamics of cognitive decline and preservation. Science, 346 (6209), 583-586.

Shafto, M. A., Burke, D. M., Stamatakis, E. A., Tam, P., \& Tyler, L. K. (2007). On the tip-of-the-tongue: Neural correlates of increased word-finding failures in normal aging. Journal of Cognitive Neuroscience, 19, 2060-2070.

Sommers, M. S. \& Danielson, S. M. (1999). Inhibitory processes and spoken word recognition in young and older adults: The interaction of lexical competition and semantic context. Psychology and Aging, 14, 458-472.

Spieler, D. H., \& Balota, D. a. (2000). Factors influencing word naming in younger and older adults. Psychology and Aging, 15(2), 225-231.

Springer, M. V., Mcintosh, A. R., Winocur, G., \& Grady C. L. (2005). The relation between brain activity during memory tasks and years of education in young and older adults. Neuropsychology, 19, 181-192.

Stamatakis, A. E., Shafto, A. M., Williams, G., Tam, P., \& Tyler, K. L. (2011). White matter changes and word finding failures with increasing age. PLOS One, 6(1). DOI: 10.1371/journal.pone.0014496.

Standage, D., Wang, D. H., Heitz, R. P., \& Simen, P. (2015). Toward a unified view of the speed-accuracy trade-off. Frontiers in Neuroscience, 9, 1-3. 
Stine, E.A.L. (1995). Aging and the distribution of resources in working memory. . In P.A. Allen \& T.R. Bashore (Eds.), Age differences in word and language processing (pp. 171-186). Amsterdam: Elsevier.

Stine-Morrow, E. A. L. \& Shake, M. C. (2009). New encyclopedia of neuroscience. Elsevier, New York.

Strijkers, K., Costa, A., \& Thierry, G. (2010). Tracking lexical access in speech production: electrophysiological correlates of word frequency and cognate effects. Cerebral Cortex (New York, N.Y. : 1991), 20(4), 912-28.

Szekely, A., D’Amico, S., Devescovi, A., Federmeier, K., Herron, D., Iyer, G., Jacobsen,T., \& Bates, E. (2003). Timed picture naming: Extended norms and validation against previous studies. Behavior Research Methods, Instruments, \& Computers, 35, 621-633.

Tachibana, H., Aragane, K., \& Sugita, M. (1996) Age-related changes in event-related potentials in visual discrimination tasks. Electroencephalography and Clinical Neurophysiology, 100, 299-309.

Taler, V., Aaron, G. P., Steinmetz, L. G., \& Pisoni, D. B. (2010). Lexical neighborhood density effects on spoken word recognition and production in healthy aging. Journals of Gerontology: Series B, 65, 551-560.

Taylor, J. K., \& Burke, D. M. (2002). Asymmetric aging effects on semantic and phonological processes: naming in the picture-word interference task. Psychology and Aging, 17(4), 662-676. 2

Taylor, M. J., Smith, M. L., \& Iron, K. S. (1990). Event-related potential evidence of sex differences in verbal and nonverbal memory tasks. Neuropsychologia, 28, 691705 .

Thornton, R., \& Light, L.L. (2006). Language comprehension and production in normal aging. In J.E. Birren \& K.W. Schaie (Eds.) Handbook of the Psychology of Aging (6th ed.) (pp. 261-287). San Diego, CA: Elsevier.

Valenzuela, M. J. \& Sachdev, P. (2006). Brain reserve and cognitive decline: a nonparametric systematic review. Psychological Medicine, 36, 1065-1073.

Van Petten, C., \& Kutas, M. (1990). Interactions between sentence context and word frequency in event-related brain potentials. Memory \& Cognition, 18(4), 380-393.

Verhaeghen, P. \& De Meersman, L. (1998). Aging and the Stroop effect: A metaanalysis. Psychology and Aging, 13, 120-126. 
Vitevitch, M. S. (2002). The influence of phonological similarity neighborhoods on speech production. Journal of Experimental Psychology: Learning, Memory, \& Cognition, 28, 735-747.

Vitevitch, S. M. \& Sommers, S. M. (2003). The facilitative influence of phonological similarity and neighborhood frequency in speech production in younger and older adults. Memory and Cognition, 31(4): 491-504.

Vogel, E. K. \& Luck, S. J. (2000). The visual N1 component as an index of a discrimination process. Psychophysiology, 37 (2), 190-203.

Welford, A.T. (1984). Between bodily changes and performance: Some possible reasons for slowing with age. Experimental Aging Research, 10(2), 73-88.

West, R. (2004). The effects of aging on controlled attention and conflict processing in the Stroop task. Journal of Cognitive Neuroscience, 16(1),103-113.

White, K. K., \& Abrams, L. (2002). Does priming specific syllables during tip-of-thetongue states facilitate word retrieval in older adults? Psychology and Aging, 17(2), $226-235$.

White, K. K., Abrams, L., \& Zoller, S. M. (2013). Perception-production asymmetries in homophone spelling: The unique influence of aging. Journal of Gerontology Series B: Psychological Sciences, 68(5), 681-90.

Woodward, S. H., Ford, J. M., Hammett, S. C. (1993). N4 to spoken sentences in young and older subjects. Electroencephalography and Clinical Neurophysiology, 87(5), 306-20.

Zec, R. F., Burkett, N. R., Markwell, S. J., \& Larsen, D. L. (2007). Normative data stratified for age, education, and gender on the Boston Naming Test. Clinical Neuropsychology, 21(4), 617-37.

Zec, R. F., Markwell, S. J., Burkett, N. R., \& Larsen, D. L. (2005). A longitudinal study of confrontation naming in the "normal" elderly. Journal of the International Neuropsychological Society, 11(6), 716-26. 
APPENDICES 


\section{APPENDIX A Naming Task Word List}

Appendix Table A.1. High frequency stimuli list for Experiment 1 (behavioral assessment of word retrieval) and corresponding lexical characteristics.

\begin{tabular}{|c|c|c|c|c|}
\hline No. & $\begin{array}{c}\text { High } \\
\text { frequency } \\
\text { words } \\
\end{array}$ & $\begin{array}{l}\text { COCA word } \\
\text { frequency }\end{array}$ & $\begin{array}{c}\text { Phonological } \\
\text { neighborhood } \\
\text { density }\end{array}$ & $\begin{array}{c}\text { Phonological } \\
\text { neighborhood } \\
\text { frequency }\end{array}$ \\
\hline 1 & bag & 9.4 & 38 & 92.11 \\
\hline 2 & barn & 13.1 & 31 & 70.78 \\
\hline 3 & bear & 52.5 & 46 & 353.71 \\
\hline 4 & bed & 115.9 & 43 & 8.10 \\
\hline 5 & belt & 24.8 & 18 & 47.23 \\
\hline 6 & boat & 7.7 & 37 & 157.12 \\
\hline 7 & book & 231.1 & 25 & 184.47 \\
\hline 8 & car & 47.1 & 33 & 192.81 \\
\hline 9 & corn & 29.8 & 42 & 147.34 \\
\hline 10 & couch & 18.9 & 9 & 26.03 \\
\hline 11 & doll & 10.1 & 30 & 231.95 \\
\hline 12 & fence & 21.9 & 12 & 14.59 \\
\hline 13 & foot & 62.4 & 14 & 109.56 \\
\hline
\end{tabular}




\begin{tabular}{rrrrr}
14 & fork & 14.1 & 21 & 377.31 \\
15 & glove & 8.1 & 6 & 189.18 \\
16 & leg & 41.3 & 16 & 174.17 \\
17 & seal & 13.8 & 48 & 99.03 \\
18 & spoon & 13.8 & 14 & 21.69 \\
19 & sun & 101.3 & 40 & 207.71 \\
20 & wheel & 25.5 & 40 & 396.71 \\
\hline & Mean & $\mathbf{4 3 . 1 3}$ & $\mathbf{2 8 . 1 5}$ & $\mathbf{1 5 5 . 0 8}$ \\
\hline
\end{tabular}

Appendix Table A.2. Low frequency stimuli list for Experiment 1 (behavioral assessment of word retrieval) and corresponding lexical characteristics.

\begin{tabular}{ccccc}
\hline No. & $\begin{array}{c}\text { Low frequency } \\
\text { words }\end{array}$ & $\begin{array}{c}\text { COCA } \\
\text { word } \\
\text { frequency }\end{array}$ & $\begin{array}{c}\text { Phonological } \\
\text { neighborhood density }\end{array}$ & $\begin{array}{c}\text { Phonological } \\
\text { neighborhood } \\
\text { frequency }\end{array}$ \\
\hline 1 & beard & 1.2 & 9 & 21.78 \\
2 & cane & 0.7 & 53 & 123.88 \\
3 & chain & 2.2 & 36 & 18.83 \\
4 & clown & 0.8 & 9 & 19.49 \\
5 & crab & 0.5 & 12 & 20.30 \\
6 & drill & 1.3 & 14 & 2.08 \\
7 & globe & 1.4 & 7 & 2.49 \\
8 & hoof & 0.1 & 13 & 197.77 \\
\hline
\end{tabular}




\begin{tabular}{|c|c|c|c|c|}
\hline 9 & kite & 0.2 & 36 & 195.99 \\
\hline 10 & lamp & 0.5 & 14 & 8.59 \\
\hline 11 & leaf & 2.0 & 21 & 82.99 \\
\hline 12 & nurse & 2.2 & 13 & 64.23 \\
\hline 13 & pants & 2.5 & 10 & 5.75 \\
\hline 14 & peas & 0.6 & 41 & 62.48 \\
\hline 15 & rose & 1.5 & 56 & 34.04 \\
\hline 16 & rug & 0.9 & 27 & 874.822 .39 \\
\hline 17 & shell & 2.3 & 29 & 198.01 \\
\hline 18 & stove & 0.6 & 7 & 24.64 \\
\hline 19 & tail & 2.1 & 49 & 89.75 \\
\hline \multirow[t]{3}{*}{20} & witch & 1.1 & 28 & 295.30 \\
\hline & Mean & 1.23 & 24.2 & 74.539 \\
\hline & SE & 0.16 & 3.60 & 18.86 \\
\hline
\end{tabular}




\section{APPENDIX B ERP Task Word List}

Appendix Table B. 1. High frequency stimuli list for Experiment 2 (Neural indices of word retrieval), corresponding lexical characteristics and phonologically matched pseudo word prime.

\begin{tabular}{|c|c|c|c|c|c|}
\hline No. & $\begin{array}{c}\text { High frequency } \\
\text { words }\end{array}$ & $\begin{array}{c}\text { COCA } \\
\text { word } \\
\text { frequency }\end{array}$ & $\begin{array}{c}\text { Phonological } \\
\text { neighborhood } \\
\text { density }\end{array}$ & $\begin{array}{l}\text { Phonological } \\
\text { neighborhood } \\
\text { frequency }\end{array}$ & $\begin{array}{c}\text { Matched } \\
\text { Pseudo } \\
\text { word } \\
\text { Prime } \\
\text { (IPA) }\end{array}$ \\
\hline 1 & bell & 37.4 & 41 & 155.0875 & bep \\
\hline 2 & bird & 7.8 & 39 & 45.0498 & bərk \\
\hline 3 & bomb & 13.5 & & 30.0466 & bak \\
\hline 4 & boot & 12.6 & 39 & 144.911 & budz \\
\hline 5 & bowl & 64.3 & 45 & 33.7917 & bop \\
\hline 6 & bread & 35.5 & 19 & 28.0279 & bret $\int$ \\
\hline 7 & bus & 46.2 & 28 & 174.2472 & bəb \\
\hline 8 & cake & 24.4 & 35 & 132.0387 & keb \\
\hline 9 & cat & 33.2 & 50 & 474.7035 & kæk \\
\hline 10 & church & 16.7 & 6 & 8.8235 & $\mathrm{t} \int \partial r g$ \\
\hline 11 & crown & 15.9 & 11 & 14.9322 & krawk \\
\hline 12 & cup & 109.8 & 26 & 313.0935 & kəx \\
\hline 13 & deer & 26.2 & 28 & 204.4972 & dıks \\
\hline 14 & desk & 47.1 & 6 & 6.5294 & $\mathrm{~d} \varepsilon \mathrm{m}$ \\
\hline 15 & door & 226.5 & 49 & 364.98 & dob \\
\hline 16 & duck & 12.8 & 42 & 52.4477 & dət \\
\hline
\end{tabular}




\begin{tabular}{|c|c|c|c|c|c|}
\hline 17 & fan & 12.2 & 34 & 254.1471 & fæt \\
\hline 18 & flag & 21.4 & 11 & 5.4546 & flæs \\
\hline 19 & fox & 41.2 & 29 & 12.9696 & fap \\
\hline 20 & girl & 39.6 & 22 & 14.0125 & gərz \\
\hline 21 & goat & 8.1 & 23 & 534.9301 & gof \\
\hline 22 & gun & 26.8 & 33 & 179.9703 & gək \\
\hline 23 & hand & 307.8 & 24 & 651.3194 & hæp \\
\hline 24 & heart & 168.1 & 29 & 62.2103 & hal \\
\hline 25 & horse & 42.5 & 18 & 64.5414 & hof \\
\hline 26 & house & 490.8 & 10 & 317.6569 & hawk \\
\hline 27 & lips & 40.1 & 19 & 4.3468 & lig \\
\hline 28 & man & 191.9 & 51 & 155.8362 & mæz \\
\hline 29 & moon & 48.2 & 32 & 141.9375 & mul \\
\hline 30 & nose & 43.7 & 37 & 359.309 & nog \\
\hline 31 & pen & 15.2 & 35 & 127.0342 & $\mathrm{p} \varepsilon \mathrm{S}$ \\
\hline 32 & pig & 10.1 & 22 & 50.0651 & pid \\
\hline 33 & pipe & 16.2 & 21 & 13.3417 & pajv \\
\hline 34 & plug & 8.4 & 11 & 6.918 & pləb \\
\hline 35 & ring & 41.8 & 35 & 71.0375 & riks \\
\hline 36 & road & 22.9 & 42 & 26.3931 & ron \\
\hline 37 & rock & 12.7 & 35 & 12.321 & $\mathrm{raz}$ \\
\hline 38 & sheep & 13.7 & 21 & 229.2213 & Jig \\
\hline
\end{tabular}




\begin{tabular}{lccccc}
\hline 39 & skirt & 13.9 & 12 & 5.8448 & skərm \\
40 & snake & 12.4 & 8 & 17.4461 & snet \\
41 & star & 95.5 & 17 & 60.947 & staj \\
42 & train & 54.0 & 22 & 14.3102 & tref \\
43 & truck & 49.1 & 8 & 20.3162 & trənd \\
44 & watch & 125.1 & 12 & 48.6062 & wag \\
\hline & Mean & $\mathbf{6 1 . 4 3}$ & $\mathbf{2 6 . 4 4}$ & $\mathbf{1 2 8 . 3 1}$ & \\
\hline & & $\mathbf{1 3 . 7 7}$ & $\mathbf{3 . 9 9}$ & $\mathbf{1 9 . 3 4}$ & \\
\hline
\end{tabular}

Appendix Table B. 2. Low frequency stimuli list for Experiment 2 (Neural indices of word retrieval), corresponding lexical characteristics and phonologically matched pseudo word prime.

\begin{tabular}{cccccc}
\hline No. & $\begin{array}{c}\text { Low frequency } \\
\text { words }\end{array}$ & $\begin{array}{c}\text { COCA } \\
\text { word } \\
\text { frequency }\end{array}$ & $\begin{array}{c}\text { Phonological } \\
\text { neighborhood } \\
\text { density }\end{array}$ & $\begin{array}{c}\text { Phonological } \\
\text { neighborhood } \\
\text { frequency }\end{array}$ & $\begin{array}{c}\text { Matched } \\
\text { Pseudo } \\
\text { word } \\
\text { Prime } \\
\text { (IPA) }\end{array}$ \\
\hline 1 & bat & 1.9 & 52 & 495.3895 & bæl \\
2 & bench & 1.2 & 9 & 21.7865 & bef \\
3 & bone & 5.5 & 44 & 78.8676 & bok \\
4 & bride & 1.3 & 22 & 23.6542 & brajks \\
5 & broom & 0.3 & 14 & 36.3711 & brub \\
6 & brush & 1.3 & 6 & 9.0131 & brən \\
7 & cheese & 3.3 & 25 & 52.7545 & tfhil \\
\hline
\end{tabular}




\begin{tabular}{|c|c|c|c|c|c|}
\hline 8 & chest & 3.2 & 20 & 46.0706 & $\mathrm{t} \int \varepsilon \mathrm{p}$ \\
\hline 9 & clock & 3.5 & 21 & 8.1634 & clas \\
\hline 10 & drum & 1.7 & 9 & 253.8911 & drəl \\
\hline 11 & flute & 3.2 & 14 & 11.4776 & fluns \\
\hline 12 & ghost & 1.5 & 14 & 38.7815 & gop \\
\hline 13 & harp & 2.2 & 20 & 50.7186 & hag \\
\hline 14 & hay & 0.4 & 50 & 940.9267 & hen \\
\hline 15 & king & 4.0 & 35 & 69.572 & kit $\int$ \\
\hline 16 & lion & 1.5 & 7 & 32.1961 & lajg \\
\hline 17 & $\log$ & 1.4 & 11 & 23.6684 & lal \\
\hline 18 & map & 5.6 & 35 & 64.9451 & $\mathrm{mæv}$ \\
\hline 19 & moose & 0.7 & 26 & 59.2685 & mudz \\
\hline 20 & mop & 0.1 & 20 & 52.3725 & mad \\
\hline 21 & nail & 1.7 & 48 & 21.9992 & nef \\
\hline 22 & pear & 0.3 & 46 & 188.8832 & $\mathrm{p} \varepsilon \mathrm{b}$ \\
\hline 23 & pot & 2.7 & 39 & 286.4907 & pag \\
\hline 24 & purse & 1.2 & 23 & 24.179 & pərn \\
\hline 25 & queen & 2.7 & 5 & 27.753 & kwig \\
\hline 26 & roof & 3.6 & 23 & 27.9881 & ruz \\
\hline 27 & rope & 1.6 & 33 & 26.8259 & rok \\
\hline 28 & salt & 4.1 & 12 & 16.2222 & $\operatorname{sp} \theta$ \\
\hline 29 & scarf & 0.6 & 6 & 2.6275 & skag \\
\hline
\end{tabular}




\begin{tabular}{|c|c|c|c|c|c|}
\hline 30 & shark & 2.5 & 20 & 19.1588 & fad \\
\hline 31 & sink & 0.8 & 27 & 114.199 & sib \\
\hline 32 & skunk & 1.4 & 4 & 1.8431 & skəv \\
\hline 33 & sled & 2.7 & 11 & 106.0731 & slen \\
\hline 34 & slide & 1.2 & 17 & 16.9562 & slajn \\
\hline 35 & sock & 3.3 & 34 & 22.1586 & sav \\
\hline 36 & swan & 3.8 & 10 & 3.4588 & swal \\
\hline 37 & swing & 2.5 & 19 & 26.7884 & swik \\
\hline 38 & tent & 2.4 & 22 & 45.2398 & $\mathrm{t} \varepsilon \mathrm{j}$ \\
\hline 39 & thumb & 1.4 & 21 & 250.2801 & $\theta$ əts \\
\hline 40 & vase & 0.2 & 20 & 43.5833 & vem \\
\hline 41 & whale & 1.5 & 52 & 162.609 & wep \\
\hline 42 & wig & 0.6 & 30 & 296.6882 & WIb \\
\hline 43 & wolf & 1.2 & 2 & 1.8137 & woj \\
\hline \multirow[t]{3}{*}{44} & wrench & 2.6 & 8 & 17.25 & $\mathrm{r} \varepsilon \mathrm{t}$ \\
\hline & Mean & 2.05 & 22.41 & 93.66 & \\
\hline & SE & 0.20 & 3.38 & 14.12 & \\
\hline
\end{tabular}


VITA 
VITA

\author{
Ranjini Mohan \\ Department of Speech, Language, and Hearing Science, Purdue University \\ 715 Clinic Dr, West Lafayette, IN 47907
}

\title{
RESEARCH INTERESTS
}

To explore cognitive and language processing in typically aging adults and those with neurogenic disorders such as aphasia and dementia

\section{EDUCATION}

2011- Purdue University, West Lafayette, IN

present Dual-title Ph. D, Cognitive Neuroscience \& Gerontology

- Dissertation: 'Neural activity reveals effects of aging on inhibitory processes during word retrieval' - The primary aim of the study was to examine age-related changes in the neural correlates of phonological processing and word retrieval in healthy adults across the lifespan.

All India Institute of Speech and
2010 M.Sc. Speech Language Pathology

2008 B.Sc. Speech \& Hearing

\section{RESEARCH EXPERIENCE}

Jan 2014- Graduate Fellow: Neural Systems for Language Processing lab, present Purdue University

- Performed cognitive-linguistic evaluations for adults 20-75 years old; designed and coded experiments; recorded, analyzed, and reported behavioral and EEG data

Jan 2013- Graduate Assistant, Speech Physiology Laboratory, Purdue

Dec 2013 University

- Analyzed language samples of persons with Parkinson's disease and typically aging older adults

Sept 2011- Graduate Assistant, Neural Systems for Language Processing

Dec 2012 lab, Purdue University

- Collected EEG data from children who stutter, performed electrophysiological and behavioral data analysis 
Aug 2010- Research Scientist, Dept. of Clinical Services, University of

July 2011 Mysore, India

- Performed baseline speech, language, and cognitive assessment, developed therapy protocols and administered language therapy for individuals with aphasia, reported treatment outcomes

\section{PEER REVIEWED PUBLICATIONS}

Mohan, R. \& Weber, C. Neural activity reveals age differences in inhibitory processes during word retrieval. Manuscript in preparation.

Mohan, R., Huber, J., \& Darling-White, M. Impact of age and Parkinson's disease on language production: A longitudinal study. Manuscript in preparation.

Mohan, R. \& Weber, C. (2015). Neural systems mediating processing of sound units of language distinguish recovery versus persistence in stuttering. Journal of Neurodevelopmental Disorders, 7: 28.

Ranjini, M. \& Shafna, J. (2010). Effect of tempo on the frequency ratio of notes in singers and instruments. Journal of ITC Sangeet Research Academy, 12, 1-6.

\section{CONFERENCE PRESENTATIONS}

Mohan, R. \& Weber, C. (2016). Neural functions mediating word retrieval in aging. Poster presented at the Cognitive Neuroscience Society Annual Meeting at New York, NY in April.

Mohan, R. \& Huber, J. (2014). Language production of persons with Parkinson's disease and older adults: A longitudinal analysis. Poster presented at the American Speech-Language and Hearing Association Convention 2014 at Orlando, FL.

Mohan, R. \& Weber-Fox, C. (2012). Phonological processing distinguishes recovery versus persistence in stuttering: Electrophysiological evidence. Poster presented at the American Speech, Language, and Hearing Association Convention 2012 at Atlanta, GA.

Ranjini, M. \& Shafna, J. (2010). Effect of tempo on the frequency ratio of notes in singers and instruments. Oral presentation at the Frontiers of Research in Speech and Music, an international conference at Gwalior, India.

Ranjini, M., Maria, R. \& Goswami, S. P. (2009). Action verb naming in bilingual children and adolescents. Poster presented at the 42nd National Conference of the Indian Speech and Hearing Association, Bangalore, India. 
TEACHING EXPERIENCE

2014

Graduate Teacher Certificate, Center for Instructional Excellence, Purdue University

2012-2013 Teaching Assistant, Dept. of Speech, Language and Hearing Science, Purdue University SLHS 304 Anatomy \& Physiology of the Speech and Hearing Mechanism, SLHS 302 Acoustic Basis of Speech and Hearing

\section{FELLOWSHIPS AND AWARDS}

\begin{tabular}{ll}
\hline 2015 & Bisland Dissertation Fellowship in Gerontology, Purdue University \\
2014 & Purdue Research Foundation Grant, Purdue University \\
2014 & Indiana Lion's McKinney research award \\
2014 & Ringel Research Scholarship \\
& Dept. of Speech, Language and Hearing Sciences, Purdue University \\
2014 & Graduate Teaching Certificate, Centre for Instructional Excellence \\
& Purdue University \\
2012 & 'Meritorious Poster Submission' for the study titled "Phonological \\
& processing distinguishes recovery vs persistence in stuttering: \\
& Electrophysiological evidence." at the 2012 American Speech- \\
& Language-Hearing Association (ASHA) Convention. \\
& Gerontology Program Lynn Fellowship, Purdue University
\end{tabular}

\section{PROFESSIONAL ENGAGEMENT}

Asian Indian Caucus (AIC), a multicultural constituency group of ASHA

- 2015-present Vice President-Professional Development

- 2013-2015 Secretary

- 2011-2013 Editor, ASHA Kiran, a newsletter published by AIC

Student Representative, Steering Committee for the Center on Aging and the Life Course, Purdue University

Cognitive Neuroscience Society

Society for Neurobiology of Language

Gerontological Society of America

National Student Speech, Language, and Hearing Association

Indian Speech and Hearing Association 